Methodology of Educational Sciences Research Group

ITEC, imec research group at KU Leuven

\title{
Psychometrics of MOOCs: How to Measure Proficiency?
}

Doctoral thesis offered to obtain the degree of Doctor of Educational Sciences

Supervisor: Prof. Dr. Wim Van den Noortgate Co-supervisor: Prof. Dr. Piet Desmet 



\section{Dmitry Abbakumov, Psychometrics of MOOCs: How to measure proficiency?}

Dissertation submitted to obtain the degree of Doctor of Educational Sciences, 2019

Supervisor: Prof. Dr. Wim Van den Noortgate, Co-supervisor: Prof. Dr. Piet Desmet

The popularity of online courses with open access and unlimited learner participation (MOOCs) has been growing intensively. Certificates of MOOC completion are becoming a significant element in learners' portfolios as well as an additional source of academic credits. That is why learners, professors, universities, and employers have an interest in accurate measures of learners' proficiency in MOOCs. Existing psychometric approaches do not serve perfectly as measurement tools for MOOCs. However, item response theory (IRT) is a flexible and well-elaborated framework, in which models could be tuned up to be applied for MOOCs. Thus, the general purpose of the doctoral dissertation is to propose model extensions that make IRT able to accurately measure learners' proficiency and to describe constructs closely linked with learners' proficiency in MOOCs.

The doctoral thesis consists of five chapters following the introductory chapter - four empirical and one conceptual. In the four empirical chapters, we have proposed Rasch model extensions aimed at solving the following problems. In Chapter 2, we have improved the proficiency measures by modeling the effect of attempts and by involving non-assessment data such as learners' interaction with video lectures and practical tasks. In Chapter $\underline{3}$, we have modeled individual growth in proficiency through the MOOC as an effect of the cumulative sum of video lectures a learner has watched before responding on a summative assessment item. In Chapter 4, we have established a more nuanced insight on the role of proficiency on the learners' performance by involving one extra latent effect, the effect of learners' interest. In Chapter 5, we have proposed a way to measure learners' activity (e.g., watching videos, reading texts) as influenced by a latent learner characteristic and a latent content characteristic. The four studies have been conducted using the single psychometric framework of cross-classification multilevel logistic models and real datasets from the Coursera platform. In the final, reflective and conceptual chapter (Chapter 6), we have summarized a connection between psychometrics, as a scientific discipline, and MOOCs, as an industry, and have sketched ideas for the future development of psychometrics of MOOCs. 



\section{Dmitry Abbakumov, Psychometrie van MOOCs: Hoe vaardigheid te meten?}

Proefschrift aangeboden tot het verkrijgen van de graad van

Doctor in de Pedagogische Wetenschappen, 2019

Promotor: Prof. Dr. Wim Van den Noortgate, Copromotor: Prof. Dr. Piet Desmet

De populariteit van onlinecursussen met open toegang en onbeperkte studentparticipatie (MOOCs) is enorm gestegen. Certificaten van de voltooiing van MOOCs- worden een belangrijk element in de portefeuilles van studenten, evenals een extra bron van studiepunten. Daarom hebben studenten, professoren, universiteiten en werkgevers belang bij nauwkeurige metingen van de vaardigheid van studenten in MOOCs. Bestaande psychometrische benaderingen zijn niet onmiddellijk inzetbaar als meetinstrumenten voor MOOCs. De item respons theorie (IRT) lijkt echter een flexibel en goed uitgewerkt raamwerk te zijn waarbinnen modellen kunnen worden afgestemd op MOOCs. Het algemene doel van het doctoraatsproefschrift is dus om uitbreidingen voor te stellen die IRT in staat stellen nauwkeurig de vaardigheid van studenten te meten en constructen te beschrijven die nauw verband houden met de vaardigheid van de studenten in MOOCs.

Het proefschrift bestaat uit vijf hoofdstukken na het inleidende hoofdstuk - vier empirische en één conceptuele. In de vier empirische hoofdstukken hebben we modeluitbreidingen van het Raschmodel voorgesteld met als doel het oplossen van de volgende problemen. In Hoofdstuk 2 hebben we de bekwaamheidsmaatregelen verbeterd door het effect van pogingen te modelleren en door niet-evaluatiegegevens te betrekken, zoals de interactie van studenten met videocolleges en praktische taken. In Hoofdstuk 3 hebben we individuele groei in vaardigheid gemodelleerd via de MOOC als een effect van de cumulatieve som van videolessen die een student heeft bekeken voordat hij antwoordt op een summatief beoordelingsitem. In Hoofdstuk 4 hebben we een genuanceerder inzicht gegeven in de rol van vaardigheid in de prestaties van de student door een extra latent effect te betrekken, het effect van de interesse van studenten. In Hoofdstuk 5 hebben we een manier voorgesteld om de activiteit van studenten te meten (bijvoorbeeld video's bekijken, teksten lezen) die worden beïnvloed door een latente studenteigenschap en een latent inhoudskenmerk. De vier onderzoeken zijn uitgevoerd met behulp van het psychometrische raamwerk van kruisclassificatie multiniveau logistische modellen en echte datasets van het Coursera-platform. In het laatste, reflectieve en conceptuele Hoofdstuk 6 hebben we het verband tussen psychometrie als wetenschappelijke discipline en MOOCs als een bedrijfstak samengevat en ideeën voor de toekomstige ontwikkeling van psychometrie van MOOCs geschetst. 

To my parents

Моим родителям 

Supervisor

Prof. Dr. Wim Van den Noortgate

Co-supervisor

Prof. Dr. Piet Desmet

Supervisory Committee Prof. Dr. Francis Tuerlinckx

Prof. Dr. Jan Elen

Examination Committee Prof. Dr. Tom Beckers (Chair), KU Leuven

Prof. Dr. Jan Elen, KU Leuven

Prof. Dr. Dylan Molenaar, University of Amsterdam

Prof. Dr. Matthieu Brinkhuis, Utrecht University 



\section{WORDS OF THANKS}

I want to thank...

... my supervisor, Wim Van den Noortgate, who has guided me during these four years. Our meetings were the highlight of my week. He is an excellent mentor who gave me the freedom and the encouragement to realize my ideas. He gave me his unfailing help and support whenever I needed it. I am deeply grateful for the chance to work with him.

... my co-supervisor, Piet Desmet, for his strategic vision and wise comments.

... the members of my doctoral jury, Tom Beckers, Jan Elen, Dylan Molenaar, and Matthieu Brinkhuis, for agreeing to read my thesis and attend the defense.

... my colleagues and friends, Darja Kravchenko, Evgenia Kulik, Sergey Roshchin, Roman Ranniy, Irina Basareva, Michael Izheykin and Artem Titorenko, Vadim and Irina Glusker, Artem Romanenko, Rene Tanious, Carlos Felipe Rodrigues Hernandes, Nike Verbesselt and Inias Crabbe, and all of I accidentally forgot to mention here, for support in Belgium and Russia, for helping me, and for thinking of me.

But most of all, I want to express the deepest gratitude to my parents, who have done everything possible and impossible for giving us, their children, a better life. 



\section{CONTENTS}

Chapter 1. Introduction 1

Chapter 2. Measuring students' proficiency in MOOCs: Multiple $\quad 7$ attempts extensions for the Rasch model

Chapter 3. Measuring growth in students' proficiency in MOOCs: Two component dynamic extensions for the Rasch model

Chapter 4. Rasch model extensions for enhanced formative assessments in MOOCs

Chapter 5. Measuring students' activity in MOOCs using a Rasch model extension

Chapter 6. Psychometrics of MOOCs: Measuring learners' proficiency 



\section{CHAPTER 1}

\section{INTRODUCTION}

Massive open online courses (MOOCs) are one of the most significant technological developments in higher education in the past decade (Deng, Benckendorff, \& Gannaway, 2019). MOOCs are large scale web-based courses made by universities, solely or in cooperation with industrial partners, in which anyone with internet access can participate. MOOCs are published on provider platforms, for instance, Coursera, edX, XuetangX, FutureLearn, Udacity, and MiriadaX. MOOCs are a relatively new instructional form - the term did not exist before 2008 (Major \& Blackmon, 2016). However, their popularity grows fast - over a decade more than 800 universities offered to learners more than 9,400 MOOCs (Shah, 2018a). In 2019, the largest MOOC provider, Coursera, achieved the milestones of 40 million registered learners and 3,200 courses made by 190 universities and industry partners (Maggioncalda, 2019).

Learners, professors, and universities - the key partners involved in MOOCs, - have an interest in accurate measures of learners' proficiency. Learners study the course and want to do it efficiently. In this case, the proficiency measures help learners to identify own strengths and weaknesses, and to map areas that need additional work within the course. Professors and their teams develop and optimize course content. In this case, changes in the proficiency show how and to what extent the content works and suggest improvements of video lectures, practical tasks, and support materials. Universities award certificates to learners. In this case, proficiency measures give evidence that the learner has mastered the course.

MOOCs are unique in the data the platforms collect - every single activity of learners is recorded in a log-file. Moreover, education science has its own measurement approaches with a strong philosophical foundation, statistical 
representation, and over 100-year history in development (Borsboom, 2005). Given that, it seems odd that MOOCs still use grades, the simple proportion of correctly solved items in assessments or the (cumulative) proportion of assessments completed in a course, as a proxy for learners' proficiency (for example, de Barba, Kennedy, \& Ainley, 2016; Guo \& Reinecke, 2014; Phan, McNeil, \& Robin, 2016). These metrics are simple and intuitive but the use of them has a risk of bias due to oversimplification and ignoring factors of learners, content, and context. Learners will have the wrong map of their strengths and weaknesses. Professors will receive biased information about learning materials functioning. Universities will run the risk of making unfair decisions in the certification of learners. Therefore, we suppose that biased measures hamper improvement and development of MOOCs and believe it is important to connect theoretically grounded data-driven educational measurement approaches and MOOC research.

In this dissertation, we have tried to establish such a connection and to tune simple psychometric models of Item Response Theory (IRT; Lord \& Novick, 1968; Rasch, 1960; van der Linden \& Hambleton, 1997; van der Linden, 2016) on complex reality of MOOCs. The main idea of IRT is that a latent construct is considered to be unobserved determinant of a set of observed scores. For instance, a researcher who views proficiency in a specific domain as a latent variable assumes that the proficiency is the common cause of the person's responses to a set of specific test items. IRT presents a broad class of models with a nonlinear link between person's responses on items (observable side) and his/her proficiency (latent construct). The IRT models are based on three basic assumptions. First, in parametric IRT models, the probability a person correctly answers an item follows a specific functional form which depends on a person parameter (or a set of parameters) and an item parameter (or a set of parameters). Second, this function increases monotonically with respect to the person's 
parameter (which therefore is often interpreted as the proficiency). Third, given the person's proficiency, the items are considered conditionally independent. However, common IRT models are not tailored to use directly for measuring proficiency in MOOCs. First, IRT assumes the proficiency does not change within a test but rather remains constant. This way of understanding critically contrasts to the reality of processes in MOOCs and any learning process where the main product is the change of proficiency. Second, IRT assumes that proficiency (or a set of proficiencies) is a common cause of the learners' responses. However, MOOC learners have a high degree of freedom because of low-stakes of such courses and learners' performance is linked to a number emotional and motivational characteristics that are relatively unrelated to knowledge (de Barba, Kennedy, \& Ainley, 2016). Therefore, neglecting the importance of such facts in performance explanation might result in biased conclusions on proficiency. Both shortcomings of existing IRT models have been covered in our studies.

The dissertation consists of five stand-alone chapters following this introductory chapter - four empirical and one conceptual. In the four empirical chapters, we have proposed extensions for the most common IRT model, the Rasch model (Rasch, 1960), aimed at solving the following problems. In Chapter 2 , we have improved the proficiency measures by modeling the effect of attempts and by involving non-assessment data such as learners' interaction with video lectures and practical tasks. In Chapter 3, we have modeled individual growth in proficiency through the $\mathrm{MOOC}$ as an effect of the cumulative sum of video lectures a learner has watched before responding on a summative assessment item. In Chapter 4, we have established a more nuanced insight on the role of proficiency on the learners' performance by involving one extra latent effect, the effect of learners' interest. In Chapter 5, we have proposed a way to measure learners' activity (e.g., watching videos, reading texts) as influenced by a latent learner characteristic and a latent content characteristic. In the final, reflective and 
conceptual Chapter 6, we have summarized a connection between psychometrics, as a scientific discipline, and MOOCs, as an industry, and have sketched the future development of psychometrics of MOOCs.

In the four empirical studies, we have used the single psychometric framework of cross-classification multilevel logistic models proposed by Van den Noortgate, De Boeck, and Meulders (2003). This flexible framework allowed extending the Rasch model without running into computational issues of model identification. The next common feature for the four studies is the data. We have used real datasets from the Coursera platform (the access has been granted by National Research University Higher School of Economics, Moscow, Russia).

Chapters 2 and 3 have been published in Heliyon and Behavior Research Methods respectively. Chapter 4 has been accepted for publication in Applied Measurement in Education. Chapters 5 and 6 have been submitted for publication. The references to the corresponding manuscripts are the following:

Chapter 2: Abbakumov, D., Desmet, P., \& Van den Noortgate, W. (2018). Measuring student's proficiency in MOOCs: Multiple attempts extensions for the Rasch model. Heliyon, 4(12), 1-15.

Chapter 3: Abbakumov, D., Desmet, P., \& Van den Noortgate, W. (2019). Measuring growth in students' proficiency in MOOCs: Two component dynamic extensions for the Rasch model. Behavior Research Methods, 51(1), $332-341$.

Chapter 4: Abbakumov, D., Desmet, P., \& Van den Noortgate, W. (in press). Rasch model extensions for enhanced formative assessments in MOOCs. Applied Measurement in Education.

Chapter 5: Abbakumov, D., Desmet, P., \& Van den Noortgate, W. Measuring students' activity in MOOCs using a Rasch model extension. Submitted for publication. 
Chapter 6: Abbakumov, D., Desmet, P., \& Van den Noortgate, W. Psychometrics of MOOCs: Measuring learners' proficiency. Submitted for publication. 


\section{CHAPTER 2}

\section{MEASURING STUDENTS' PROFICIENCY IN MOOCS: MULTIPLE ATTEMPTS EXTENSIONS FOR THE RASCH MODEL ${ }^{1}$}

Popularity of online courses with open access and unlimited student participation, the socalled massive open online courses (MOOCs), has been growing intensively. Students, professors, and universities have an interest in accurate measures of students' proficiency in MOOCs. However, these measurements face several challenges: (a) assessments are dynamic: items can be added, removed or replaced by a course author at any time; (b) students may be allowed to make several attempts within one assessment; (c) assessments may include an insufficient number of items for accurate individual-level conclusions. Therefore, common psychometric models and techniques of Classical Test Theory (CTT) and Item Response Theory (IRT) do not serve perfectly to measure proficiency. In this study we try to cover this gap and propose cross-classification multilevel logistic extensions of the common IRT model, the Rasch model, aimed at improving the assessment of the student's proficiency by modeling the effect of attempts and by involving non-assessment data such as student's interaction with video lectures and practical tasks. We illustrate these extensions on the logged data from one MOOC and check the quality using a cross-validation procedure on three MOOCs. We found that (a) the performance changes over attempts depend on the student: whereas for some students performance ameliorates, for other students, the performance might deteriorate; (b) similarly, the change over attempts varies over items; (c) student's activity with video lectures and practical tasks are significant predictors of response correctness in a sense of higher activity leads to higher chances of a correct response; (d) overall accuracy of prediction of student's item responses using the extensions is $6 \%$ higher than using the traditional Rasch model. In sum, our results show that the approach is an improvement in assessment procedures in MOOCs and could serve as an additional source for accurate conclusions on student's proficiency.

Massive open online courses (MOOCs) are a recent progressive phenomenon in education. A MOOC is an online course with open access and participation of unlimited number of students. A MOOC typically consists of prerecorded video lectures, reading assignments, assessments, and forums. MOOCs

1 The text in this chapter has been published as Abbakumov, D., Desmet, P., \& Van den Noortgate, W. (2018). Measuring student's proficiency in MOOCs: Multiple attempts extensions for the Rasch model. Heliyon, 4(12), 1-15. 
are mainly developed by universities and run on platforms such as Coursera, edX, XuetangX, FutureLearn, Udacity, and MiriadaX. In 2017, more than 800 universities offered students more than 9,400 MOOCs (Shah, 2018a). The same year, the largest MOOC provider, Coursera, achieved the milestones of 30 million students and 2,700 courses (Shah, 2017).

Students, professors and universities - the key partners involved in MOOCs, - have an interest in accurate student proficiency measuring. Students take an online course and want to study efficiently. Proficiency measuring specifies student's position on the course-line, helps him/her to identify his/her strong and weak points and map areas that need additional work. Professors and their teams develop and optimize the course content. At this stage, the aggregated proficiency measures show to what degree the content incites learning and suggest improvements of video lectures, practical tasks, and support materials. Finally, universities award online course certificates to students. Proficiency measures can provide evidence whether student has mastered the course.

Proficiency is, however, a latent variable. We cannot observe it directly; yet, we can see, for example, student's performance on assessment items. To link the observable side to the latent side, we need specific rules. These rules are called measurement or psychometric theory. Today, there exist two major psychometric theories: Classical Test Theory (CTT) and Item Response Theory (IRT) and dozens of models based on them.

CTT appeared around 100 years ago (Borsboom, 2005). It includes three main concepts - test score (observed), true score (latent), and error score (latent) (Lord \& Novick, 1968). The theory introduces a simple linear model that links the observable test score to the sum of two latent variables, true score and error score, that is,

$$
Y_{j}=\theta_{j}+\varepsilon_{j}
$$


According to this model, the test score of the $j^{\prime}$ th student $\left(Y_{j}\right)$ is the result of his/her proficiency $\left(\theta_{j}\right)$ with a random measurement error $\left(\varepsilon_{j}\right)$. The error term $\left(\varepsilon_{j}\right)$ has the expected value of zero, is assumed normally distributed and unrelated to the proficiency: $E\left(\varepsilon_{j}\right)=0, \varepsilon_{j} \sim N\left(0, \sigma_{\varepsilon}^{2}\right)$, and $\rho_{\varepsilon \theta}=0$. Thus, the expected value of $Y_{j}$, $E\left(Y_{j}\right)$, is $\theta_{j}$. As a result, the average score is normally distributed around $\theta_{j}$ with variance $\sigma_{\varepsilon}^{2} / n$ with $n$ being the number of observations. Hence, the more observations, the closer the average score is in general to the proficiency.

The CTT has several limitations (see Hambleton \& Jones, 1993). For MOOCs the critical limitation is the dependence of proficiency measures on test difficulty: when the test is difficult, the student receives a low estimate of proficiency and when the test is easy, the student receives a high estimate of proficiency. This is a problem for assessments in MOOCs, since changes in tests are relatively frequent in MOOCs - professors often replace or add new items on the fly. Universities run the risk of making unfair decisions in certification of students. Professors will receive biased information about learning materials functioning. Students will have the wrong map of their strengths and weaknesses.

IRT was developed 50 years ago (Lord \& Novick, 1968; Rasch, 1960). It presents a class of models with nonlinear linking between student's item responses (observable variables) and his/her proficiency (latent variable). In the basic IRT model, the Rasch model (Rasch, 1960),

$$
\operatorname{Logit}\left(\pi_{i j}\right)=\ln \left(\frac{\pi_{i j}}{1-\pi_{i j}}\right)=\theta_{j}-\delta_{i} \text { and } Y_{i j} \sim \operatorname{Bernoulli}\left(\pi_{i j}\right),
$$

probability $\left(\pi_{i j}\right)$ of the correct response of student $j$ to the item $i$ is described by a logistic function of the difference between the student's proficiency parameter $\left(\theta_{j}\right)$ and the item difficulty parameter $\left(\delta_{i}\right)$. To fit the Rasch model, a marginal maximum likelihood procedure is often used to estimate the item difficulty parameters, 
assuming that the students are a random sample from population where the student proficiencies are normally distributed with $\theta_{j} \sim N\left(0, \sigma_{\theta}^{2}\right)$, while the items have fixed difficulty. Individual student parameters can be estimated afterwards using empirical Bayes procedures.

In comparison to CTT, student's proficiency parameters in IRT are independent from the test difficulty. It allows comparing students even in case of partial replacement of items. However, the use of IRT in MOOCs is also challenging. Firstly, IRT requires a relatively large number of items in assessments to provide accurate proficiency measures. Kruyen, Emons, \& Sijtsma (2012) stated that the minimal test length for individual level decisions is 40 items. By contrast, MOOCs often offer 15 or even fewer items in summative assessments. At the same time, MOOCs yield additional observable data such as student's activity with video lectures and his/her performance in practice, which might be used as proficiency indicators to cover the lack of items in summative assessments. Secondly, the proficiency parameter in IRT as well as in CTT is typically considered constant (Lord \& Novick, 1968). This point contrasts to the reality of MOOCs where students get feedback after responding to assessment items. In addition, students may be allowed to do several attempts within one assessment. If the student fails at one attempt, he/she can be provided with help information, review a video lecture, and then make a new attempt. Thus, the student's proficiency may grow with each new attempt to solve the certain item. However, better performance with new attempts does not necessarily imply growth in proficiency, as it might also appear if the student uses attempts to enumerate the item options. The challenge here is to distinguish between these kinds of growth.

As can be seen from the above, the common psychometric models of CTT and IRT are not tailored to use directly for measuring proficiency in MOOCs. At the same time, IRT is a well-elaborated and flexible framework, and could serve as the basis for such measurements. 
In this study we extend and tune up the common IRT model, the Rasch model, for application in MOOCs. We start with proposing four extensions, which model the growth of student's proficiency with attempts and involve data of student's interaction with video lectures and practical tasks to compensate for the insufficient number of items in the assessment. Then we illustrate these extensions using data from one MOOC. Finally, we check the performance of these extensions in predicting correctness of students' responses in summative assessments and show the advantage in accuracy in comparison to the common IRT model using a cross-validation procedure applied in the data from three MOOCs.

\section{Four Extensions for the Rasch Model}

As the general framework, we use reformulation of the Rasch model presented by Van den Noortgate, De Boeck, and Meulders (2003):

$$
\operatorname{Logit}\left(\pi_{i j}\right)=b_{0}+u_{1 j}+u_{2 i} \text { and } Y_{i j} \sim \operatorname{Bernoulli}\left(\pi_{i j}\right)
$$

where $u_{1 j} \sim N\left(0, \sigma_{u 1}^{2}\right)$ and $u_{2 i} \sim N\left(0, \sigma_{u 2}^{2}\right)$.

This reformulation is based on the principle of cross-classification multilevel models. Instead of two parameters (student's proficiency parameter and item difficulty parameter), in this reformulation, we have an intercept and two residual terms referring to the student and the item respectively. The intercept equals the estimated logit of probability of a correct response of an average student on an average item. The intercept can be interpreted as the difference between the overall proficiency and the overall difficulty. The mean of both residual terms is zero. The first residual term shows the deviation of proficiency of student $j$ from the overall proficiency. The second residual term shows the deviation of the difficulty of item $i$ from the overall difficulty, in the sense that the larger the residual, the easier the item. 
We prefer this reformulation to the traditional Rasch model formulation because it is very flexible for making extensions. Considering items and students as random, there are still degrees of freedom left to include various predictors in the model, whereas, for instance, inserting item characteristics as predictors to a model where the items are considered as fixed (and therefore the difficulty is estimated for each item separately) leads to computational issues of model identification (Van den Noortgate, De Boeck, \& Meulders, 2003).

\section{MOOC Structure}

Before presenting extensions, we should describe the general structure of MOOCs. In this study we focus on the structure of courses on Coursera, but this structure is common for other MOOCs. Courses on Coursera are composed of modules, which consist of lessons. Each lesson includes several video lectures accompanied by at least one task of formative assessment. Each video lecture lasts 4-9 minutes. Thus, it takes a student about 30 minutes to complete a lesson. Typically, each lesson is structured around one or two objectives of learning. The

module is a collection of lessons that comprises a larger unit of learning. Each module is structured around a cohesive subtopic and usually lasts a week. Modules are concluded by summative assessment. Summative assessments are realized as a 10-15 item test, a programming task, or a peer-review task. In this study we use courses with test-based summative assessments; we work with the data of each weekly summative assessment separately.

\section{Extension One}

In the first extension we consider two components of proficiency within weekly summative assessment: the fixed component and the dynamic component. We assume that during the assessment the student's proficiency is fixed. However, if the student takes several attempts, there may be a change in the expected student's performance from one attempt to another within the assessment. To model this growth, we use the dynamic component. 
Thus, in our first extension,

$$
\begin{gathered}
\operatorname{Logit}\left(\pi_{i j}\right)=b_{0}+\left(b_{10}+b_{1 j}\right) * \operatorname{attempt}_{i j}+u_{1 j}+ \\
u_{2 i} \text { and } Y_{i j} \sim \operatorname{Bernoulli}\left(\pi_{i j}\right)
\end{gathered}
$$

$b_{0}$ equals the estimated logit of probability of the correct response of an average student on an average item in weekly summative assessment; attempt $_{i j}$ is $0,1,2$, 3 or 4 and means the first, the second, the third, the fourth, or the fifth or higher attempt respectively; $b_{10}$ is overall effect of attempt, while $b_{1 j} \sim N\left(0, \sigma_{b 1}^{2}\right)$ is a deviation of the attempt effect for student $j$ from the overall effect; and $u_{1 j} \sim N\left(0, \sigma_{u 1}^{2}\right)$ and $u_{2 i} \sim N\left(0, \sigma_{u 2}^{2}\right)$.

We expect a positive average effect of attempts $\left(b_{10}\right)$. It means that with each new attempt the chances for the correct response grow. The first reason for this is learning. For instance, online courses provide students with hints in case of a wrong response. This instructional content is aimed at helping the student to understand his/her mistake, guiding through relevant learning materials and preparing for the next attempt. The second reason is that the student can simply enumerate possibilities, for example, by clicking repeatedly on alternative options in multiple-choice questions. Therefore we expect that increase of the correct response probability for a student who does not learn at all, will be lower than with the average student, that is, the student's random effect $b_{1 j}$ is expected to be negative, and its combination with the average effect of attempts $\left(b_{10}\right)$ is expected to be close to zero. For fast learning students, on the contrary, we expect positive random effect $b_{1 j}$.

\section{Extension Two}

It is important to note that the effect of additional attempt may vary from item to item. For some items, the expected increase of probability of giving the correct response from one attempt to the next attempt may be larger than for 
other items. For instance, a multiple-choice item with four options could be solved correctly (using simple enumeration) by four attempts maximally. For solving an open-ended item, where the student should indicate a number or a word, the number of attempts may be much higher. To account for this variation, we propose the second extension:

$$
\begin{aligned}
\operatorname{Logit}\left(\pi_{i j}\right)= & b_{0}+\left(b_{10}+b_{1 j}+b_{1 i}\right) * \operatorname{attempt}_{i j}+u_{1 j}+ \\
& u_{2 i} \text { and } Y_{i j} \sim \operatorname{Bernoulli}\left(\pi_{i j}\right)
\end{aligned}
$$

where $b_{1 i} \sim N\left(0, \sigma_{b 1}^{2}\right)$ is a deviation of the attempt effect for item $i$ from the overall effect.

\section{Extension Three}

As students with different patterns of using attempts may have different growth with each new attempt, we propose the third extension. We could split the course students in classes by maximum number of attempts, they used to solve items in weekly summative assessment, where for instance, classes "0", "1", "2", and " 3 " mean that the maximum number of attempts for this student was 1 or 2 , 3 or 4,5 or 6 , and more than 6 respectively. We use these classes in interaction with the number of attempts in the third extension:

$$
\begin{gathered}
\operatorname{Logit}\left(\pi_{i j}\right)=b_{0}+\left(b_{10}+b_{1 j}+b_{1 i}\right) * \operatorname{attempt}_{i j}+b_{2} * \operatorname{class}_{j}+b_{3} * \\
\text { attempt }_{i j} * \operatorname{class}_{j}+u_{1 j}+u_{2 i} \text { and } Y_{i j} \sim \operatorname{Bernoulli}\left(\pi_{i j}\right)
\end{gathered}
$$

where class $_{j}$ is "0", "1", "2", and "3".

We expect that the more attempts one makes, the less he/she learns per an additional attempt, and hence, $b_{3}$ is negative. We also expect a negative main effect of the class, in the sense that students with a higher maximum number of 
attempts are less proficient. For instance, it could be students, interested in formal achievements in assessment rather than in mastering the course.

\section{Extension Four}

Finally, we propose to include predictors indicating student's week activity before assessment, for instance, how active he/she was in watching video lectures and how productive he/she was with formative assessments. These predictors may show systematic differences in probability of the correct response for students with different quality of course activity. Thus, our fourth extension is:

$$
\begin{aligned}
& \operatorname{Logit}\left(\pi_{i j}\right)=b_{0}+\left(b_{10}+b_{1 j}+b_{1 i}\right) * \operatorname{attempt~}_{i j}+b_{2} * \text { class }_{j}+b_{3} * \\
& \text { attempt }_{i j} * \text { class }_{j}+b_{4} * \text { formative.assessment.performance }{ }_{j}+b_{5} * \\
& \text { lecture.activity }{ }_{j}+u_{1 j}+u_{2 i} \text { and } Y_{i j} \sim \operatorname{Bernoulli}\left(\pi_{i j}\right) \text {, }
\end{aligned}
$$

where formative.assessment.performance ${ }_{j}$ is the index that refers to the student's performance in the previous formative assessments of the module; it equals the number of correct attempts, divided by the sum of the number of student's correct and wrong attempts, that may take values from 0 to 1 ;

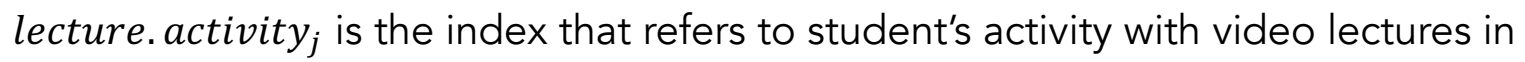
the module; it takes values from 0 , which means that the student did not watch video lectures at all, to 2, which means that the student watched all video lectures in the module. Therefore, $b_{4}$ and $b_{5}$ are overall effects of performance in formative assessments and activity with video lectures respectively. The coefficients of the formative assessment performance and the lecture activity do not vary from student to student because these variables were measured only once, before the summative assessment starts, and therefore only one value of the variable corresponds to each single student. In this extension we expect these both effects to be positive. 


\section{Method}

\section{Data}

The course data we use are coded in the following way. Students have a unique identification number. The course and all its elements - a module, a lesson, a video lecture, and an item in assessment, - have their individual identification number. Student's actions, for instance interaction with video lecture or item response, also have an individual identification number and a time stamp. Student's responses on formative and summative assessment items are dichotomous variables where 1 and 0 correspond to correct and wrong response in a certain attempt respectively. Attempts are marked with the time stamp. Student's interactions with each video lecture are coded as 0,1 or 2 where 2 means the student finished watching the lecture, 1 means the student started but did not finish watching the lecture, 0 means the student did not start watching the lecture. The platform does not track intermediate progress stages, which means, for instance, that $70 \%$ and $99 \%$ of a progress in watching a video lecture are coded in the same way (using code 1). We use the last record for each video, which indicates the actual state of the student with certain video during weekly assessment.

To illustrate the extensions, we fit them on the data of "Economics for NonEconomists" MOOC on Coursera (Higher School of Economics, n.d.a). This course is taught in Russian. The distribution of students among countries is as follows: Russia (72\%), Ukraine (8.4\%), Kazakhstan (3.9\%), Belarus (3.2\%), USA (1.2\%), other countries (11.3\%). The percentage of female students is $47 \%$. We used the data from the first module of the course. During this study, the number of students who attended the module was 1,609. The weekly summative assessment includes 10 items. The number of responses is 51,550 . Students used 2.04 attempts in average, the standard deviation is 1.52 . After recoding the attempts to $0,1,2,3$, and 4 that means the first, the second, the third, the fourth, or the fifth or higher attempt 
respectively, the mean of attempts is 0.95 and standard deviation is 1.19 . The average student's activity with video lectures is 1.87 and standard deviation is 0.38 , where the minimum value of 0 means that the student did not watch any lectures at all, and the maximum value of 2 means that the student watched all lectures till the end. The average student performance with the formative assessment during the week is .60 and standard deviation is .28 , where the minimum value of 0 means that the number of his/her correct attempts was 0 , and the maximum value of 1 means that all his/her first attempts were correct (or the number of his/her correct attempts, divided by the sum of the number of correct and wrong attempts was 1).

To show the performance of the extensions in the cross-validation procedure we used three MOOCs on Coursera: "Economics for Non-Economists", "Game Theory" (Higher School of Economics, n.d.c), and "Introduction to Neuroeconomics: How the Brain Makes Decisions" (Higher School of Economics, n.d.d). The "Game Theory" course is taught in Russian. The distribution of students among countries is as follows: Russia (57\%), Ukraine (10\%), Kazakhstan (3.3\%), USA (3.2\%), Belarus (3\%), other countries (23.5\%). The percentage of female students is $37 \%$. The "Introduction to Neuroeconomics: How the brain Makes Decisions" course is taught in English. The distribution of students among countries is as follows: USA (19\%), India (8.7\%), Russia (6.8\%), Mexico (4.7\%), United Kingdom (4\%), other countries (56.8\%). The percentage of female students is $41 \%$. We used the data from first three modules of each of these courses. Selected descriptive statistics of these courses are presented in Table 2.1. 
Table 2.1

Overview of the courses used in the cross-validation procedure

\begin{tabular}{lllll}
\hline & & Course 1 & Course 2 & Course 3 \\
\hline Module 1 & Students & 1,609 & 3,069 & 4,806 \\
& Items & 10 & 10 & 15 \\
Module 2 & Responses & 51,550 & 88,210 & 141,735 \\
& Students & 986 & 2,050 & 2,609 \\
& Items & 10 & 10 & 15 \\
Module 3 & Responses & 30,430 & 55,100 & 83,940 \\
& Students & 700 & 1,465 & 1,735 \\
& Items & 10 & 10 & 15 \\
& Responses & 13,810 & 36,940 & 42,750
\end{tabular}

Note: In the table, Course 1 is "Economics for Non-Economists", Course 2 is "Game Theory", and Course 3 is "Introduction to Neuroeconomics: How the brain Makes Decisions". 


\section{Fitting the Extensions}

To fit the extensions, the "glmer" function of the "Ime4" package (Bates, Maechler, Bolker, \& Walker, 2015) of the R language and environment for statistical computing (R Core Team, 2013) can be used. The "Ime4" package is used for fitting various IRT models (De Boeck, et al., 2011). To compare the models, we use the Akaike's information criterion (AIC; Akaike, 1974) provided by the "glmer" function ${ }^{2}$.

\section{Cross-Validation}

To understand the quality of the extensions, we will use a cross-validation procedure. By the quality of the extensions, we mean the accuracy of predicting correctness of students' responses in summative assessments using the extensions that is an existing procedure (Ekanadham \& Karklin, 2015). We use three MOOCs on Coursera with 1,000-4,000 active students in each course and three weekly modules from each of these courses. We randomly split students' responses at summative assessment in each module in three different ways: (a) $50 \%$ in the training set and $50 \%$ in the test set, (b) $75 \%$ in the training set and $25 \%$ in the test set, and (c) $95 \%$ in the training set and $5 \%$ in the test set. Then we fit the extensions and the Rasch model on the training sets and use them to make predictions on the test sets. Then we build a table of confusion with two rows and two columns that report the number of false positives, false negatives, true positives, and true negatives. This table allows us to understand the quality of predictions as well as the improvement of prediction from the Rasch model to the proposed extensions. Using this table, we calculate the accuracy index:

${ }^{2}$ Although the AIC is widely used to compare different models, its application for models with a different number of random effects has been criticized (Vaida \& Blanchard, 2005). For better comparison, the conditional Akaike information criterion (cAIC) can be used. 


$$
\text { Accuracy }=\frac{T P+T N}{P+N},
$$

where $T P$ is true positives; $T N$ is true negatives; $P$ is all positives; $N$ is all negatives.

This procedure of splitting the data, fitting the models, making predictions and calculating the accuracy is repeated five more times. Finally, we save all the accuracy indices and calculate average indexes for each model.

\section{Results}

\section{Illustration of the Extensions}

We start with the general model presented in Equation 2.3. As shown in the first column of Table 2.2, the estimate of the intercept equals 0.63 . To calculate the expected probability that the student gives the correct response to the item, we use the inverse logit function, or antilogit, showing that the expected probability of the correct response is .65 (Table 2.3 ). The probability of the correct response varies from student to student and especially from item to item. To understand the size of variance among students, we calculated the expected probability of a successful response to an average item, for a student with proficiency of one standard deviation lower, and for a student with proficiency of one standard deviation higher than the average proficiency. These probabilities are .46 , the antilogit of $(0.63-0.78)$, and .80 , the antilogit of $(0.63+0.78)$. The same procedure for items shows us that the probabilities of an average student to give a correct response to an item with difficulty of one standard deviation lower, and to an item with difficulty of one standard deviation higher than the average difficulty are .41 , the antilogit of $(0.63-1.01)$, and .84 , the antilogit of $(0.63+1.01)$, respectively. 
Table 2.2

Parameters of the extensions

\begin{tabular}{|c|c|c|c|c|c|c|c|c|c|c|c|c|}
\hline \multirow{3}{*}{ Fixed } & \multirow{2}{*}{ Intercept } & & \multicolumn{2}{|c|}{ Basic Model } & \multicolumn{2}{|c|}{ Extension 1} & \multicolumn{2}{|c|}{ Extension 2} & \multicolumn{2}{|c|}{ Extension 3} & \multicolumn{2}{|c|}{ Extension 4} \\
\hline & & & \multicolumn{2}{|c|}{$0.63(0.22)$} & \multicolumn{2}{|c|}{$0.27(0.25)$} & & & \multicolumn{2}{|c|}{$-0.75(0.30)$} \\
\hline & & & \multicolumn{4}{|l|}{ ** } & \multicolumn{2}{|c|}{$0.29(0.27)$} & \multicolumn{2}{|c|}{$0.65(0.27)$ * } & \multicolumn{2}{|l|}{ * } \\
\hline & \multicolumn{2}{|l|}{ Attempt } & & & \multicolumn{2}{|c|}{$0.92(0.03)$} & \multicolumn{2}{|c|}{$0.90(0.06)$} & \multicolumn{2}{|c|}{$1.34(0.07)$} & \multicolumn{2}{|c|}{$1.34(0.07)$} \\
\hline & & & & & \multicolumn{2}{|l|}{ 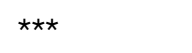 } & \multicolumn{2}{|l|}{ 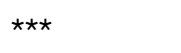 } & \multicolumn{2}{|l|}{ 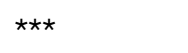 } & \multicolumn{2}{|l|}{ *** } \\
\hline & \multirow{2}{*}{\multicolumn{2}{|c|}{ Class }} & & & & & & & \multicolumn{2}{|c|}{$-0.48(0.03)$} & \multicolumn{2}{|c|}{$-0.42(0.03)$} \\
\hline & & & & & & & & & \multicolumn{2}{|l|}{$\star \star \star *$} & \multicolumn{2}{|l|}{ *** } \\
\hline & \multicolumn{2}{|l|}{ Attempt } & & & & & & & \multicolumn{2}{|c|}{$-0.33(0.03)$} & \multicolumn{2}{|c|}{$-0.33(0.03)$} \\
\hline & *Class & & & & & & & & $\star \star \star \star ~$ & & *** & \\
\hline & Lect. Act. & & & & & & & & & & 0.32 & .07) \\
\hline & & & & & & & & & & & 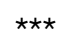 & \\
\hline & Prac. & & & & & & & & & & 1.16 & .09) \\
\hline & Perf. & & & & & & & & & & $\star \star \star \star ~$ & \\
\hline & & & Var & SD & Var & SD & Var & SD & Var & SD & Var & SD \\
\hline Random & Intercept & Stud. & 0.61 & 0.78 & 0.84 & 0.92 & 0.92 & 0.96 & 0.74 & 0.86 & 0.59 & 0.77 \\
\hline & & Item & 1.02 & 1.01 & 1.25 & 1.12 & 1.49 & 1.22 & 1.49 & 1.22 & 1.49 & 1.22 \\
\hline & Attempt & Stud. & & & 0.36 & 0.60 & 0.35 & 0.59 & 0.26 & 0.52 & 0.26 & 0.52 \\
\hline & & Item & & & & & 0.04 & 0.21 & 0.04 & 0.21 & 0.04 & 0.21 \\
\hline $\mathrm{AIC}$ & & & 58,77 & & 55,40 & & 54,9 & & $54,4 \varepsilon$ & & 54,2 & \\
\hline
\end{tabular}

Note: ${ }^{\star \star *}: p<.001 ;{ }^{\star \star}: p<.01 ;{ }^{*}: p<.05$. 
Probability of the correct response grows with a new attempt to solve the item. To illustrate it, we continue with the first extension presented in Equation 2.4. The antilogits derived from Table 2.2 are summarized in Table 2.3. The expected probability that the student gives the correct response to the item from the first attempt is .57 , while the probabilities that the student gives the correct response to the item at the second and the third attempt are .77 and .89 respectively. However, the effect of attempt varies among students. Thus, the chances for the correct response for a student with average proficiency and an effect of attempt of one standard deviation lower than the average effect of attempt are $.57, .64$, and .71 , at the first, the second, and the third attempt respectively. While the chances to the correct response for a student with average proficiency and an effect of attempt of one standard deviation higher than the average effect of attempt are $.57, .86$, and .96 , at the first, the second, and the third attempt respectively. It is important to note that in the first extension, the standard deviation between items and students is higher than in the general model, 0.92 versus 0.78 for students, and 1.12 versus 1.01 for items (see Table 2.2). 
Table 2.3

Probabilities of correct response on an item with average difficulty

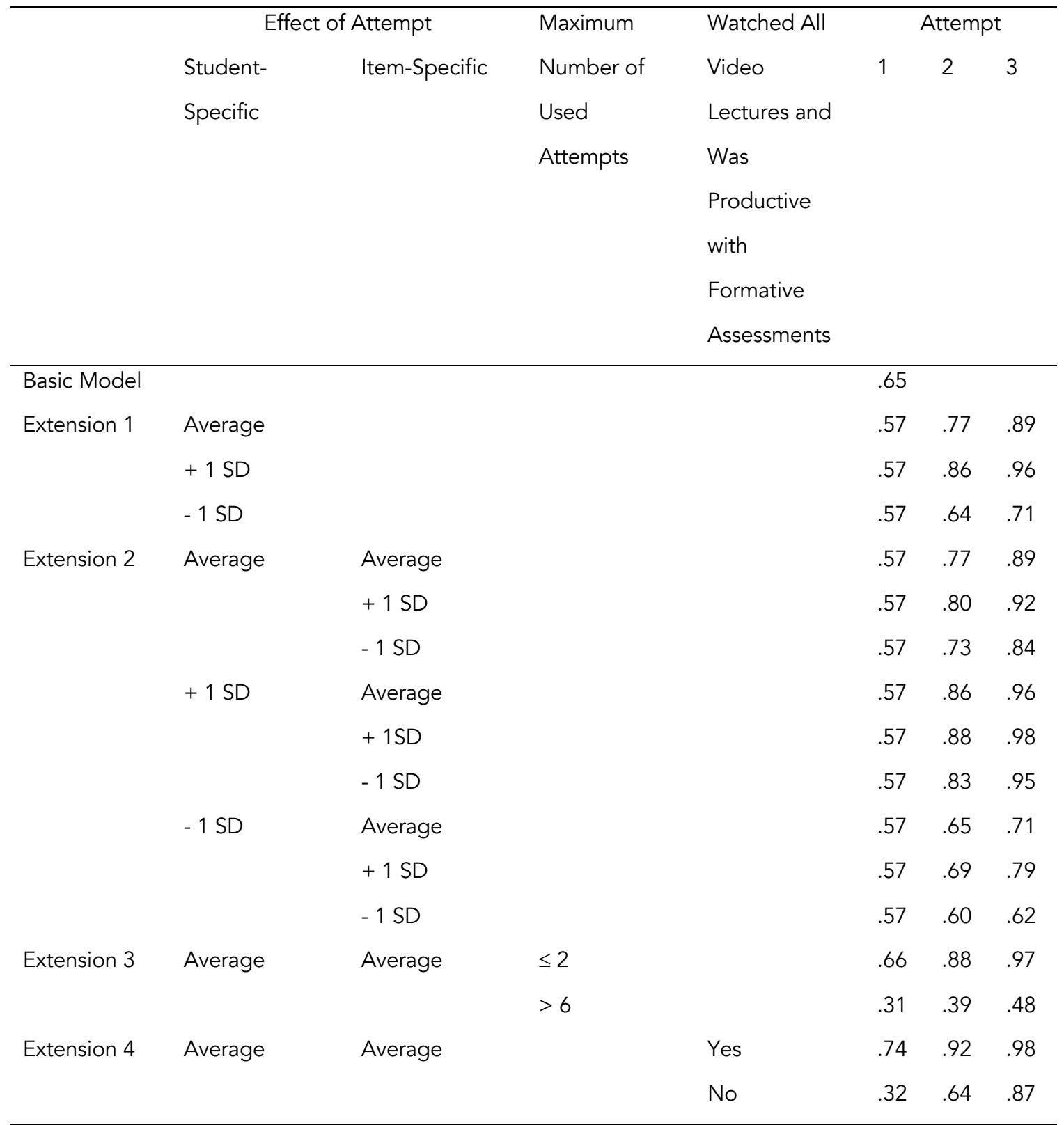

Note: In the table, for the basic model and extensions 1 and 2 the student's proficiency is considered as average. 
The effect of attempt also varies from item to item. As presented in Table 2.3, the chances to the correct response for a student with the average proficiency and the average effect of attempt on an item with an effect of attempt of one standard deviation lower than the average effect of attempt are .57, .73, and .84, at the first, the second, and the third attempt respectively. At the same time, the chances for the correct response for a student with average proficiency and the average effect of attempt on an item with an effect of attempt of one standard deviation higher than the average effect of attempt are $.57, .80$, and .92, from the first, the second, and the third attempt respectively. Compared to the basic model, also for the second extension the standard deviation of the probability of the correct response for items and students is higher than in the general model, 0.96 versus 0.78 for students, and 1.22 versus 1.01 for items (see Table 2.2).

The analysis of the data using Extension 3 (Equation 2.6) teaches us that, as expected, the effect per additional attempt is lower for students who use a higher number of attempts. Let us consider the example in which we calculate the expected probability of the correct response from the first and from the second attempt to an item with the average difficulty for two students. The first student (at least once) used more than six attempts in the summative assessment, while the maximum number of attempts for the second student was not more than two. From the first attempt, the expected probability for the first student is .31 , while for the second student it is .66. Probability of the correct response at the second attempt for the same students is .39 , for the first student, and .88 , for the second student.

Students, active with video lectures and productive with formative assessments, have higher chances to solve items correctly. In the fourth extension (Equation 2.7), presented in Table 2.2, we see that the effects of video lectures and formative assessments are significant and positive. For instance, the expected probability of the correct response from the first attempt for the student who did 
not watch video lectures during the week and who was not productive with formative assessments is .32. At the same time, the expected probability of the correct response from the first attempt for the student who watched all video lectures during the week and was productive with formative assessments is .74. It is important to note that including activity with video lectures and productivity with formative assessments to the model explains $20 \%$ of the variance among students (in comparison to the third extension).

Finally, we can see that model fit is improving with each further extension, with the AIC decreasing from 58,779 for the general model to 54,260 for the fourth extension respectively.

\section{Value of the Extensions}

To show the improvements in the performance better, we started the crossvalidation study from the Rasch model fitted on the first attempts only. The overall accuracy of the predictions using the Rasch model is .710 (Table 2.4). The basic model, a reformulation of the Rasch model fitted on all responses, has higher accuracy (.739). Including the effects of attempts varying among students improves the accuracy by .029 to .768 . Then, including the effect of attempts varying among items, effect of class of students, and the explanatory predictors slightly improve the accuracy by $.002, .000$, and .001 respectively. We can see that the highest improvement of accuracy was from .638 to .738 in Course 2, the lowest improvements were in Course 3, changing from .797 to .821. 
Table 2.4

Accuracy in predicting correctness

\begin{tabular}{lllllllll}
\hline & Overall & \multicolumn{3}{c}{ Course 1 } & \multicolumn{2}{c}{ Course 2 } & \multicolumn{2}{c}{ Course 3 } \\
& $\mathrm{M}$ & $\mathrm{SD}$ & $\mathrm{M}$ & $\mathrm{SD}$ & $\mathrm{M}$ & $\mathrm{SD}$ & $\mathrm{M}$ & $\mathrm{SD}$ \\
\hline Rasch (15t att.) & .710 & .07 & .695 & .03 & .638 & .02 & .797 & .02 \\
Basic Model & .739 & .06 & .719 & .03 & .688 & .01 & .811 & .02 \\
Extension 1 & .768 & .04 & .751 & .02 & .734 & .02 & .819 & .02 \\
Extension 2 & .770 & .04 & .753 & .02 & .737 & .02 & .820 & .02 \\
Extension 3 & .770 & .04 & .753 & .02 & .737 & .02 & .821 & .02 \\
Extension 4 & .771 & .04 & .754 & .02 & .738 & .02 & .821 & .02 \\
\hline
\end{tabular}

Note: In the table, Course 1 is "Economics for Non-Economists", Course 2 is "Game Theory", and

Course 3 is "Introduction to Neuroeconomics: How the brain Makes Decisions". 


\section{Discussion}

In this study several extensions for the Rasch model for applications on MOOC data were presented. The importance of our findings could be described by three points: novelty, relevance for practice, and development of IRT. Firstly, application of IRT in MOOC research is a new field. For instance, the Science Direct search by "title, abstract, and keywords" showed no papers for the combination "massive open online course" or "MOOC" and "psychometrics", "item response theory", "IRT", or "Rasch model". We can link it to the newness of online learning as a phenomenon in education. Secondly, as can be seen, these extensions allow to measure student's proficiency in MOOCs more accurately in comparison to the original model. This effect is mainly achieved by involving attempts as a predictor to the proficiency computation process. These findings support the ideas of the explanatory IRT movement started by De Boeck and Wilson (2004) and collaborators, showing that enriching the IRT models with predictors could significantly improve the quality of explanation and understanding of the latent constructs. Finally, the results of this study could be considered as the first steps in transition from the traditional psychometric approaches focused on accurate locating student on the proficiency scale to more flexible approaches for MOOCs, oriented at understanding student's behavior and linking this behavior to his/her proficiency. We found that the analysis of attempts and student's individual attempt pattern in MOOCs could be an important source of evidence and might support the analysis of correctness of student's responses, realized by the traditional psychometric approaches. Linking student's activity with video-lectures and productivity in formative assessments to correctness of his/her responses in summative assessments allowed us to consider and understand student's proficiency from the position of the whole module instead of the position of 10 items in summative assessment. We believe it means an important contribution to the field of psychometrics of MOOCs (although the proposed 
extensions might be applicable in other contexts, it requires additional feasibility studies).

The proposed extensions work with test-based assessments, where, according to the theory, the performance is a function of two parameters, student's proficiency and difficulty of test items. However, assessments in MOOCs could be realized as peer-reviewed assignments where students write an essay or make a design project and then check works of their peers using rubrics with criteria, proposed by the course author. In peer-reviewed assignments, the performance is a function of at least three parameters: student's proficiency, assignment difficulty and reviewer's leniency or severity. This example shows us the limitation of our extensions, but the limitation could be considered as a direction for future research. As a solution, we propose to extend the existing psychometric models for peer-reviews such as Many-Facet Rasch Model (Linacre, 1992). The resulting set of extensions will greatly improve measurements in MOOCs. 


\title{
CHAPTER 3
}

\section{MEASURING GROWTH IN STUDENTS' PROFICIENCY IN MOOCS: TWO COMPONENT DYNAMIC EXTENSIONS FOR THE RASCH MODEL ${ }^{3}$}

\begin{abstract}
Massive open online courses (MOOCs) are increasingly popular among students of various ages and universities around the world. The main aim of $\mathrm{MOOC}$ is a growth in students' proficiency. That is why students, professors, and universities are interested in an accurate measurement of growth. Traditional psychometric approaches based on Item Response Theory (IRT) assume that student's proficiency is constant over time and therefore are not well suited for measuring the growth. In this study we try to release this assumption, and (a) propose to measure two components of growth in proficiency in MOOCs; (b) apply this idea in two dynamic extensions of the most common IRT model, the Rasch model; (c) illustrate these extensions on the logged data from three MOOCs and (d) check the quality of the extensions using a cross-validation procedure. We found that proficiency grows both through the whole course and within learning objectives. The dynamic extensions fit the data better than the original Rasch model. Finally, both extensions perform well, with the average accuracy of .763 in predicting students' responses from real MOOCs.
\end{abstract}

Emerged a decade ago, massive open online courses (MOOCs) are a progressive phenomenon in distance education. $\mathrm{A} \mathrm{MOOC}$ is a free online course available for anyone to enroll. For students of various ages, MOOCs are a flexible way to obtain new skills and advance careers. For universities, MOOCs are an efficient way to deliver education at scale. Typically, a MOOC consists of prerecorded video lectures, reading assignments, assessments and forums. There are several provider platforms on which universities publish MOOCs, for instance, Coursera, edX, XuetangX, FutureLearn, Udacity, and MiriadaX. In December 2016 , the estimated total number of MOOCs was 6,850 from over 700 universities around the world. Coursera, edX, and XuetangX are the largest MOOC provider platforms with over 39 million learners (Shah, 2016).

${ }^{3}$ The text in this chapter has been published as Abbakumov, D., Desmet, P., \& Van den Noortgate, W. (2019). Measuring growth in students' proficiency in MOOCs: Two component dynamic extensions for the Rasch model. Behavior Research Methods, 51(1), 332-341. 
The main aim of MOOCs, like of any other learning environment, is a growth in students' proficiency. Growth tracking is essential for all involved parties: for a student, to understand his/her progress in the proficiency level; for a professor, to infer how efficient his/her course is and/or to decide when to support a student (or to advance him/her) through the course. Unfortunately, proficiency is a latent variable that cannot be observed directly; yet, it can be estimated on the basis of observable variables, for example, student's performance on assessment items. As proficiency itself is a latent variable, its growth is also a latent variable. To link the observable side to the latent side, there are specific rules, called psychometric theories.

Psychometric approaches based on Item Response Theory (IRT) traditionally consider proficiency as a constant variable (Lord \& Novick, 1968). These approaches were developed for measuring proficiency but not for measuring its change. For example, the most common psychometric model, the Rasch model (Lord \& Novick, 1968; Rasch, 1960), states that,

$$
\operatorname{Logit}\left(\pi_{i j}\right)=\ln \left(\frac{\pi_{i j}}{1-\pi_{i j}}\right)=\theta_{j}-\delta_{i} \text { and } Y_{i j} \sim \operatorname{Bernoulli}\left(\pi_{i j}\right)
$$

In this model, $Y_{i j}$ is an observable score of student $j$ to an item $i$, which equals 1 for a correct response, 0 for an incorrect response. This variable therefore can be considered as Bernouilli distributed, with probability $\pi_{i j}$, which in turn is described by a logistic function of the difference between a static student's parameter $\left(\theta_{j}\right)$ and an item parameter $\left(\delta_{i}\right)$, which are often interpreted as proficiency and difficulty respectively. The values for the proficiency parameter are typically considered as a random sample from a normal population distribution, with $\theta_{j} \sim N\left(0, \sigma_{\theta}^{2}\right)$, while the items are considered as a fixed set. Hence, the parameters that are estimated are the difficulty parameters and the variance between students in the proficiency parameter (the mean of the distribution of proficiencies is constrained to zero, in 
order to make the model identified). The main assumptions of the Rasch model are unidimensionality, which means that only one kind of proficiency is measured by a set of items in a test; and local independence, which means that when the proficiency influencing test performance is held constant, students' responses to any pair of items are statistically independent (Hambleton, Swaminathan, \& Rogers, 1991; Molenaar, 1995).

One of the common approaches to detect the growth in the course is to administer the same test to a student, the first at the beginning and the second at the end of that course. Following the Classical Test Theory (CTT), the first score can be subtracted from the second score and the resulting difference is used as a value of the student's growth (Davis, 1964). Based on the IRT tradition, however, the value of growth comes from the difference in proficiency estimates obtained in two measurement occasions (Andersen, 1985). IRT makes it possible to use sets of items in two measurement occasions that only partially overlap and in general are not equally difficult. Such overlapping allows to place items from both sets on a common scale (Hambleton, Swaminathan, \& Rogers, 1991), and, as a result, to get the difference in proficiency estimates between the beginning and the end of the course. When we can make use of items that were already calibrated before, we can even render items to new users at two measurement occasions that do not overlap at all.

Yet, psychometricians have successfully attempted to model dynamic processes within the framework of the Rasch model. The first class of such models is focused on assessments, the second one on learning environments. The first class might be decomposed further in two subclasses that differ from each other in whether the change in students' proficiency between assessments or within the assessment is modelled.

Fisher (1976, 1995) presented linear logistic models that measure the change in proficiency between assessments, for instance, between a pre-test and 
a post-test. These models are based on the idea that an item given to the same student at two different time points can be considered as a pair of items, with two different item difficulty parameters. Thus, any change in proficiency occurring between the measurement occasions is described through a change of the item parameters. During the assessment, proficiency is assumed to remain constant.

Another subclass of models is aimed at measuring the change in proficiency within the assessment, for instance, due to a learning effect. Verhelst and Glas $(1993,1995)$ proposed a dynamic generalization for the Rasch model:

$$
\operatorname{Logit}\left(\pi_{i j}\right)=\ln \left(\frac{\pi_{i j}}{1-\pi_{i j}}\right)=\theta_{j}+t_{j i} \gamma-\delta_{i} \text { and } Y_{i j} \sim \operatorname{Bernoulli}\left(\pi_{i j}\right),
$$

where $t_{j i}$ is the number of correct answers or the number of items viewed by student $j$ up to item $i-1 . \gamma$ links $t_{j i}$ with the probability of the correct answer, and therefore represents the growth. The presentation of $t_{j i}$ depends on the dynamic process within the assessment that a researcher aims to estimate or control. For instance, if the only feedback displayed after a student's response is that the response was correct, it is assumed that students learn from correctly answered items only (Verguts \& De Boeck, 2000). In this case, to control the proficiency growth in within the assessment, a researcher can define $t_{j i}$ as the number of correct answers. On the other hand, if more extended feedback is displayed after a student's response (e.g., hints or even the correct response), students may also learn from incorrect answers. Here, $t_{j i}$ might be presented as the number of items viewed or even be decomposed on two variables, the number of correct answers and the number of incorrect answers, in order to control separately the growth from correctly answered items and from correct answers displayed after fails. Despite its flexibility, the model is limited as it does not represent individual differences in growth, it only indicates the average learning trend. To overcome this limitation, it was proposed to allow the growth effect $\gamma$ vary from student to 
student (Verguts \& De Boeck, 2000; De Boeck, et al., 2011). The resulting model is:

$$
\operatorname{Logit}\left(\pi_{i j}\right)=\ln \left(\frac{\pi_{i j}}{1-\pi_{i j}}\right)=\theta_{j}+t_{j i} \gamma_{j}-\delta_{i} \text { and } Y_{i j} \sim \operatorname{Bernoulli}\left(\pi_{i j}\right),
$$

where the students' growth parameters are considered as a random sample from the population where the growth parameters are normally distributed, $\gamma_{j} \sim N\left(0, \sigma_{\gamma}^{2}\right)$.

The second class of models focuses on learning environments. Kadengye, Ceulemans and Van den Noortgate $(2014,2015)$ proposed longitudinal IRT models where proficiency is considered as a function of time within learning sessions and the time between learning sessions, for instance:

$$
\begin{gathered}
\operatorname{Logit}\left(\pi_{i j}\right)=\left(\alpha_{0}+\omega_{0 j}\right)+\left(\alpha_{1}+\omega_{1 j}\right) * \text { wtime }_{i j}+\left(\alpha_{2}+\omega_{2 j}\right) * \text { btime }_{i j}+ \\
v_{i} \text { and } Y_{i j} \sim \operatorname{Bernoulli}\left(\pi_{i j}\right)
\end{gathered}
$$

where $\alpha_{0}$ is the overall initial proficiency, $\omega_{0 j}$ is the deviation of student $j$ from $\alpha_{0}$, wtime $_{i j}$ and btime $_{i j}$ is the amount of time that passed for student $j$ while respectively using and not using the learning environment, up to the moment student $j$ response to item $i, \alpha_{1}$ and $\alpha_{2}$ are overall population linear time trends within and between sessions respectively, $\omega_{1 j}$ and $\omega_{2 j}$ are deviations of student $j$ from $\alpha_{1}$ and $\alpha_{2}$ respectively, student-specific random effects are assumed to have a multivariate normal distribution, and $v_{i}$ are random item effects with $v_{i} \sim N\left(0, \sigma_{v}^{2}\right)$. Thus, the authors introduce a dynamic concept $\theta_{i j}=\left(\alpha_{0}+\omega_{0 j}\right)+\left(\alpha_{1}+\omega_{1 j}\right) *$ wtime $_{i j}+\left(\alpha_{2}+\omega_{2 j}\right) *$ btime $_{i j}$, which corresponds to the proficiency of student $j$ at the moment of responding item $i$.

The direct use of approaches presented above for measuring the growth in students' proficiency in MOOCs is hampered by a few challenges. Assessments 
have no common items, which makes the usage of a scaling approach impossible. In addition, the time a student spends in a MOOC is often not logged, which complicates the use of time-based approaches. Also the MOOCs instructional design impede the usage of the models mentioned above. Firstly, video lectures are considered the central instructional tool of a MOOC which support learning objectives and prepare students for associated assessments (Coursera, n.d.c). Secondly, the way a student interacts with an assessment item in MOOCs is more complex: he/she can make several attempts to solve it, and after the wrong response, he/she receives tips aimed at learning facilitation. It means that proficiency is expected to change mainly from video lectures but also from interaction with items in assessments. We believe that the psychometric approach for modeling the growth in MOOCs could be improved by involving information from these complex student-content interactions.

This study extends on the growing research domain of modeling dynamic processes with IRT but focuses on the specificity and data structure of MOOCs. We propose to incorporate two novel growth trends, from video lectures and from interaction with items in assessments, into the IRT framework in order to estimate differential latent growth that might be present in MOOC datasets. We realize this idea in two dynamic extensions for the Rasch model. Next, we illustrate these extensions using the data from three MOOC. Finally, we check the performance of these extensions using a cross-validation procedure applied on the data from these MOOCs. We expect that these extensions will provide possibilities for a more accurate estimate of student latent traits in MOOCs.

\section{Measuring Two Components of Growth in Proficiency in MOOCs}

In this study, we start with the structure of MOOCs, typical for Coursera courses. They are composed of modules each of which is structured around a cohesive subtopic and typically lasts for one week. Each module consists of a set of lessons. Typically, a lesson is structured around 1-2 learning objectives and 
includes several video lectures which might be accompanied by additional instructional content, for instance, reading material, forum discussions and practice items. Each video lecture lasts 4-9 minutes. It takes a student about 30 minutes to complete a lesson. Each module is concluded by a summative assessment, which is realized as a 10-15 items test, a programming task, or a peerreview task. In this study, we focus on tests, which are the most popular types of assessment. Items in tests are typically multiple choice or open-ended questions where a student is expected to choose an option or options, put a number, a sequence, a word, or a phrase.

Growth through the course. During the course, a student watches video lectures to master learning objectives assigned to a certain lesson of a certain module. Typically, a student has freedom in interaction with video lectures. He/she can watch or skip a certain video lecture. It means, that each student has an individual pattern of interaction with video content, and the number of watched video lectures varies among students. To catch the growth in students' proficiency from video lectures, we can place all video lectures and all summative assessments of the course in one line successively, for instance, a sequence of video lectures of the first week, summative assessment items of the first week, then a sequence of video lectures of the second week and so on. Now we can count a progressive sum of video lectures (the observable variable) which a student watched before a certain summative assessment. In this case, the effect of the progressive sum on the students' performance with summative assessment items represents the continuous growth in the students' proficiency (the latent variable) from the video content. Accumulation of watched video lectures will probably boost a student's chances of the correct response on a certain summative assessment item. We remember that according to the MOOCs design, video lectures are the core instructional tool. Thus, the growth in students' proficiency from video lectures might be considered as the growth through the course. 
Growth within a certain learning objective. As we mentioned above, in MOOCs students can make several attempts for each item in assessment. Thus, after the wrong response, the student may analyze his/her mistake, use the hint if it is assigned to the item, review the video lecture and notes, consult on forums, or even use extracurricular materials, and afterwards make the second attempt. In this case, the added activity will probably lead to an increased chance of the correct response on that item from one attempt to the next attempt, and we catch the local growth within a certain learning objective or even its part. However, it is important to note, that the increasing chances might be explained by a specific strategy of interacting with item chosen by a student - clicking repeatedly on alternative options in multiple-choice items or guessing in open ended items. In this case we deal with no real growth (or pseudo growth) within a certain learning objective.

In the following section, we model, visualize and explain these dynamic concepts.

\section{Two-Component Dynamic Extensions for the Rasch Model}

As the basis for the two-component dynamic extensions, we use a reformulation of the Rasch model presented by Van den Noortgate, De Boeck, and Meulders (2003):

$$
\operatorname{Logit}\left(\pi_{i j}\right)=b_{0}+u_{1 j}+u_{2 i} \text { and } Y_{i j} \sim \operatorname{Bernoulli}\left(\pi_{i j}\right),
$$

where $u_{1 j} \sim N\left(0, \sigma_{u 1}^{2}\right)$ and $u_{2 i} \sim N\left(0, \sigma_{u 2}^{2}\right)$.

In this reformulation based on the principle of cross-classification multilevel models, which are generalizability theory models with logit-link functions, we have the intercept, and two residual terms referring to the student and the item respectively. The mean of both residual terms equals zero. Thus, the intercept equals the estimated logit of the probability of the correct response of an average 
student on an average item. The first residual term shows the deviation of the expected logit from student $j$ from the overall logit. The higher this deviation, the higher the probability of the correct response is. Therefore, this residual term can be interpreted as the proficiency of student $j$, and equals $\theta_{j}$ from Equation 3.1. The second residual term shows the deviation of the expected logit from item $i$ from the mean logit, in the sense that the larger the residual - the higher the expected performance. The difficulty parameter $\delta_{i}$ from Equation 3.1 is equivalent to $-\left(b_{0}+u_{2 i}\right)$ from Equation 3.5. Hence, the residual term $u_{2 i}$ refers to the relative easiness of the item $i$, compared to the mean easiness of items, $b_{0}$. The strength of this reformulation is, that in comparison to the original formulation of the Rasch model, the items are considered as random, that makes the model very flexible for making extensions, because there are still degrees of freedom left to include various item predictors (Van den Noortgate, De Boeck, \& Meulders, 2003).

\section{Extension with Fixed Growth Effects}

In the first extension, we transform the growth trend proposed by Verhelst and Glas $(1993,1995)$ into the two components introduced above: the progressive sum of watched video lectures is used to model the continuous growth through the course, and the response pattern for a certain item in summative assessment is used to model the local growth within a certain learning objective. Thus, in our first extension,

$$
\begin{aligned}
\operatorname{Logit}\left(\pi_{i j}\right)= & b_{0}+b_{1} * \text { video }_{i j}+b_{2} * \operatorname{attempt}_{i j}+u_{1 j}+ \\
& u_{2 i} \text { and } Y_{i j} \sim \operatorname{Bernoulli}\left(\pi_{i j}\right)
\end{aligned}
$$

$b_{0}$ equals the estimated logit of the probability of the correct response of an average student on an average item in the course summative assessments; $v_{i d e o_{i j}}$ is the progressive sum of video lectures which student $j$ watched before responding an item $i$ divided by 100 for better scaling; $b_{1}$ is the effect of the 
progressive sum, and is interpreted as the growth effect through the course; attempt $_{i j}$ takes on values $0,1,2,3$ or 4 for the first, second, third, fourth, or fifth or higher attempt of student $j$ on item $i$ respectively; $b_{2}$ is the effect of attempt, and can be interpreted as the growth effect within a certain learning objective; $u_{1 j} \sim N\left(0, \sigma_{u 1}^{2}\right)$ and $u_{2 i} \sim N\left(0, \sigma_{u 2}^{2}\right)$.

From Equation 3.6, it can be deduced that the value $\theta_{0 j}=u_{1 j}$ corresponds to the initial proficiency of student $j$ at the start of the course. On Figure 3.1, this value is presented by the point with index 1 . The value $\theta_{i j}=u_{1 j}+b_{1} * v_{i d e o_{i j}}$ corresponds to the proficiency of student $j$ at the moment of responding on item $i$. This dynamic value represents the continuous evolution of proficiency of student $j$ through the whole course and determines his/her chances on a correct response on item $i$ from the first, initial, attempt. This value is presented on Figure 3.1 by the point with index 2. However, if student $j$ fails this attempt, he/she would probably go on the second attempt. The logit of probability of correct response in that case would increase with $b_{2}$, which represents the local rise of student's proficiency within a learning objective. This value is presented on Figure 3.1 by the vertical segment with index 3 . 


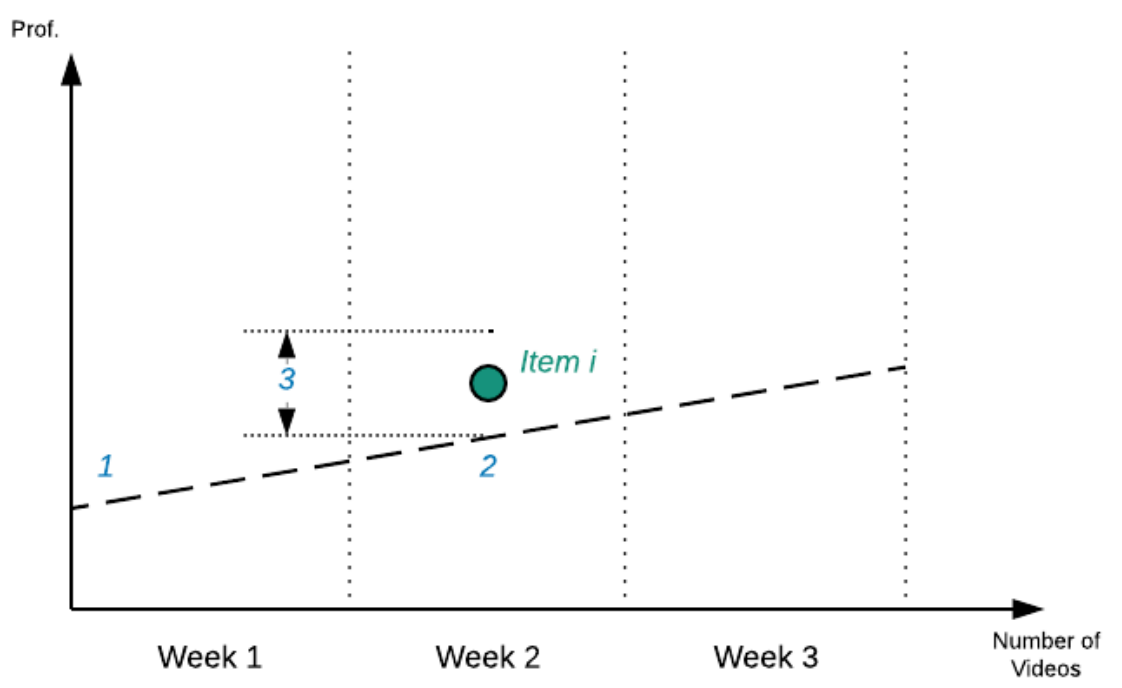

Figure 3.1. The point with index 1 presents the initial proficiency of a student. The point with index 2 corresponds to the proficiency of a student at the moment of responding on item i. The continuous growth of proficiency through the course is illustrated by inclined dashed line. The local growth of proficiency within a certain learning objective is illustrated as vertical segment with index 3. 
As in the model of Verhelst and Glas (1993,1995), all students are assumed to have the same dynamics in their proficiency. We expect both growth effects, $b_{1}$ and $b_{2}$, to be positive. It means that with each new video lecture watched, that is indicated by the progressive sum, and with each new attempt made the chances of the correct response are growing. We can explain it by learning through the course and within a certain learning objective.

\section{Extension with Random Growth Effects}

The next extension follows the logic of modeling individual dynamics in proficiency presented in works of Verguts \& De Boeck (2000), De Boeck, et al. (2011), and Kadengue, Ceulemans, and Van den Noortgate $(2014,2015)$ by including the student-specific random effects. We assume that both effects introduced in the first extension can vary randomly from subject to subject. Thus, in our second extension,

$$
\begin{gathered}
\operatorname{Logit}\left(\pi_{i j}\right)=b_{0}+\left(b_{10}+b_{1 j}\right) * \operatorname{video}_{i j}+\left(b_{20}+b_{2 j}\right) * \operatorname{attempt}_{i j}+u_{1 j}+ \\
u_{2 i} \text { and } Y_{i j} \sim \operatorname{Bernoulli}\left(\pi_{i j}\right)
\end{gathered}
$$

$b_{10}$ is the overall effect of progressive sum, the overall growth effect through the course, while $b_{1 j}$ is a deviation of the progressive sum effect for student $j$ from the overall effect, the individual growth effect through a course; $b_{20}$ is the overall effect of attempt, the overall growth effect within a certain learning objective, while $b_{2 j}$ is the deviation of the attempt effect for student $j$ from the overall attempt effect, the individual growth effect within a certain learning objective; in the first version of this extension $u_{1 j}, b_{1 j}$, and $b_{2 j}$ follow univariate normal distributions, $N\left(0, \sigma_{u 1}^{2}\right), N\left(0, \sigma_{b 1}^{2}\right)$, and $N\left(0, \sigma_{b 2}^{2}\right)$, respectively, while in the second version $u_{1 j}, b_{1 j}$, and $b_{2 j}$ follow a multivariate normal distribution $N(\mathbf{0}, \boldsymbol{\Sigma})$ with $\boldsymbol{\Sigma}$ as the variance-covariance matrix. 
From Equation 3.7, it can be derived that the value $\theta_{0 j}=u_{1 j}$ represents the initial proficiency of student $j$ at the start of the course (the point with index 1 on Figure 3.1). The value $\theta_{i j}=u_{1 j}+\left(b_{10}+b_{1 j}\right) * v i d e o_{i j}$ corresponds to the proficiency of student $j$ at the moment of responding on item $i$, and represents the continuous evolution of proficiency of student $j$ through the whole course and determines his/her chances on a correct response on item $i$ from the first, initial, attempt (the point with index 2 on Figure 3.1). In case of student $j$ fails this attempt, and go on the second attempt, the logit of probability of correct response would increase with $\left(b_{20}+b_{2 j}\right)$, which represents the local rise of student's proficiency within a learning objective (the vertical segment with index 3 on Figure 3.1).

As a result, we expect both overall growth effects, $b_{10}$ and $b_{20}$, to be positive. However, an individual student might show a smaller or no growth through the course, for instance, if he/she knows the course content before the course, or, on the contrary, if the course is too difficult for the student to understand. In this case, the student's random effect $b_{1 j}$ is negative: the learning rate is smaller than overall learning rate across students. As we mentioned before, it is also possible that a student can simply enumerate possibilities, for example, by clicking repeatedly on alternative options in multiple-choice questions. It means, there is no real growth within the learning objective. Therefore, the effect of attempt for this student is smaller than for an average student, hence his/her deviation $b_{2 j}$ from the mean effect $b_{20}$ is expected to be negative. For a student who is learning fast through the course and within a certain learning objective, in contrast, we expect both student-specific random effects $b_{1 j}$ and $b_{2 j}$ to be positive. Note that this approach can be distinguished from modeling possible guessing with the three-parameter logistic model (3PL; Lord \& Novick, 1968) which is used for items that are attempted once and models pseudo guessing, but not a growth in chances which comes with extra attempts. 
In the following section, we illustrate these extensions using the data from three MOOCs and check the performance of the extensions using a crossvalidation procedure applied on the same datasets.

\section{Method}

\section{Data}

In this study, we use the data of three MOOCs from Coursera platform: "Economics for Non-Economists" (Higher School of Economics, n.d.a), "Game Theory" (Higher School of Economics, n.d.c), and "Introduction to Neuroeconomics: How the Brain Makes Decisions" (Higher School of Economics, n.d.d). We involve the data of five weekly modules for each course.

In the data, each student and all course elements such as a video lecture or an assessment item have a unique identification number. Interactions of students with course elements have an individual identification number and a time stamp. Student's responses on summative assessment items have dichotomous coding where 1 and 0 correspond to the correct and wrong response in a certain attempt respectively. The assessment items are multiple choice and open-ended questions where a student is expected to choose one option or multiple options, put a number, a sequence, a word, or a phrase. There is no overlap in items between summative assessments of different weeks. The correctness of students' responses is checked automatically. Attempts are marked with a time stamp. Student's interactions with video lectures are coded as 0 or 1 where 1 means the student watched the lecture, and 0 means the student did not watch the lecture. The platform does not track how many times a student watched a certain video.

The first course, "Economics for Non-Economists", is taught in Russian. At the moment of conducting this study, there were 1,632 active students in the course. The distribution of students among countries is as follows: Russia (72\%), Ukraine (8.4\%), Kazakhstan (3.9\%), Belarus (3.2\%), USA (1.2\%), and others (11.3\%). The number of items in weekly summative assessments for these 5 modules is 68 
in total, 10 items for weeks 1 to 4,8 items for week 5, and 20 items in concluding assessment. The total number of responses for the first course is 134,068 . Students used 1.89 attempts in average, the standard deviation is 1.41. After recoding the attempts to $0,1,2,3$, and 4 that means the first, the second, the third, the fourth, or the fifth or higher attempt respectively, the mean of attempts is 0.82 and standard deviation is 1.12. The number of video lectures for these five modules is 48 in total, 9 in the first week, and 8, 9, 13, and 9 in the following weeks respectively. Students watched on average $6.70,6.60,7.35,9.99$, and 7.27 with standard deviation of $3.00,2.30,2.65,4.32$, and 2.79 during the first, the second, and the following three weeks respectively.

The second course, "Game Theory", is taught in Russian. The distribution of students among countries is as follows: Russia (57\%), Ukraine (10\%), Kazakhstan (3.3\%), USA (3.2\%), Belarus (3\%), and others (23.5\%). The third course, "Introduction to Neuroeconomics: How the brain Makes Decisions", is taught in English. The distribution of students among countries is as follows: USA (19\%), India (8.7\%), Russia (6.8\%), Mexico (4.7\%), United Kingdom (4\%), and others (56.8\%).

Descriptive statistics over the students, items, responses, attempts, and video lectures for these courses are given in Table 3.1. 
Table 3.1

Data overview

\begin{tabular}{llll}
\hline & Course 1 & Course 2 & Course 3 \\
\hline Students & 1,632 & 3,092 & 4,873 \\
Items & 68 & 50 & 60 \\
Responses & 134,068 & 228,490 & 339,330 \\
Attempts & $1.89(1.41)$ & $1.92(1.50)$ & $2.10(2.01)$ \\
Video Lectures & 48 & 44 & 26 \\
Number of Video Lectures Looked at in & & & \\
$\quad$ Week 1 & $6.70(3.00)$ & $6.14(2.66)$ & $3.75(1.57)$ \\
$\quad$ Week 2 & $6.60(2.30)$ & $7.53(2.63)$ & $3.18(1.15)$ \\
$\quad$ Week 3 & $7.35(2.65)$ & $8.31(2.96)$ & $5.26(2.24)$ \\
$\quad$ Week 4 & $9.99(4.32)$ & $6.98(2.10)$ & $5.12(1.62)$ \\
$\quad$ Week 5 & $7.27(2.79)$ & $7.65(2.54)$ & $3.63(0.89)$
\end{tabular}

Note: In the table, Course 1 is "Economics for Non-Economists", Course 2 is "Game Theory", and Course 3 is "Introduction to Neuroeconomics: How the brain Makes Decisions". For Attempts and Number of Video Lectures, we have mean values and, in parentheses, standard deviations. 


\section{Illustration of the Extensions}

We start with the Rasch model from Equation 3.5. As we discussed above, the Rasch model has no growth effects. However, we fitted this model to get a benchmark for comparing the model and its dynamic extensions, and to provide an empirical check for the unidimensionality assumption. Then we continue with fitting the extension with fixed growth effects from Equation 3.6 and the extension with (uncorrelated and correlated) random growth effects from Equation 3.7. To fit the Rasch model and the extensions, we use the "glmer" function of the "Ime4" package (Bates, Maechler, Bolker, \& Walker, 2015) of the $R$ language and environment for statistical computing ( $R$ Core Team, 2013). To check the unidimensionality assumption, we use the "unidimTest" function of the "Itm" package (Rizopoulos, 2006) of $\mathrm{R}$, which implements the approach proposed by Drasgow and Lissak (1983) where the latent dimensionality is checked via a comparison of the eigenvalues of a factor analysis of the observed data and one of data generated under the assumed unidimensional IRT model. The null hypothesis of unidimensionality is rejected if the second eigenvalue of the observed data is substantially larger than the second eigenvalue of the simulated data. To approximate the distribution of the test statistic under the null hypothesis, we used 100 samples in the Monte Carlo procedure implemented in the unidimTest function. To compare the model fit, we use the Akaike's information criterion (AIC; Akaike, 1974) provided by the "glmer" function".

\section{Cross-Validation}

When we talk about the value of the extensions in the cross-validation, we refer to the accuracy of predicting correctness of students' responses in the

${ }^{4}$ Although the AIC is widely used to compare different models, its application for models with a different number of random effects has been criticized (Vaida \& Blanchard, 2005). For better comparison, the conditional Akaike information criterion (cAIC) can be used. 
summative assessments. The procedure looks as follows: first we randomly split the students' responses on a summative assessment from the three MOOCs to training and test datasets. There are $75 \%$ of all responses in the training set and $25 \%$ of responses in the test set. Then we fit the Rasch model and both extensions on the training sets and use the fitted models to derive the probabilities of the correct responses on the test sets. Using the probabilities, we derive the expected responses in sense of if they are smaller than .50 , the expected response is 0 , and if they are larger than .50 , the expected response is 1 . Next, using the predicted and the real responses from the test sets, we build a confusion matrix with two rows and two columns with the number of false positives, false negatives, true positives, and true negatives respectively. This matrix allows us to understand the quality of predictions as well as the improvements in prediction across the models. Using this matrix, we calculate an accuracy index:

$$
\text { Accuracy }=\frac{T P+T N}{P+N}
$$

where $T P$ is true positives; $T N$ is true negatives; $P$ is all positives; $N$ is all negatives. Then we repeat this procedure five times and finish by counting the average accuracy for each model.

\section{Results}

We start from the Rasch model from Equation 3.5. The dimensionality check did not reveal significant evidence against unidimensionality $(p=.15)$. As shown in Table 3.2, the estimate of the intercept equals 0.96 . The inverse logit, or the antilogit, of this value is .72 . This means that, the expected probability that an average student of the "Economics for Non-Economists" course gives the correct response on an average item is .72 . This probability of the correct response varies among students (and over items). A student with proficiency of one standard deviation lower, and a student with proficiency of one standard deviation higher 
than the average proficiency have proficiencies of 0.24 and 1.68, which correspond to probabilities of the correct answer on an average item of .56 and .84 respectively. As we mentioned above, the Rasch model assumes that the student's proficiency remains constant within the course. 
Table 3.2

Parameters of the extension for Course 1

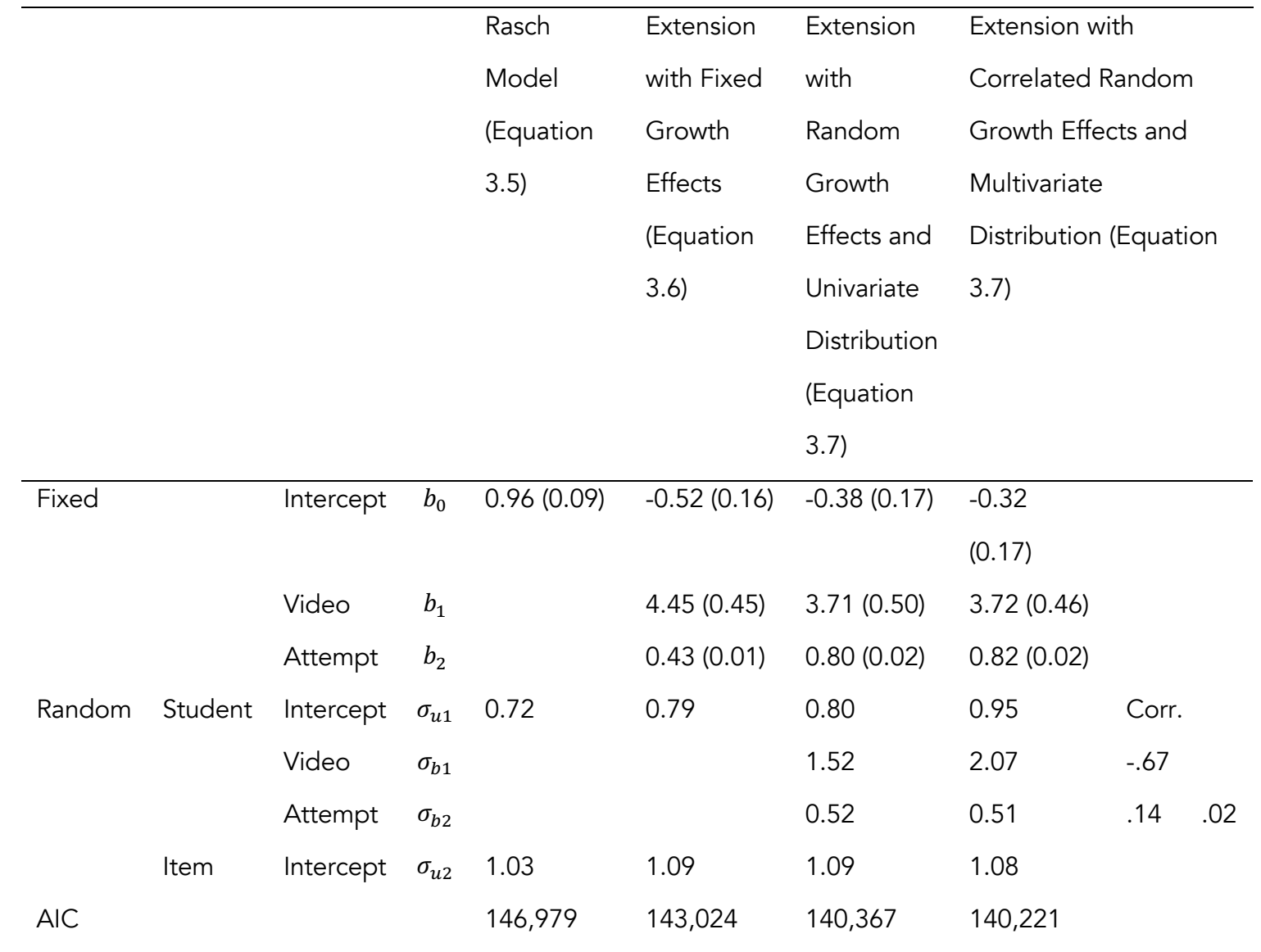

Note: In the table, Course 1 is "Economics for Non-Economists". For fixed effects, the standard error is presented in parentheses. For random effects the standard deviation is presented. 
However, extending the Rasch model by fixed growth effects (the first extension; Equation 3.6), shows that the probability of the correct response grows with every new watched lecture and with every new attempt to solve an item. As can be derived from Table 3.2, watching all nine video lectures from the first week improves the chances of the correct response of an average student on an average item grows from .37 to .47 (see Table 3.3), these are the antilogits of -0.52 and ($0.52+9 / 100 * 4.45)$. By the end of the third week, the chances of the correct response (on the same, average item) rise to .65 (Table 3.3). By the end of the fifth week, the chances of the correct response approach the value of .83. In order to get a better idea of the size of the growth within a certain learning objective, we compare the chances of the correct response of an average student on an average item from the first, the second and the third attempt. These values are $.37, .48$, and .58 respectively (Table 3.4). It is important to note, that in accordance with the extension, the growth in both components is assumed to be the same for all students. 
Table 3.3

Dynamics of antilogits through Course 1

\begin{tabular}{|c|c|c|c|c|c|c|c|}
\hline & \multirow{2}{*}{$\begin{array}{l}\text { Start } \\
\text { Avg. }\end{array}$} & \multicolumn{3}{|c|}{ Week 1} & \multicolumn{3}{|c|}{ Week 5} \\
\hline & & Avg. & $-S D$ & $+\mathrm{SD}$ & Avg. & $-S D$ & $+\mathrm{SD}$ \\
\hline Rasch Model & .72 & .72 & & & .72 & & \\
\hline (Equation 3.5) & & & & & & & \\
\hline Extension with Fixed Growth Effects & .37 & .47 & & & .83 & & \\
\hline (Equation 3.6) & & & & & & & \\
\hline Extension with Random Growth Effects and & .41 & .49 & .45 & .52 & .80 & .66 & .89 \\
\hline Univariate Distribution (Equation 3.7) & & & & & & & \\
\hline $\begin{array}{l}\text { Extension with Correlated Random Growth Effects } \\
\text { and Multivariate Distribution (Equation 3.7) }\end{array}$ & .42 & .50 & .46 & .55 & .81 & .62 & .92 \\
\hline
\end{tabular}

Note: In the table, the antilogits for a student with average (initial) ability and for an item with average difficulty are presented. The dynamics of antilogits for the start, the end of the first week, and the end of the fifth week of the course is presented. For the model with random growth effects, the average, one standard deviation lower than the average, and one standard deviation higher than the average continuous growth effect are presented. Course 1 is "Economics for NonEconomists". 
Table 3.4

Dynamics of antilogits with attempts for Course 1

\begin{tabular}{|c|c|c|c|c|c|c|c|}
\hline & \multicolumn{4}{|c|}{ Attempt 2} & \multicolumn{3}{|c|}{ Attempt 3} \\
\hline & Avg. & Avg. & $-S D$ & $+\mathrm{SD}$ & Avg. & $-S D$ & $+\mathrm{SD}$ \\
\hline $\begin{array}{l}\text { Rasch Model } \\
\text { (Equation 3.5) }\end{array}$ & .72 & .72 & & & .72 & & \\
\hline $\begin{array}{l}\text { Extension with Fixed Growth Effects } \\
\text { (Equation 3.6) }\end{array}$ & .37 & .48 & & & .58 & & \\
\hline $\begin{array}{l}\text { Extension with Random Growth Effects and Univariate } \\
\text { Distribution (Equation 3.7) }\end{array}$ & .41 & .60 & .48 & .72 & .77 & .54 & .91 \\
\hline $\begin{array}{l}\text { Extension with Correlated Random Growth Effects and } \\
\text { Multivariate Distribution (Equation 3.7) }\end{array}$ & .42 & .62 & .50 & .73 & .79 & .57 & .91 \\
\hline
\end{tabular}

Note: In the table, the antilogits for a student with average ability and for an item with average difficulty in the start of the course are presented. The dynamics of antilogits for the first, the second, and the third attempts is presented. For the model with random growth effects, the average, one standard deviation lower than the average, and one standard deviation higher than the average local growth effect are presented. Course 1 is "Economics for Non-Economists". 
If we allow the growth parameters to vary over students in accordance to the second extension (Equation 3.7), we can derive the individual differences in the both components. First, we look at the results of the first version of the second extension, with univariate distributions of random effects. As can be seen from Table 3.3, by the end of the first week, two students with an average initial proficiency but a growth through a course parameter of one standard deviation lower and one standard deviation higher than the average have probabilities of the correct answer of .45 and .52 respectively. By the end of the fifth week, the values are .66 and .89 for these two students respectively.

The second component of the growth in proficiency, the growth within a certain learning objective, varies among students as well. As can be found in Table 3.4 , on average, the chances of the correct response grow from .41 for the first attempt, over .60 for the second attempt to .77 for the third attempt. However, two students with the average initial proficiency but the growth effect parameter within a certain learning objective of one standard deviation lower and one standard deviation higher than the average have at the second attempt probabilities for the correct answer of .48 and .72 respectively. For the same students the chances of the correct response from the third attempt are .54 and .91 respectively.

The results of the second version of the second extension (Equation 3.7), with multivariate distribution of random effects presented in Table 3.2, allow us to understand the relation between student-specific effects. The moderate negative correlation between student-specific random intercept and random effect of video lectures (-.67) advices us that for students with lower initial proficiency, there is a higher effect of the number of watched video lectures on their performance in this course. At the same time, there are only weak correlations between the studentspecific random intercept and random effect of attempts, and between both random slopes respectively (.14 and .02). 
In the other two courses, the dimensionality check did not show substantial evidence against unidimensionality (with p-values equal to .30 and .07). We detect similar growth through the course and within a certain learning objective in both these courses. As can be derived from Table 3.5 and Table 3.6, in "Game Theory" and "Introduction to Neuroeconomics: How the brain Makes Decisions" courses, the probability of the correct response grows with every new watched lecture and with every new attempt to solve an item. Both growth parameters vary among students and show the individual differences in the both components. As in the first course, the model fit for the extensions is better than for the Rasch model. 
Table 3.5

Parameters of the extension for Course 2

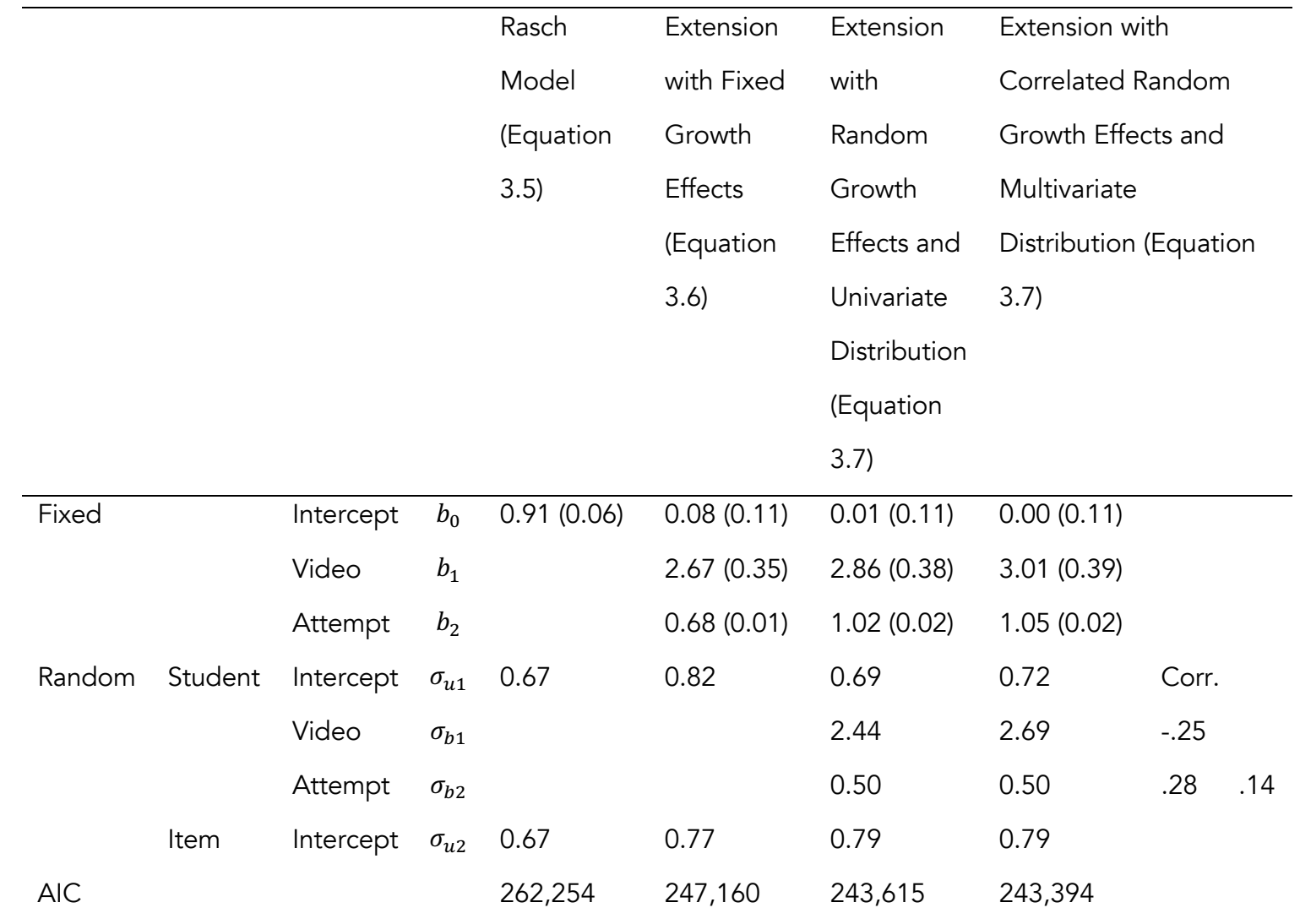

Note: In the table, Course 2 is "Game Theory". For fixed effects, the standard error is presented in parentheses. For random effects the standard deviation is presented. 


\section{Table 3.6}

Parameters of the extension for Course 3

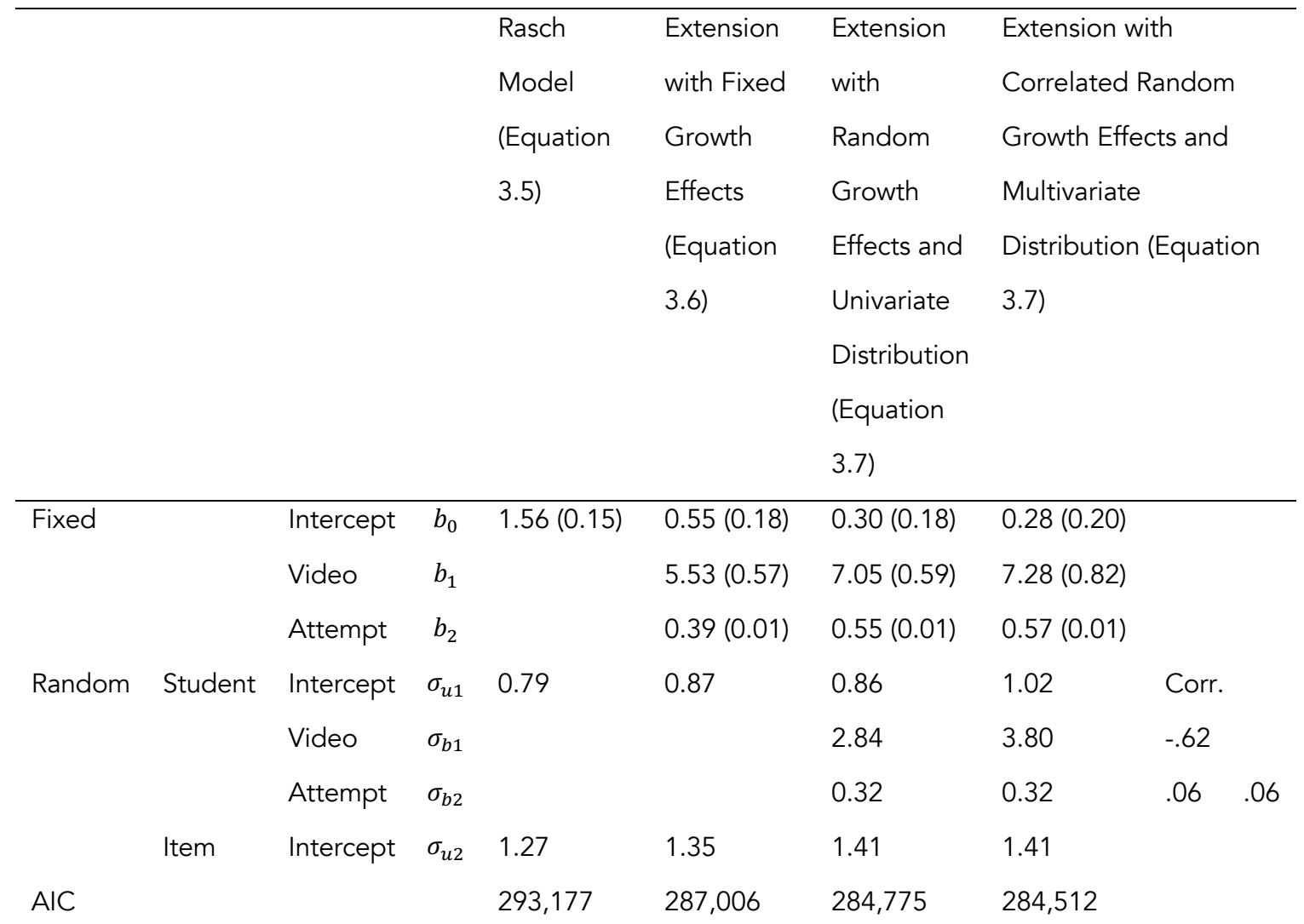

Note: In the table, Course 3 is "Introduction to Neuroeconomics: How the brain Makes Decisions". For fixed effects, the standard error is presented in parentheses. For random effects the standard deviation is presented. 


\section{Value of the Extensions}

The model fit improves with each extension. Table 3.2 shows that for the "Economics for Non-Economists" course, the AIC decreases from 146,979 for the Rasch model to 143,024 for the extension with fixed growth effects, 140,367 and 140,221 for the extensions with uncorrelated and correlated random growth effects respectively. The similar improvement of the model fit is found for the other two courses (Table 3.5 and 3.6).

The results of the cross-validation procedure presented in Table 3.7 show that over the three courses, both extensions are better in measuring the proficiency and its growth in terms of accuracy of predicting students' responses in comparison to the Rasch model. The overall accuracy of the Rasch model is .743 while the overall accuracies of the extensions are .760 for the extension with fixed growth effects, .766 , and .766 for the extensions with uncorrelated and correlated random growth effects respectively. We see the improvements in accuracy in all three courses we analyzed. Yet, the improvements are rather small, and they come along with a higher number of model parameters. 
Table 3.7

Accuracy in predicting correctness

\begin{tabular}{llllllllllll}
\hline & Overal & \multicolumn{3}{c}{ Course 1 } & \multicolumn{2}{c}{ Course 2 } & \multicolumn{2}{c}{ Course 3 } \\
& M & SD & M & SD & M & SD & M & SD \\
\hline Rasch Model & .743 & .047 & .724 & .002 & .699 & .002 & .806 & .000 \\
Extension with Fixed Growth Effects & .760 & .038 & .737 & .002 & .732 & .002 & .812 & .001 \\
$\begin{array}{l}\text { Extension with Random Growth Effects } \\
\text { and Univariate Distribution }\end{array}$ & & & & & & & & \\
$\begin{array}{l}\text { Extension with Random Growth Effects } \\
\text { and Multivariate Distribution }\end{array}$ & .766 & .034 & .747 & .002 & .740 & .001 & .813 & .001 \\
& .766 & .034 & .747 & .002 & .739 & .001 & .812 & .001 \\
\hline
\end{tabular}

Note: In the table, Course 1 is "Economics for Non-Economists", Course 2 is "Game Theory", and

Course 3 is "Introduction to Neuroeconomics: How the brain Makes Decisions". 


\section{Discussion and Conclusion}

In this study, two extensions for the Rasch model for measuring the growth in students' proficiency in MOOCs were presented. Firstly, the study contributes to the psychometric methodology. It focuses on existing ideas of modeling dynamic processes in the framework of IRT but extends their ability to detect the novel latent growth trends that appears in datasets from MOOCs. For instance, while Verhelst and Glas (1993) and De Boeck et al. (2011) presented two ways in dynamic generalization of the traditional psychometric model, the Rasch model, in our extensions, we follow this movement and show two components of the dynamic processes in students' proficiency - the continuous and the local growth. Secondly, we introduce IRT in a new application area. While Kadengye, Ceulemans, and Van den Noortgate $(2014,2015)$ applied their models to the item-based learning environments, we implement IRT models in the new and fast developing context of MOOCs. Finally, our findings are important for the practice of online learning. Measuring growth in student's proficiency might be essential for MOOC developers because these measurements help to understand how efficient the course is in terms of group and individual dynamic of the students, and for students themselves in understanding personal progress in the sense of formative feedback.

The study, however, has limitations. We used the proposed extensions work for post-hoc measuring the growth, not for a dynamic tracking of the growth, crucial for navigation and recommendations engines which decide about when to support a student or to advance him/her through a course based on on-the-fly estimation of the progress. We believe it could be realized by combining these models with techniques for tracking growth, for example, the Elo (1978) Rating System in the work of Klinkenberg, Straatemeier, and van der Maas (2011). This is a topic for future research. 
To conclude, we consider this study as an additional step in transition from traditional psychometric approaches focused on accurate locating the student on the proficiency scale to flexible approaches of computational psychometrics (von Davier, 2017) oriented at regarding student's behavior as a dynamic process. 


\section{CHAPTER 4}

\section{RASCH MODEL EXTENSIONS FOR ENHANCED FORMATIVE ASSESSMENTS IN MOOCS $^{5}$}

Formative assessments are an important component of massive open online courses (MOOCs), online courses with open access and unlimited student participation. Accurate conclusions on students' proficiency via formative, however, face several challenges: (a) students are typically allowed to make several attempts; and (b) student performance might be affected by other variables, such as interest. Thus, neglecting effects of attempts and interest in proficiency evaluation might result in biased conclusions. In this study we try to solve this limitation and propose two extensions of the common psychometric model, the Rasch model, by including the effects of attempts and interest. We illustrate these extensions using real MOOC data and evaluate them using cross-validation. We found that (a) the effects of attempts and interest on the performance are positive on average but both vary among students; (b) a part of the variance in proficiency parameters is due to variation between students in the effect of interest; and (c) the overall accuracy of prediction of student's item responses using the extensions is $4.3 \%$ higher than using the Rasch model.

Massive open online courses (MOOCs) are a means for universities to make courses available to thousands of students via the web at zero or low cost. MOOCs are often developed in collaboration with industrial partners and run on platforms such as Coursera, edX, XuetangX, FutureLearn, Udacity, and MiriadaX. In 2017, over 800 universities offered students more than 9,400 MOOCs (Shah, 2018a). In 2018 , the largest MOOC provider, Coursera, achieved the milestones of 36 million students and 3,000 courses (Shah, 2018b).

A typical MOOC is composed of modules each of which normally lasts a week and is structured around a single topic. Modules consist of smaller units, lessons. A lesson is structured around one or two learning objectives within a module topic. Each lesson includes a set of video lectures, reading assignments

5 The text in this chapter has been accepted for publication as Abbakumov, D., Desmet, P., \& Van den Noortgate, W. (in press). Rasch model extensions for enhanced formative assessments in MOOCs. Applied Measurement in Education. 
and formative assessments. Typically, every video lecture lasts 4-9 minutes and is accompanied by one or a set of formative assessment items that are incorporated in the lecture. Reading assignments are typically followed by one or a few formative assessment items. Usually it takes a student about 30 minutes to complete a lesson. Weekly modules are concluded by summative assessment, which is typically realized via a test, a programming task, a peer-review task or a combination of them.

Formative assessments are an essential component of a MOOC. First, they provide students with opportunities to deepen their understanding and prepare for summative assessments (Coursera, n.d.b). Second, they allow students to understand their own progress and map areas which need additional work to be mastered. Third, they show course authors the students' individual and group dynamics in mastering the course, which afterward may help course authors to tune content. Yet, given the small number of items that are typically rendered, attaining these goals is challenging.

Psychometrics, a field within behavioral sciences, provides theories and statistical models aimed at measuring (and explaining) unobservable variables, for instance proficiency, on the basis of observable variables, for instance students' responses to assessment items. Major psychometric theories, Classical Test Theory (CTT) and Item Response Theory (IRT), assume the proficiency as the only student characteristic that determines performance (Lord \& Novick, 1968). For example, one of the most popular psychometric models, the Rasch model (Rasch, 1960), assumes a nonlinear link between student's performance on assessment items and his/her proficiency:

$$
\operatorname{Logit}\left(\pi_{i j}\right)=\ln \left(\frac{\pi_{i j}}{1-\pi_{i j}}\right)=\theta_{j}-\delta_{i} \text { and } Y_{i j} \sim \operatorname{Bernoulli}\left(\pi_{i j}\right)
$$


where probability $\left(\pi_{i j}\right)$ of the correct response of student $j$ to item $i$ is described by a logistic function of the difference between the student's proficiency parameter $\left(\theta_{j}\right)$ and the item difficulty parameter $\left(\delta_{i}\right)$. Typically, it is assumed that students are a random sample from a population in which the student proficiencies are normally distributed, $\theta_{j} \sim N\left(0, \sigma_{\theta}^{2}\right)$. To estimate the unknown parameters, like the item difficulties and the student proficiency variance, a maximum likelihood procedure can be used. While the item difficulties therefore are estimated directly, student proficiency parameters can be estimated afterwards using empirical Bayes procedures.

Such a way of performance modeling is widely used in educational assessments because of its compact form and clear interpretation. However, its applicability in formative assessments in MOOCs is not straightforward because of several reasons. First, students in MOOCs are allowed to do several attempts to solve formative assessment items. There is possibly an increase in chances of a correct response between attempts. This increase might be a result of learning from received support between attempts, but also may refer to pseudo-growth caused by simple enumerating the item options or guessing. Therefore, unless we opt for looking at the performance at the first attempt only (therefore losing valuable information in the data), performance modeling should explicitly take into account the change of the probability over attempts. Second, unlike regular educational assessments, which are isolated from the educational content, formative assessments in MOOCs are incorporated into video lectures - students interact with formative assessment items alongside interacting with video lectures. As a result, the performance might not only be determined by proficiency, but also by other factors. As has been reported by many researchers, interest may be such a variable influencing the performance. This "critical cognitive and affective motivational variable" (Renninger \& Hidi, 2011, p. 169), boosts learning in different content areas (for example, Ainley, Hidi, \& Berndorff, 2002; Denissen, 
Zarrett, \& Eccles, 2007), positively influences motivation, attention, memorization, and, as a result, performance (for example, Hidi \& Baird, 1988; McDaniel, Waddill, Finstad, \& Bourg, 2000; Schaeffner \& Schiefele, 2007), and has this effect on students of all ages (for example, Nolen, 2007; Palmer, 2009). Thus, performance modeling should take into account the possible effect of interest as well. We believe both effects might be modeled by extending existing psychometric models. As a result, we expect it improves the proficiency measures in formative assessments.

In this study, we suggest two extensions of the Rasch model: the first one includes the effect of attempts, and the second one models the effect of interest. Both effects are considered as random effects varying among students to reveal individual differences. The first extension is nested in the second extension (in order to demonstrate a cumulative effect on the model fit and the quality of proficiency measures). Then we illustrate these extensions on the logged data from a MOOC from the Coursera platform. Finally, to demonstrate the added value of using the extensions, we make use of the technique of cross-validation. In this procedure, we evaluate the ability of the Rasch model and the extensions to predict the correctness of students' responses to formative assessment items from two courses from the Coursera platform.

\section{MOOC Data}

The MOOC data we use in this study have the following structure and are coded in the following way. Students have a unique identification number. All course elements, including video lectures and formative items, have their individual identification number as well. A course has a hierarchical structure video lectures are nested in lessons, and lessons are nested in modules. All these links are recorded in a course structure file. As far as formative assessment items are incorporated into video lectures, the course structure file consists of this linking information as well. The place of formative assessment items within the video 
lecture varies for different videos and depends on the content design. Student's actions, for instance, responses to a formative assessment item, also have an individual identification number and a time stamp and stored in a course log file. Student's responses to formative assessment items are dichotomously scored where 1 and 0 correspond to the correct and wrong response respectively.

The attempt variable can be easily calculated from the course log file described above. We sort all the responses on formative assessment items by their time stamp. Then we number sequentially every response of a student $j$ to an item $i$ from 0 for the first attempt to $n_{i j}$ for the last attempt (for modeling purposes attempts are numbered starting from 0 instead of 1 ).

The interest variable cannot be obtained directly from the existing data files. Moreover, there are not many examples of online learning environments that gather data about interest. However, there is an interesting methodology "Between the lines (BTL)" that uses computer software to monitor student's changing interest when he/she progresses through a learning task (Ainley \& Ainley, 2006). Students respond to questions about the current state of interest directly during the online learning procedure. Typically, the software uses a Likert scale to score interest accompanied by smiley expressions (Ainley, 2007). Following this methodology, we incorporated the request "Please rate the level of your interest during the video" with five Likert-type options: "very high", "high", "neutral", "low", and "very low" at the end of each video lecture that includes a formative assessment item. Due to the platform technical capabilities, we do not use smiley expressions, only the written Likert-type options. Student's responses to interest questions are polytomously scored, where the values of $-4,-3,-2,-1,0$ correspond to the response at "very low", "low", "neutral", "high", and "very high" respectively (this way of scoring is opted for modeling purposes). Unlike responding to formative assessment items, students respond to items about interest only one time. 
Thus, our study is based on (a) records of students' responses to formative assessment items incorporated into video lectures (each record including the student's unique identification number, the item's unique identification number, a unique identification number of the video lecture in which the item is integrated, a dichotomous response, and the attempt number); and (b) records of students' responses to the interest questions about the video lectures (each record including of the student's unique identification number, the video lecture's unique identification number, a response on the interest Likert scale). By means of the unique video lecture identification number, we can merge the two types of records into a single working data set.

\section{Modeling}

As the framework for modeling students' performance in formative assessments, we use the reformulation of the Rasch model presented by Van den Noortgate, De Boeck, and Meulders (2003):

$$
\operatorname{Logit}\left(\pi_{i j}\right)=b_{0}+u_{1 j}+u_{2 i} \text { and } Y_{i j} \sim \operatorname{Bernoulli}\left(\pi_{i j}\right) \text {, }
$$

where $u_{1 j} \sim N\left(0, \sigma_{u 1}^{2}\right)$ and $u_{2 i} \sim N\left(0, \sigma_{u 2}^{2}\right)$.

In this reformulation, based on the principle of cross-classification multilevel models, we have an intercept and two residual terms referring to the student and the item respectively. As the mean of both residual terms equals zero, the intercept corresponds to the estimated logit of the probability of the correct response for an average student on an average item. The first residual term, $u_{1 j}$, shows the deviation of the expected logit from student $j$ from the mean logit. The higher this deviation, the higher the expected performance. In terms of the original formulation of the Rasch model from Equation 4.1, this residual term can be interpreted as the proficiency of student $j$, and is equivalent to $\theta_{j}$. The second residual term shows the deviation of the expected logit from item i from the overall 
logit. Here, the larger the residual - the higher the probability of the correct response is. In that sense, the residual term $u_{2 i}$ presents the relative difficulty of item $i$, compared to the mean difficulty of item $b_{0}$. Therefore, the difficulty parameter $\delta_{i}$ from the original formulation of the Rasch model is equivalent to $-\left(b_{0}+u_{2 i}\right)$ in the reformulation from Equation 4.2.

We prefer this reformulation to the original Rasch model formulation because of its flexibility for making extensions. The key point is that considering items and students as random leaves degrees of freedom to add predictors without running into computational issues of model identification (Van den Noortgate, De Boeck, \& Meulders, 2003).

\section{Extension with Effect of Attempts}

As mentioned in introduction, students in MOOCs are allowed to make several attempts in interaction with formative assessment items. Thus, chances of success are expected to grow with each new attempt due to learning or guessing. To control for these effects, we propose the following extension:

$$
\begin{gathered}
\operatorname{Logit}\left(\pi_{i j}\right)=b_{0}+\left(b_{10}+b_{1 j}\right) * \operatorname{attempt}_{i j}+u_{1 j}+ \\
u_{2 i} \text { and } Y_{i j} \sim \operatorname{Bernoulli}\left(\pi_{i j}\right)
\end{gathered}
$$

where attempt $_{i j}$ is 0, 1, 2, 3 or 4, referring to the first, the second, the third, the fourth, or the fifth or higher attempt of student $j$ to solve item $i$ respectively; $b_{10}$ is the overall effect of attempt, while $b_{1 j} \sim N\left(0, \sigma_{b 1}^{2}\right)$ is a deviation of the attempt effect for student $j$ from the overall effect; and $u_{1 j} \sim N\left(0, \sigma_{u 1}^{2}\right)$ and $u_{2 i} \sim N\left(0, \sigma_{u 2}^{2}\right)$ refer as before to the random person and item effects, respectively.

Therefore, the intercept $b_{0}$, means the estimated logit of probability of the correct response of an average student on an average item from the first attempt. If student $j$ fails the first attempt and makes the second attempt, the logit of probability of correct response in that case would change with $\left(b_{10}+b_{1 j}\right)$. We 
expect $b_{10}$ to be a positive, which means that across persons the probability of correct response grows with each new attempt. As we mentioned above, the first reason for this is learning from bits of help which student receives in case of a wrong response on a formative assessment item. The second reason is that the student can simply click repeatedly on alternative options in a formative assessment item. Because for the latter students, we expect that the probability of a correct response will increase less with each attempt, compared to the former students who really learn from their errors, the student's random effect $b_{1 j}$ to be negative. For the former students, on the contrary, we expect positive random effects $b_{1 j}$. The meaning of the residual terms $u_{1 j}$ and $u_{2 i}$ remains the same as in Equation 4.2.

\section{Extension with Effects of Attempts and Interest}

As has been reported by many researchers, interest positively influences performance (see the extensive review by Renninger \& Hidi, 2011). Therefore, in formative assessments in MOOCs, we can expect that performance with items incorporated in the video lectures is higher for a student who feels more interested than for a student who feels less interested or not interested at all. In this case, if we estimate proficiency on the base of performance only, we could get biased estimates: students may have low performance, not because they are not proficient, but rather because they are not interested.

In order to control the effect of interest while measuring the proficiency, we propose to expand the first extension (Equation 4.3) by adding the overall and the student-specific random effects of interest:

$$
\begin{gathered}
\operatorname{Logit}\left(\pi_{i j}\right)=b_{0}+\left(b_{10}+b_{1 j}\right) * \text { attempt }_{i j}+\left(b_{20}+b_{2 j}\right) * \text { interest }_{i j}+ \\
u_{1 j}+u_{2 i} \text { and } Y_{i j} \sim \operatorname{Bernoulli}\left(\pi_{i j}\right)
\end{gathered}
$$


where interest $_{i j}$ reflects the response of student $j$ on the interest question of the video lecture in which the formative assessment item $i$ is incorporated, with scores $-4,-3,-2,-1,0$ corresponding to the category selected by the student, being "very low", "low", "neutral", "high", and "very high" respectively; $b_{0}$ equals the estimated logit of the probability of the correct response of an average student to an average formative assessment item incorporated into the video lecture of the course from the first attempt in case of very high reported interest; $b_{20}$ reflects the overall effect of interest on the expected performance, this is the expected increase of the logit when interest increases with one unit; however, the effect of interest may not be the same for all students, thus, to model such individual differences, we use a random deviation of the interest effect for student $j$ from the overall effect, $b_{2 j} \sim N\left(0, \sigma_{b 2}^{2}\right)$; and $u_{1 j} \sim N\left(0, \sigma_{u 1}^{2}\right)$ and $u_{2 i} \sim N\left(0, \sigma_{u 2}^{2}\right)$. We expect that the random effects $u_{1 j}$ express students' proficiencies in a more unbiased way.

\section{Method}

\section{Illustrating the Extensions}

To illustrate the extensions, we fit them on the data of the "Introduction to Neuroeconomics: How the Brain Makes Decisions" (Higher School of Economics, n.d.d) MOOC from the Coursera platform. The course is taught in English. The distribution of students by countries is as follows: USA (18\%), India (8.9\%), Russia (7.3\%), Mexico (4.8\%), United Kingdom (4.0\%), Brazil (3.6\%), China (3.3\%), Canada (3.0\%) and other countries (47.1\%). During this study, the number of active students who responded to the formative assessment items and questions about interest was 9,354. The number of video lectures in which formative assessment items and questions about interest are incorporated, is 32, and each of these video lectures includes one formative assessment item and was followed by one question about interest. The number of responses to formative assessment items is 64,510 . The average score on a formative assessment item is .80 with the standard deviation of 0.40 , which reflects individual differences between students 
and items. The average number of attempts is 1.54 . The distribution of students' responses to the question about interest is "very low" (0.3\%), "low" (2.0\%), "neutral" (17.2\%), "high" (47.3\%), and "very high" (33.1\%). Outliers, for instance, faulty data with extreme values caused by technical issues or human factors are not detected.

In order to show the feasibility of using the Rasch model and extending it, we check the fundamental assumption of the Rasch model, the unidimensionality assumption. This assumption means that only one kind of proficiency is measured by a set of items in a test (Hambleton, Swaminathan, \& Rogers, 1991; Molenaar, 1995). We use the "unidimTest" function of the "Itm" package (Rizopoulos, 2006) of $R$, which implements the approach proposed by Drasgow and Lissak (1983) where the latent dimensionality is checked via a comparison of the eigenvalues of a factor analysis of the observed data and one of data generated under the assumed unidimensional Rasch model. The null hypothesis of unidimensionality is rejected if the second eigenvalue of the observed data is substantially larger than the second eigenvalue of the simulated data. To approximate the distribution of the test statistic under the null hypothesis, we used 500 samples in the Monte Carlo procedure implemented in the "unidimTest" function.

To fit the Rasch model from Equation 4.2 and the extensions from Equations 4.3 and 4.4, we use the "glmer" function of the "Ime4" package (Bates, Maechler, Bolker, \& Walker, 2015) of the $\mathrm{R}$ language and environment for statistical computing (R Core Team, 2013), which is widely utilized for fitting various IRT models (De Boeck, et al., 2011). To compare the models, we use the Akaike's 
information criterion (AIC; Akaike, 1974), provided by the "glmer" function and the likelihood ratio test performed in $\mathrm{R}$ as well ${ }^{6}$.

\section{Cross-Validation}

To evaluate the added value of using the extensions, we used a crossvalidation procedure. We use part of the dataset to predict the students' scores on the remaining part and compare these predicted scores to the observed scores (Ekanadham \& Karklin, 2015). In this procedure, we evaluate the predictions for the Rasch model and both extensions.

For cross-validation we use datasets of two courses from the Coursera platform - "Introduction to Neuroeconomics: How the Brain Makes Decisions" introduced above and "Financial Markets and Institutions" (Higher School of Economics, n.d.b). The latter course is taught in Russian. The distribution of students by countries is as follows: Russia (64\%), Ukraine (7.1\%), China (5.7\%), Kazakhstan (3.0\%) and other countries (20.2\%). The number of active students who responded on the formative items and questions about interest was 6,802. The number of video lectures, as well as formative assessment items and questions about interest, is 13 . The number of responses to formative assessment items is 47,288 . The average score on a formative item is .63 with the standard deviation of 0.48 , which reflects individual differences in students and items. The average number of attempts is 1.72 . The distribution of students' responses to a question about interest is "very low" (0.1\%), "low" (0.8\%), "neutral" (13.4\%), "high" (49.2\%), and "very high" (36.4\%). Outliers are not detected.

The procedure of cross-validation is as follows. We randomly split students' responses to formative items to a training set with $75 \%$ of the responses and a

${ }^{6}$ Although the AIC is widely used to compare different models, its application for models with a different number of random effects has been criticized (Vaida \& Blanchard, 2005). For better comparison, the conditional Akaike information criterion (cAIC) can be used. 
test set with $25 \%$ of the responses. Then we fit the Rasch model from Equation 4.2 and the extensions on the training set and use them to make predictions on the test set (if the estimated probability is larger than .50, a score of 1 is predicted, otherwise a 0 is predicted). Then we build a table of confusion with two rows and two columns that reports the number of false positives, false negatives, true positives, and true negatives. This table allows us to understand the quality of predictions as well as the improvement of prediction when using the extensions rather than the basic model. Using this table, we calculate the accuracy index:

$$
\text { Accuracy }=\frac{T P+T N}{P+N}
$$

where $T P$ is true positives; $T N$ is true negatives; $P$ is all positives; $N$ is all negatives. Therefore, the model with a larger accuracy index can be considered as the better model.

This procedure of randomly splitting the data, fitting the models, making predictions and calculating accuracy is repeated 25 times. Finally, we save all the accuracy indexes and calculate the average indexes for each model.

\section{Results}

The dimensionality check did not reveal significant evidence against unidimensionality $(p=.168)$. Thus, the Rasch model can be applied to the data.

In the illustration, we start with the Rasch model from Equation 4.2. As presented in Table 4.1, the estimate of the intercept equals 1.94. The inverse logit,

or the antilogit, of this value (this is $\frac{e^{1.94}}{1+e^{1.94}}$ ) provides us with expected probability that an average student of the MOOC "Introduction to Neuroeconomics: How the Brain Makes Decisions" responds correctly to an average formative assessment item incorporated into the video lecture from this course, which is .87. As can be seen, the probability of the correct response varies both among students and items. To get the probability of a correct response for an average student and 
items with difficulty of one standard deviation lower and one standard deviation higher than the average, we apply the inverse logit function to (1.94 - 0.95) and $(1.94+0.95)$, which lead to probabilities equal to of .73 and .95 respectively. Similarly, the probability that a student with proficiency of one standard deviation lower than the average gives a correct response on these items is equal to .56 and .90, which correspond to antilogits of (1.94 - $0.75-0.95)$ and (1.94 - $0.75+$ 0.95) respectively. Calculated in the same way, the probabilities of correctness for students with various levels of proficiency and items with different levels of difficulty are summarized in Table 4.2. 
Table 4.1

Parameter estimates of different models

\begin{tabular}{|c|c|c|c|c|c|}
\hline & & & Rasch Model & Extension 1 & Extension 2 \\
\hline \multirow[t]{3}{*}{ Fixed } & & Intercept & 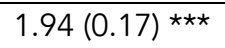 & $1.89(0.19) * \star \star$ & $2.13(0.19) * \star \star$ \\
\hline & & Attempt & & 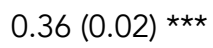 & $0.37(0.02) * \star \star$ \\
\hline & & Interest & & & $0.24(0.02) * \star \star$ \\
\hline \multirow[t]{4}{*}{ Random } & Student & Intercept & 0.75 & 0.90 & 0.78 \\
\hline & & Attempt & & 0.23 & 0.24 \\
\hline & & Interest & & & 0.11 \\
\hline & Item & Intercept & 0.95 & 1.04 & 1.04 \\
\hline $\mathrm{AIC}$ & & & 57,075 & 56,547 & 56,354 \\
\hline
\end{tabular}

Note: In the table, for fixed effects the coefficient standard error is presented in parentheses. For

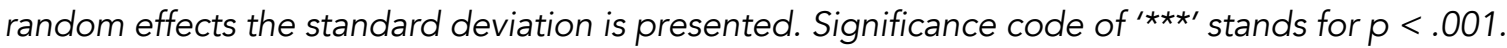


Table 4.2

Antilogits for the Rasch model and the extension with effect of attempts

\begin{tabular}{|c|c|c|c|c|c|c|}
\hline & \multirow[t]{2}{*}{ Proficiency } & \multirow[t]{2}{*}{ Difficulty } & \multirow[t]{2}{*}{ Effect of Attempt } & \multicolumn{3}{|c|}{ Attempt } \\
\hline & & & & 1 & 2 & 3 \\
\hline \multirow[t]{9}{*}{ Rasch Model } & Average & Average & - & .87 & & \\
\hline & & $-S D$ & - & .73 & & \\
\hline & & $+\mathrm{SD}$ & - & .95 & & \\
\hline & $-\mathrm{SD}$ & Average & - & .77 & & \\
\hline & & $-S D$ & - & .56 & & \\
\hline & & $+\mathrm{SD}$ & - & .90 & & \\
\hline & $+\mathrm{SD}$ & Average & - & .94 & & \\
\hline & & $-S D$ & - & .85 & & \\
\hline & & $+\mathrm{SD}$ & - & .97 & & \\
\hline \multirow[t]{27}{*}{ Extension 1} & Average & Average & Average & .87 & .90 & .93 \\
\hline & & & $-S D$ & .87 & .88 & .90 \\
\hline & & & $+\mathrm{SD}$ & .87 & .92 & .96 \\
\hline & & $-\mathrm{SD}$ & Average & .70 & .77 & .83 \\
\hline & & & $-\mathrm{SD}$ & .70 & .73 & .75 \\
\hline & & & $+\mathrm{SD}$ & .70 & .81 & .88 \\
\hline & & $+\mathrm{SD}$ & Average & .95 & .96 & .97 \\
\hline & & & $-S D$ & .95 & .96 & .96 \\
\hline & & & $+\mathrm{SD}$ & .95 & .97 & .98 \\
\hline & $-\mathrm{SD}$ & Average & Average & .73 & .79 & .85 \\
\hline & & & $-\mathrm{SD}$ & .73 & .75 & .78 \\
\hline & & & $+\mathrm{SD}$ & .73 & .83 & .90 \\
\hline & & $-\mathrm{SD}$ & Average & .49 & .58 & .66 \\
\hline & & & $-S D$ & .49 & .52 & .55 \\
\hline & & & $+\mathrm{SD}$ & .49 & .63 & .76 \\
\hline & & $+\mathrm{SD}$ & Average & .88 & .92 & .94 \\
\hline & & & $-\mathrm{SD}$ & .88 & .90 & .91 \\
\hline & & & $+\mathrm{SD}$ & .88 & .93 & .96 \\
\hline & $+\mathrm{SD}$ & Average & Average & .94 & .96 & .97 \\
\hline & & & $-S D$ & .94 & .95 & .95 \\
\hline & & & $+\mathrm{SD}$ & .94 & .97 & .98 \\
\hline & & $-\mathrm{SD}$ & Average & .85 & .89 & .92 \\
\hline & & & $-S D$ & .85 & .87 & .88 \\
\hline & & & $+\mathrm{SD}$ & .85 & .91 & .95 \\
\hline & & $+\mathrm{SD}$ & Average & .98 & .99 & .99 \\
\hline & & & $-S D$ & .98 & .98 & .98 \\
\hline & & & $+\mathrm{SD}$ & .98 & .99 & .99 \\
\hline
\end{tabular}


The first extension (Equation 4.3) allows us to see that the probability of the correct response grows with a new attempt to solve the item - the effect of attempt presented in Table 4.1 is positive (0.36) and significantly different from zero $(p<.001)$. However, the effect of attempt is not the same for all students as the student-specific random deviation of the effect of attempt is 0.23 . For illustration, consider an example in which a student with average proficiency responds to an item with average difficulty. The probability of a correct response from the first attempt in this case is .87 which corresponds to the antilogit of 1.89 . Assuming the average effect of attempt for this student and applying the inverse logit function to $(1.89+1 * 0.36)$ and $(1.89+2 * 0.36)$, we get the probability of a correct response from the second and the third attempts, which are .90 and .93. However, if the effect of attempt is one standard deviation lower than the average, the probabilities of correctness from the second and the third attempts are .88 and .90 which correspond to antilogits of $(1.89+1$ * $(0.36-0.23))$ and $(1.89+2$ * $(0.36-0.23))$ respectively. At the same time, if the effect of attempt is one standard deviation higher than the average, we get the values of .92 and .96 for the probability of a correct response from the second and the third attempts and refer to antilogits of $(1.89+1 *(0.36+0.23))$ and $(1.89+2 *(0.36+0.23))$ respectively respectively. The illustrative results for various combinations of proficiencies, difficulties and attempt effects are presented in the rest part of Table 4.2.

The first extension results in bigger individual differences in students' proficiency. The student-specific standard deviation of random intercept in the extension is 0.90 versus 0.75 for the Rasch model (see Table 4.1). That the estimated differences between students' proficiency levels become larger is no surprise. The deviation reflects differences between students in the intercept, this is the expected logit at the first attempts. In the previous model, the deviation reflects differences between students across attempts. The more attempts are made, the higher the probability that a correct answer is given, and therefore 
differences between students in their performance indeed become smaller. The model fit for the first extension is better than for the Rasch model with AIC of 56,547 for the extension and 57,075 for the Rasch model which is supported by the likelihood ratio test $\left(\chi^{2}(2)=532.55, p<.001\right)$.

The overall effect of interest on performance from Equation 4.4 presented in Table 4.1 is positive $(0.24)$ and significant $(p<.001)$. Higher scores given to the interest question about the video lecture correspond to higher chances of the correct response to the formative assessment item associated with this video lecture. At the same time, this effect is not the same for all students as the studentspecific random deviation for this effect is 0.11 . To illustrate it, we calculate probabilities of a correct response for a student with average proficiency but different person-specific effects of interest and items with different difficulty (see Table 4.3). For instance, if we consider an item with average difficulty and the average effect of interest, the probabilities calculated using inverse logit are $.89, .84$, and .76 in case the interest level was reported as very high, neutral, and very low respectively. In the same case but the effects of interest are one standard deviation lower and one standard deviation higher than average, the probabilities are $.89, .87, .83$ and $.89, .81, .67$ respectively. The antilogits calculated for various combinations of item difficulties and interest effects are presented in the rest part of Table 4.3. 
Table 4.3

Antilogits for the extension with effects of attempts and interest

\begin{tabular}{|c|c|c|c|c|c|c|}
\hline \multirow[t]{2}{*}{ Difficulty } & \multirow{2}{*}{$\begin{array}{l}\text { Effect of } \\
\text { Interest }\end{array}$} & \multicolumn{5}{|c|}{ Interest } \\
\hline & & Very High & High & Neutral & Low & Very Low \\
\hline \multirow[t]{3}{*}{ Average } & Average & .89 & .87 & .84 & .80 & .76 \\
\hline & $-S D$ & .89 & .88 & .87 & .85 & .83 \\
\hline & $+\mathrm{SD}$ & .89 & .86 & .81 & .75 & .67 \\
\hline \multirow[t]{3}{*}{$-S D$} & Average & .75 & .70 & .65 & .60 & .53 \\
\hline & $-S D$ & .75 & .72 & .70 & .67 & .64 \\
\hline & $+\mathrm{SD}$ & .75 & .68 & .60 & .51 & .42 \\
\hline \multirow[t]{3}{*}{$+S D$} & Average & .96 & .95 & .94 & .92 & .90 \\
\hline & $-S D$ & .96 & .95 & .95 & .94 & .93 \\
\hline & $+\mathrm{SD}$ & .96 & .94 & .92 & .89 & .85 \\
\hline
\end{tabular}

Note: In the table, the probabilities are given for the first attempt and a student with average proficiency. 
Including the effect of interest affects student-specific variance in the expected performance. The variance in proficiency parameters as estimated with the first extension is reduced by about $25 \%$ when accounting for the variation between students in the effect of interest. The model fit improves in comparison to the first extension - AIC for the second extension is 56,344, while for the first extension AIC is 56,354 . The likelihood ratio test result comparing the first and the second extensions is $\chi^{2}(2)=196.80, p<.001$.

The results of the cross-validation procedure presented in Table 4.4 show that over the two courses, the quality in terms of accuracy of predicting correctness in students' responses improves from .724 for the Rasch model to .769 and .770 corresponding to the first and the second extension respectively. The major improvement comes with including the effect of attempts (4.2\%). The improvement when adding the effect of interest is small (0.1\%). Within the course, the standard deviation of accuracy is .003 . 
Table 4.4

Quality of different models

\begin{tabular}{lllllll}
\hline & Overall & & Course 1 & Course 2 \\
& $\mathrm{M}$ & $\mathrm{SD}$ & $\mathrm{M}$ & $\mathrm{SD}$ & $\mathrm{M}$ & $\mathrm{SD}$ \\
\hline Rasch Model & .724 & .076 & .799 & .003 & .649 & .004 \\
Extension 1 & .769 & .037 & .806 & .003 & .732 & .003 \\
Extension 2 & .770 & .038 & .807 & .003 & .733 & .003 \\
\hline
\end{tabular}

Note: In the table, Course 1 stands for "Introduction to Neuroeconomics: How the brain Makes Decisions", and Course 2 stands for "Financial Markets and Institutions". 


\section{Discussion and Conclusion}

In this study, we have proposed a way to improve the accuracy of students' proficiency measurement via formative assessments in MOOCs. The improvements are achieved by including effects of attempts and interest to the common psychometric model, the Rasch model, based on the ideas of the explanatory IRT movement started by De Boeck and Wilson (2004) and collaborators, showing that enriching the IRT models with predictors could improve the quality of the latent constructs' measures. First, we showed how we can take into account the number of attempts. This variable was coded such that at the first attempt this variable equals zero. In this way, the variation between students in the intercept reflects differences in expected performance at the first attempt. The number of correct answers is increasing with additional attempts, so including these answers in the analysis without accounting for the number of attempts, would obscure real differences between students in their proficiency. Alternatively, including only the scores at the first attempt, would reduce the amount of information used and hence decrease the accuracy of estimates and the power of statistical tests. The proposed approach allows including all scores, giving an unbiased view on the proficiencies and moreover studying the evolution of the performance over attempts. Second, we also have found that besides the attempt number, the interest is a significant predictor of students' performance, although the effect is not very large. This is in line with other the interest research, starting about a century ago (Dewey, 1913). We coded the interest variable such that the value zero was given when somebody showed very high interest. As a result, the intercept refers to the expected performance when one is highly interested, and therefore is expected to reflect better the proficiency. As a novel contribution, we show that the effect of interest is not the same for all students. In addition, an interesting finding is that by including a random interest effect, the intercept variance, this is the variance between students in the effect of proficiency 
is reduced by $25 \%$, giving a more nuanced insight in the role of proficiency on the students' performance and confirming the importance of taking interest into account. Thus, our findings are important for the practice of online learning.

Although the broader use of these models seems possible, we believe that the presented approach is less appropriate in high-stakes testing, because it is likely that students will answer questions on interest in the direction they think will be most advantageous for their grade. At the same time, we think that the effect of interest on the performance of students will be smaller in high-stakes tests because the examinee is expected to answer and item correctly, even if he/she does not really experience this content as interesting.

The proposed approach, however, has limitations. The key limitation is the necessity to collect additional data on interest and the repeated use of the same question that might be annoying to students. However, this limitation might be released by using less disturbing techniques of collecting data such as the use of a like-button and presenting the question only for a random set of video lectures. Another limitation is that the interest was measured after the video lectures that incorporated the formative assessment items. It is therefore possible that the performance on these assessment items influenced students' scores on the interest question. As a result, we cannot exclude that part of the variance we found between students in the effect of interest, in fact may be attributed to differences in proficiency.

To conclude, we believe that the study adds MOOCs to existing areas of IRT applications, mainly large-scale assessment, psychological testing, cognitive diagnostic assessment, health measurement, marketing research, measuring change (van der Linden, 2016). The paper is also meant as an illustration of how the basic IRT models can be extended by modeling the effect of additional information that may be available. The paper therefore might inspire applied researchers looking for how to improve their assessment by using additional 
information. Finally, we consider this study as a fresh step in transition from traditional psychometric approaches of one variable, proficiency, to flexible approaches of computational psychometrics (von Davier, 2017) involving a set of variables to modeling performance. 


\section{CHAPTER 5}

\section{MEASURING STUDENTS' ACTIVITY IN MOOCS USING A RASCH MODEL EXTENSION $^{7}$}

Studying the activity of students is essential for online learning platforms and course developers, because the activity is directly related to the performance of students at the end of the course. Researchers and practitioners typically describe students' activity through the proportion of videos viewed, the number of assessments taken, and the proportion of correct responses in assessments. These measures are simple and intuitive. However, by aggregating the information on activity per student, we lose information on how a student interacts with individual units of content, therefore hampering predictions on how a student would interact with specific content. In order to cover this gap, we address to Item Response Theory (IRT) and propose to consider students' interaction with a unit of content as influenced by a latent student characteristic and a latent item characteristic. We realize this idea in an extension of the most common IRT model, the Rasch model, and illustrate it on logged data from one massive open online course (MOOC). Finally, we use cross-validation on the data from two MOOCs to evaluate the quality of predictions on how students interact with units of content. We found that (a) the probability of completing a unit of content varies among students and among units; (b) the probability that a student will actively work on content is higher for video lectures than for reading assignments; (c) in general, the probability of a student's active engagement in general decreases throughout a MOOC, but the evolution varies among students. Finally, the proposed IRT approach shows high capacity in predicting whether students will interact actively with the units of content.

Emerged a decade ago, massive open online courses (MOOCs) are a recent progressive phenomenon in education. A MOOC is an online course with open access and participation of an unlimited number of students. Typically, a MOOC consists of pre-recorded video lectures, reading assignments, formative and summative assessments, and forums. MOOCs are mainly developed by universities and published on platforms such as Coursera, edX, XuetangX, FutureLearn, Udacity, and MiriadaX. In 2017, more than 800 universities offered

${ }^{7}$ The text in this chapter has been submitted for publication as Abbakumov, D., Desmet, P., \& Van den Noortgate, W. Measuring students' activity in MOOCs using a Rasch model extension. 
students more than 9,400 MOOCs (Shah, 2018a). In 2018, the largest MOOC provider, Coursera, achieved the milestones of 36 million students and 3,000 courses (Shah, 2018b).

A typical MOOC is composed of modules, which consist of lessons. A lesson is structured around one or two learning objectives and includes several video lectures, each of which lasts 4-9 minutes, and reading assignments. Video lectures and reading assignments are accompanied by one or several formative assessment tasks. Typically, it takes a student about 30 minutes to complete a lesson. A module is structured around a cohesive subtopic, usually lasts a week, and is finalized by a summative assessment. Therefore, students' activity during a major part of a week is comprised around watching video lectures, reading attached materials, and practicing with formative assessment tasks. Commonly, this activity is not graded but it prepares a student to accomplish a graded summative assessment at the end of each module.

Understanding students' activity is essential for online learning platforms and course developers because the activity is directly related to the performance of students in summative assessments (Abbakumov, Desmet, \& Van den Noortgate, 2018). It gives ideas about dynamics within a course and helps to adjust a course structure and design, improve the content, and enrich students' experience (for example, Guo, Kim, \& Rubin, 2014). Typically, researchers describe students' activity by its type, for instance "auditing" (didn't do the assessment but watched a video) or "on track" (did the assessment on time) (Kizilcec, Piech, \& Schneider, 2013), or using the number or proportion of videos viewed, assessments taken, and correct responses on assessment items (Halawa, Greene, \& Mitchell, 2014; Kovanovic, et al., 2016). These simple and intuitive measures are often delivered to course developers via progress bars on provider platform dashboards (for example, Coursera, 2016). However, the nature of such measures limits their information and application value. First, it stops the understanding 
students' activity at an aggregated level - we cannot go deeper to the level of a student or a unit of content. By a unit of content, we mean the smallest, atomic, piece of content in a MOOC stored on and indexed by a MOOC platform, for instance, one video lecture or one reading assignment. Second, it hampers predictions on how a student may interact with a unit of content, which is an object of interest for both online learning platforms and course developers.

In this study, we try to deepen the understanding of students' activity by means of benefits of psychometrics, an area within behavioral sciences focused on quantitative measurement. We address to the modern psychometric theory, Item Response Theory (IRT; Lord \& Novick, 1968; van der Linden \& Hambleton, 1997; van der Linden, 2016) and consider the interaction of a student with a unit of content as influenced by a latent student characteristic and a latent item characteristic. To realize this idea, we use the most popular IRT model, the Rasch model (Rasch, 1960), propose an extension that accounts for two major types of units of content in MOOCs, and model overall and individual dynamics of students' activity through a course. We illustrate this approach on logged data from one MOOC from the Coursera platform. Finally, we conduct cross-validation to estimate the performance of proposed models in predicting on how students interact with units of content on the data from two MOOCs.

\section{Item Response Theory}

IRT originated from the work of Rasch (1960) and Lord and Novick (1968) and is focused on the measurement of a latent construct via a set of observations. The main idea of IRT is that a latent construct is a common cause of observations. A latent construct represents a knowledge, skill, ability, trait, or another characteristic of a person. Observations are responses or records that come from assessments, questionnaires, surveys, checklists, or other types of registered behavior. 
IRT models provide a link between observations and a latent construct. For instance, the Rasch model (Equation 5.1; Rasch, 1960), which is one of the most commonly used IRT model, determines the probability $\left(\pi_{i j}\right)$ of a specific response for a pair of a person $j$ and an item $i$ :

$$
\operatorname{Logit}\left(\pi_{i j}\right)=\ln \left(\frac{\pi_{i j}}{1-\pi_{i j}}\right)=\theta_{j}-\delta_{i} \text { and } Y_{i j} \sim \operatorname{Bernoulli}\left(\pi_{i j}\right)
$$

The observable score $\left(Y_{i j}\right)$ is Bernoulli distributed with probability $\pi_{i j}$, which is described by a logistic function of the difference between two parameters, a person parameter $\left(\theta_{j}\right)$ and an item parameter $\left(\delta_{i}\right)$.

Typically, it is assumed that persons are a random sample from population where the person parameters are normally distributed, $\theta_{j} \sim N\left(0, \sigma_{\theta}^{2}\right)$, while item parameters are considered to be fixed. To estimate the unknown parameters, like the fixed item parameters and the person parameter variance, the maximum likelihood procedure can be used. While the item parameters are estimated directly, person parameters can be estimated afterwards using empirical Bayes procedures.

The traditional application of the Rasch model is knowledge testing. Therefore, $Y_{i j}$ is typically considered as an observable score of student $j$ to an item $i$ in a test, which equals 1 for a correct response, 0 for an incorrect response. In their turn, the person parameter $\left(\theta_{j}\right)$ is comprehended as the student's proficiency, while the item parameter $\left(\delta_{i}\right)$ represents the item difficulty. Both parameters $\left(\theta_{j}\right.$ and $\delta_{i}$ ) are placed on an interval scale, the logit scale. This key feature of IRT allows to specify the probability of a discrete outcome in terms of person and item parameters. This feature is used in adaptive testing (Lord, 1970; van der Linden \& Glas, 2000; Wainer, 2000) and adaptive learning (Wauters, Desmet, \& Van den Noortgate, 2010) to decide on the appropriate task to present for a specific student. 


\section{Modeling Student's Activity in MOOCs}

In this study, we understand student's activity in a MOOC as a reaction to units of content. We propose to consider this reaction as affected by a latent student construct. In terms of the Rasch model presented in Equation 5.1, the observation $Y_{i j}$ now is the interaction of student $j$ with a unit of content $i$, where 1 means that unit $i$ was completed by student $j$, and 0 means that unit $i$ was not completed by a student $j$ during the course. It is important that we may start processing the data only when (completely) sure that student $j$ was not and will not complete unit i. For instance, this moment might be the course deadline for courses with strict deadline policy, or we have to wait for several weeks or even months after a soft deadline to start processing the data. Thus, students who dropped out of the course will have 0-es for all the units after dropout. The outcome $\left(Y_{i j}\right)$ is Bernoulli distributed with probability $\pi_{i j}$, which is described by a logistic function of difference between two parameters - person parameter $\left(\theta_{j}\right)$ and parameter of a unit of content $\left(\delta_{i}\right)$. We can interpret the person parameter $\left(\theta_{j}\right)$ as student's activeness, a latent characteristic of a student. In its turn, the item parameter $\left(\delta_{i}\right)$ can be interpreted as the effect of a unit of content on the probability of interaction, and therefore is a latent characteristic of a unit of content.

As a basic representation of the link between the latent characteristics and observations and as a benchmark in our study, we use the reformulation of the Rasch model presented by Van den Noortgate, De Boeck, and Meulders (2003):

$$
\operatorname{Logit}\left(\pi_{i j}\right)=b_{0}+u_{1 j}+u_{2 i}
$$

where $u_{1 j} \sim N\left(0, \sigma_{u 1}^{2}\right)$ and $u_{2 i} \sim N\left(0, \sigma_{u 2}^{2}\right)$, and $Y_{i j} \sim \operatorname{Bernoulli}\left(\pi_{i j}\right)$.

In this reformulation based on the principle of cross-classification multilevel models, we have the intercept, and two residual terms referring to the student $j$ 
and the unit of content $i$ respectively. The mean of both residual terms equals zero. Thus, the intercept equals the estimated logit of the probability that a student with average activeness complete a unit of content with average effect on the probability of interaction. The first residual term shows the deviation of the expected logit from student $j$ from the overall logit. The higher this deviation, the higher the probability of completing is (this residual term equals parameter $\theta_{j}$ from Equation 5.1). The second residual term shows the deviation of the expected logit from unit of content $i$ from the mean logit, in the sense that the larger the residual - the higher probability to complete a unit (the parameter $\delta_{i}$ from Equation 5.1 is equivalent to $-\left(b_{0}+u_{2 i}\right)$ from Equation 5.2).

Students' activity in a MOOC varies for different types of content and has own dynamics (Hill, 2013; Kizilcec, Piech, \& Schneider, 2013). Therefore, the Rasch model, which assumes the latent characteristics of a person and an item to be constant (Lord \& Novick, 1968), needs some tuning to allow a researcher to model and understand the students' behavior better. Now we may explain why we prefer the reformulation of the Rasch model from Equation 5.2 to its original formulation from Equation 5.1. The strength of the reformulation is that the units of content are considered as random, which makes the model to be very flexible for making extensions, because there are still degrees of freedom left to include various predictors (Van den Noortgate, De Boeck, \& Meulders, 2003).

In order to model differences and dynamics in students' activity, we propose to include predictor variables. For instance, consider the following extension:

$$
\begin{gathered}
\operatorname{Logit}\left(\pi_{i j}\right)=b_{0}+b_{10} * \text { type }_{i}+\left(b_{20}+b_{2 j}\right) * \text { week }_{i j}+u_{1 j}+ \\
u_{2 i} \text { and } Y_{i j} \sim \operatorname{Bernoulli}\left(\pi_{i j}\right)
\end{gathered}
$$


where type $e_{i}$ is a dummy variable, which distinguishes between two major types of content in a MOOC (where 0 stands for video lecture and 1 for reading assignment); $b_{10}$ therefore is the overall content type effect, which shows the increase in the logit of the probability of interacting when confronted with a reading assignment rather than with a video lecture; week $_{i j}$ is $0,1,2, \ldots, \mathrm{n}-1$ and means the first, the second, the third, ..., or n-th week of a MOOC at which student $j$ interacts with unit of content $i$ respectively; $b_{20}$ is the overall effect of week, which shows the average trend in the logit of probability; $b_{2 j}$ is a random deviation of the effect of week for the student $j$ from the overall effect; $b_{2 j}$ and $u_{1 j}$ are assumed to follow the bivariate normal distribution $N\left(\mathbf{0}, \boldsymbol{\Sigma}_{j}\right)$.

Therefore, the activeness of student $j$ now is a dynamic parameter, that varies over time: $\left(u_{1 j}+\left(b_{20}+b_{2 j}\right) * w_{e e} k_{i j}\right)$. The effect of a unit of content on the probability of interaction now is modelled as $\left(b_{0}+b_{10} *\right.$ type $\left.e_{i}+u_{2 i}\right)$, which accounts for the type of unit.

Previous research suggests that students' activity tends to decrease through the course (Hill, 2013; Halawa, Greene, \& Mitchell, 2014; Wan, Ding, Gao, \& Pritchard, 2017). Therefore, we expect the overall effect of week $\left(b_{20}\right)$ to be negative. However, the effect of week might vary over students which is reflected in individual values of $b_{2 j}$. We have no prior expectations on the value of the overall content type effect $\left(b_{10}\right)$, although we think this parameter may be different for different courses.

Various extensions of the model are possible. For instance, to check whether the activity is decreasing faster or slower for reading assignments compared to video lectures, we may add the interaction component $b_{3} *$ type $_{i} *$ $w_{e e} k_{i j}$ to Equation 5.3.

\section{Illustration}

To illustrate the proposed modeling approach, we use the logged data from the "Introduction to Neuroeconomics: How the Brain Makes Decisions" 
MOOC (Higher School of Economics, n.d.d). This course was launched on the Coursera platform in October 2015 and is still active. The course taught in English. The course consists of 11 weeks. In December 2018 the course had over 40,000 students who started and over 3,300 students who received certificates of course completion. Enrolled students have the following distribution among continents: Africa (3.4\%), Asia (21.5\%), Europe (35.5\%), North America (28.2\%), Oceania (2.5\%), and South America (8.9\%). The number of female students in the course is $48 \%$. The age distribution of students is as follows: $18.2 \%$ are $18-24,49.5 \%$ are $25-34,18.7 \%$ are $35-44,7.7 \%$ are $45-54$ years old respectively, and $5.9 \%$ are from other age groups. We have downloaded the course data in December 2018, and selected students who were active in 2017 to be sure that in December 2018 all these students had chances to complete the course, thus we have valid observations on completion and non-completion for all units of content. The number of these students is 11,826 . We used the data from five weeks (modules) from the course. We use data about interaction of students with two main types of units of content - video lectures and reading assignments. The number of video lectures is 27 and the number of reading assignments is 10 . Thus, the total number of observations is 319,302 (96,889 completed and 222,413 non-completed) for video lectures and 118,260 (51,036 completed and 67,224 non-completed) for reading assignments. Completed interactions are logged using code 1, noncompleted interactions are logged with code 0.

To fit the Rasch model from Equation 2 and the extension from Equation 3 we use the "glmer" function of the "Ime4" package (Bates, Maechler, Bolker, \& Walker, 2015) of the R language and environment for statistical computing (R Core 
Team, 2013). To compare the model fit, we use the Akaike's information criterion (AIC; Akaike, 1974) provided by the "glmer" function".

To study to what extent this approach can help to accurately specify the probability of completing units of content, we used a cross-validation procedure. We randomly split the students' logged data in three ways: (a) $25 \%$ in the training set and $75 \%$ in the test set, (b) 50\% in the training set and $50 \%$ in the test set, and (c) $75 \%$ in the training set and $25 \%$ in the test set. Then we fit the Rasch model and the extension on the training sets and use them to make predictions on the test sets. Next we build a table of confusion with two rows and two columns that report the number of false positives, false negatives, true positives, and true negatives. This table allows us to calculate the accuracy index:

$$
\text { Accuracy }=\frac{T P+T N}{P+N}
$$

where TP is true positives; $T N$ is true negatives; $P$ is all positives; $N$ is all negatives.

This procedure of splitting the data, fitting the Rasch model and the extension, making predictions and calculating the accuracy is repeated five times. Finally, we save all the accuracy indexes and calculate average indexes for each model.

For this cross-validation, we also used the data from one more course, the "Economics for Non-Economists" (Higher School of Economics, n.d.a) from the Coursera platform. As in the first course, we used the data from five weeks (modules) from the course. The "Economics for Non-Economists" course is taught in Russian and was launched in July 2016. The course consists of 10 weeks. In

${ }^{8}$ Although the AIC is widely used to compare different models, its application for models with a different number of random effects has been criticized (Vaida \& Blanchard, 2005). For better comparison, the conditional Akaike information criterion (cAIC) can be used. 
December 2018 the course had over 29,000 students who started and over 1,500 students who received certificates of course completion. Enrolled students are mainly from Europe (91.0\%). The number of female students in the course is $52 \%$. The age distribution of students is as follows: $31.7 \%$ are $18-24,47.9 \%$ are $25-34$, $14.6 \%$ are $35-44,3.5 \%$ are $45-54$ years old respectively, and $2.3 \%$ are from other age groups. As in the course above, we have downloaded the course data in December 2018, and selected students who were active in 2017 . The number of these students is 9,290. We used the data on video lectures and reading assignments from five weeks (modules) of the course. The number of video lectures is 59 and the number of reading assignments is 7 . Thus, the total number of observations is 538,820 (161,364 completed and 377,456 non-completed) for video lectures and 74,320 (26,948 completed and 47,372 non-completed) for reading assignments.

\section{Results}

We start with the Rasch model from Equation 5.2. The results allow us to reveal three key things about students' activity in MOOCs. First, as shown in the first column of Table 5.1, the estimate of the intercept equals -1.55. Using the inverse logit function, or antilogit, we can estimate the expected probability that an average student completes an average unit of content, which is .18. Second, the probability of completing a unit of content varies from student to student. To understand the size of variance among students, we calculated the expected probability of completing an average unit of content, for a student with activeness of one standard deviation lower, and for a student with activeness of one standard deviation higher than the average activeness. These probabilities are .01, the antilogit of $(-1.55-3.43)$, and .87 , the antilogit of $(-1.55+3.43)$. Third, the probability of completing a unit of content varies from unit to unit. The same procedure for units shows us that the probabilities of an average student to complete a unit the effect of one standard deviation lower, and a unit with the 
effect of one standard deviation higher than the average are .02 , the antilogit of $(-1.55-2.29)$, and .68 , the antilogit of $(-1.55+2.29)$, respectively. The antilogits calculated for different student parameters and unit parameters combinations are summarized in a comprehensive Table 5.2. We can conclude that there are very large differences between students and between units of content in the activity rate. As we mentioned above, the Rasch model does not take into account the types of content and possible dynamics in students' performance through a course. 
Table 5.1

Parameter estimates

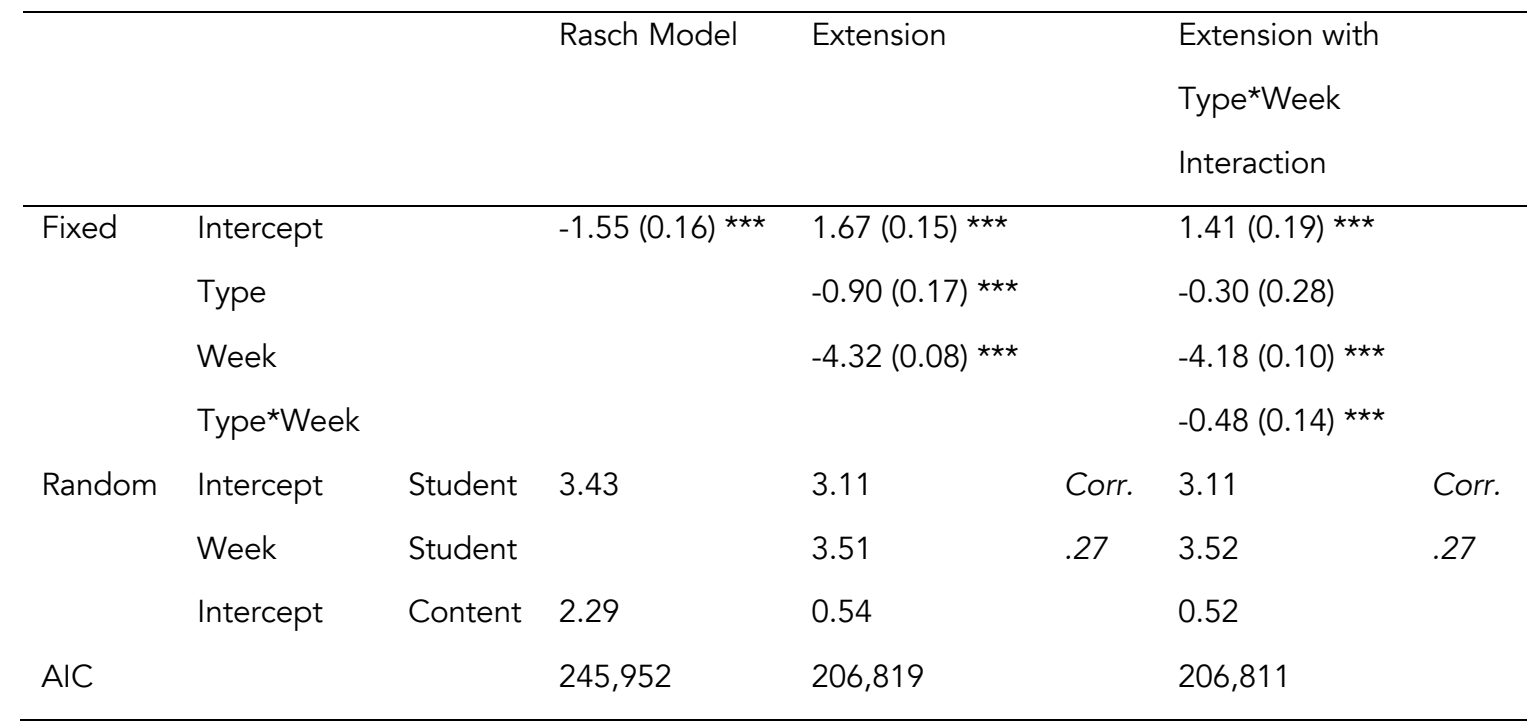

Note: In the table, for fixed effects the coefficient standard error is presented in parentheses, for random effects the standard deviation is presented. Significance code of '***' stands for $p<.001$. 
The probability to complete a video lecture is higher than the probability to complete a reading assignment. The effect of reading assignments versus video lectures is negative $(-0.90)$ and significantly different from zero $(p<.001)$, which means that reading assignments are less likely to be completed. The antilogits derived from Table 5.1 and summarized in Table 5.2 teach us that a student with average activeness will complete a video lecture on the first week of a $\mathrm{MOOC}$ with probability of .84 , which corresponds to the antilogit of 1.67 . For a reading assignment of the same week the probability is .68 corresponding to the antilogit of (1.67-0.90).

The activity decreases through a MOOC. The overall effect of week is significantly negative $(-4.32, p<.001)$. Table 5.2 shows us that a student with average activeness will complete a video lecture on the first week of the course with probability of .84 , while the probability to complete a video lecture on the third week is .00 , which is in congruence with the intensive character of dropouts in MOOCs. For a reading assignment and average student, the probabilities are .68 and .00 on the first and the third weeks of a MOOC. However, the effect of week varies from student to student. Table 5.1 informs us that the effect has a between-student standard deviation of 3.51. This value advices us that for some students the probability to complete units of content decreases more intensively than on average, while for some students the probability even increases through a MOOC. The student-specific intercept and student-specific effect of week are correlated weakly (.27). 
Table 5.2

Antilogits for the Rasch model and the extension

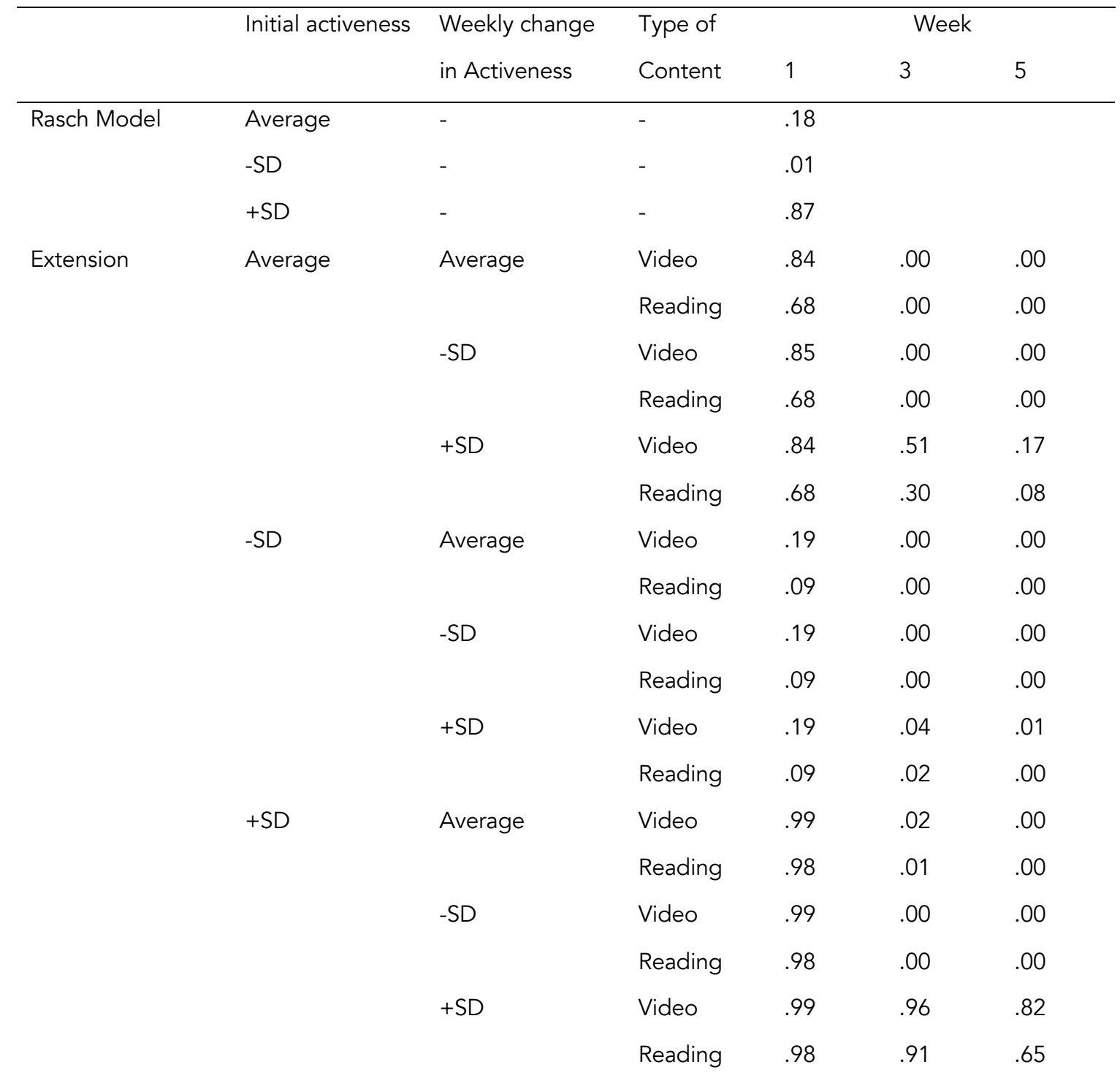

Note: In the Rasch model, we consider units of content with average latent stimulating property, while in the extension, we distinguish units of content to video lectures and reading assignments with average latent stimulating property. 
An interesting finding is that the inclusion of the effects of type and the week results in explaining $94 \%$ of between-units variance in activity. It informs us that the major part of between-units variation in activity is supposed to be due to the unit type and unit position in the course.

The extension with effect of interaction between the type of content and the week presented in Table 5.1 teaches us that the activity is decreasing faster for reading assignments than for video lectures. The interaction effect is negative $(-0.48)$ and significantly different from zero $(p<.001)$.

Including the effects of type and week improves the model fit. The extension fits the data better than the Rasch model with AIC of 206,819 for the extension and 245,952 for the Rasch model, which is supported by the likelihood ratio test $\left(\chi^{2}(4)=39,140, p<.001\right)$. Including the interaction between the type and the week improves the fit in a very minor way the AIC value of 206,811 and the likelihood ratio test results of $\chi^{2}(2)=10.79, p=.001$.

Finally, the cross-validation results presented in Table 5.3 show a high capacity of the benchmark model and the extension in predicting completing units of content by students. However, we see that the extension model outperforms the Rasch model with $1.2 \%$. The accuracy in $25 / 75$ proportion in training and test set is .904 for the benchmark model and .914 for the extension; in the 50/50 proportion the accuracies are .914 and .926 , while in the $75 / 25$ proportion the accuracies are .918 and .930 for the benchmark model and the extension respectively. 
Table 5.3

Accuracy in predicting completing units of content

\begin{tabular}{|c|c|c|c|c|c|c|c|}
\hline \multirow{2}{*}{$\begin{array}{l}\text { Training / } \\
\text { Test Prop. }\end{array}$} & \multirow[t]{2}{*}{ Model } & \multicolumn{2}{|c|}{ Overall } & \multicolumn{2}{|c|}{ Course 1} & \multicolumn{2}{|c|}{ Course 2} \\
\hline & & M & SD & M & SD & M & SD \\
\hline \multirow[t]{4}{*}{$25 / 75$} & Rasch Model & .904 & .010 & .894 & .001 & .914 & .000 \\
\hline & Extension & .914 & .013 & .901 & .001 & .927 & .000 \\
\hline & Extension with Type*Week & & & & & & \\
\hline & Interaction & .914 & .013 & .901 & .001 & .927 & .000 \\
\hline \multirow[t]{4}{*}{$50 / 50$} & Rasch Model & .914 & .008 & .906 & .000 & .922 & .000 \\
\hline & Extension & .926 & .011 & .916 & .000 & .937 & .000 \\
\hline & Extension with Type*Week & & & & & & \\
\hline & Interaction & .926 & .011 & .916 & .000 & .937 & .000 \\
\hline \multirow[t]{4}{*}{$75 / 25$} & Rasch Model & .918 & .007 & .911 & .001 & .924 & .001 \\
\hline & Extension & .930 & .011 & .920 & .001 & .941 & .001 \\
\hline & Extension with Type*Week & & & & & & \\
\hline & Interaction & .930 & .011 & .920 & .001 & .941 & .001 \\
\hline
\end{tabular}

Note: In the table, Course 1 stands for "Introduction to Neuroeconomics: How the brain Makes Decisions" and Course 2 stands for "Economics for Non-Economists". 


\section{Discussion and Conclusion}

In the study, a new way of exploring students' activity in MOOCs was presented. The results are important from four points. First, the proposed way expands the area of IRT applications by adding the activity measurement in online learning environments to the following row: large scale assessment, psychological testing, cognitive diagnostic assessment, health measurement, marketing research, measuring change (van der Linden, 2016). Second, the presented approach involves new kinds of data such as logs of student-content interaction, which are typically non-graded, to understanding the students' behavior, which on its turn follows the movement of computational psychometrics (von Davier, 2017) oriented at regarding student's behavior as a complex dynamic process. Third, the results support an existing point about students' activity in MOOCs, for instance, decreasing character of dynamics through the course (Halawa, Greene, \& Mitchell, 2014; Hill, 2013; Kizilcec, Piech, \& Schneider, 2013; Wan, Ding, Gao, \& Pritchard, 2017). However, they make a novel contribution to the understanding by showing that when we look at individual students, we can find a variety of dynamics, such as an increase through a course. Fourth, the proposed way might be applicable in dropout predictions. In comparison to the survival or time-to-event analysis which predicts time until a dropout occurs and is often used in MOOC research (Greene, Oswald, \& Pomerantz, 2015), the IRT-based approach describes students' behavior in a granular way being focused on each single interaction with a unit of content through the course. In sum, we believe that the results might be considered as an option or a component for "a theoretically driven, psychometrically sound instrument to measure learner engagement in $\mathrm{MOOC}^{\prime \prime}$ (Deng, Benckendorff, \& Gannaway, 2019, p. 57).

The study, however, has limitations. First, the benchmark model and the extensions work with a binary dependent variable. It limits understanding about 
intermediate stages of activity. Second, although we described well the betweenunits variation, there is a lot of between-students variation, which we did not succeed in explaining. These limitations could be considered as a direction for future research focused on in-depth modeling. For instance, if available, the ordered category variable (for example, "started", "paused", "continued", "finished") might be considered as a dependent variable to extend understanding of the activity, and additional student-specific predictors might be used to explain the between-students variation in the activity. 


\section{CHAPTER 6}

\section{PSYCHOMETRICS OF MOOCS: MEASURING LEARNERS' PROFICIENCY9}

Massive open online courses (MOOCs) generate learners' performance data that can be used to understand learners' proficiency and to improve their efficiency. However, the approaches currently used, such as assessing the proportion of correct responses in assessments, are oversimplified and may lead to poor conclusions and decisions because they do not account for additional information on learner, content, and context. There is a need in theoretically grounded data-driven educational measurement approaches for MOOCs. In this conceptual paper, we try to establish a connection between psychometrics, a scientific discipline concerned with techniques for educational and psychological measurement, and MOOCs. First, we describe general principles of traditional measurement of learners' proficiency in education. Second, we discuss qualities of MOOCs which hamper direct application of approaches based on these general principles. Third, we discuss recent developments in measuring proficiency that may be relevant for analyzing MOOC data. Finally, we draw directions in psychometric modeling that might be interesting for future MOOC research.

Massive open online courses (MOOCs) are "one of the most significant technological developments in higher education in the past decade" (Deng, Benckendorff, \& Gannaway, 2019, p. 48). MOOCs are large scale web-based courses developed by universities, solely or in cooperation with industrial partners (for example, Coursera, 2015), in which anyone with internet access can participate. At the same time, universities may use MOOCs locally for on-campus students; such courses have limited enrollment and called small private online courses (SPOCs). MOOCs are published on provider platforms, for instance, Coursera, edX, XuetangX, FutureLearn, Udacity, and MiriadaX. MOOCs are a relatively new instructional form - the term did not exist before 2008 (Major \& Blackmon, 2016). However, their popularity grows fast - over a decade more than 800 universities offered to learners more than 9,400 MOOCs (Shah, 2018a). In

\footnotetext{
${ }^{9}$ The text in this chapter has been submitted for publication as Abbakumov, D., Desmet, P., \& Van den Noortgate, W. Psychometrics of MOOCs: Measuring learners' proficiency.
} 
2018, the largest MOOC provider, Coursera, achieved the milestones of 36 million registered learners and 3,000 courses (Shah, 2018b).

A typical MOOC is composed of modules, each of which lasts a week and is structured around a single topic. Modules consist of smaller units, lessons. A lesson is structured around one or two learning objectives within a module topic. Each lesson includes a set of video lectures, reading assignments and formative assessments. A video lecture lasts 4-9 minutes and is accompanied by one or a set of formative assessment items that are incorporated in the lecture. It takes a student about 30 minutes to complete a lesson. Weekly modules are concluded by summative assessment, which is realized via a test, a peer-review task, or a combination of them. However, there are differences between courses, for instance, in length, workload, or options for self-paced learning.

The rapid development and expansion of MOOCs resulted in a growing body of related research, for instance, the investigation of learning effectiveness, challenges of teaching and learning, motivation of both learners and teachers, learners' experience (Bozkurt, Keskin, \& de Waard, 2016; Deng, Benckendorff, \& Gannaway, 2019; Ebben \& Murphy, 2014; Hew \& Cheung, 2014; Liyanagunawardena \& Williams, 2013; Raffaghelli, Cucchiara, \& Persico, 2015; Veletsianos, Collier, \& Schneider, 2015; Veletsianos \& Shepherdson, 2015). Surprisingly, although the aim of MOOCs is learning, in other words, a growth of learners' proficiency, and MOOC platforms state that enhancing learning is a key focus (edX, n.d.; Coursera, n.d.a), there is a lack of studies on modeling and measuring learners' proficiency in MOOC research. For instance, Abbakumov, Desmet, and Van den Noortgate (2018) stated that a Science Direct search revealed no papers for the combination of "MOOC" and "psychometrics" (or related keywords), the field within behavioral sciences focused on measurement.

MOOCs are unique in the data the platforms collect - every single activity of learners is recorded in a log. Moreover, education science has its own 
measurement approaches with a strong philosophical foundation, statistical representation, and over 100-year history in development (Borsboom, 2005). Given that, and given that various industries in the world, such as energy, transport, and agriculture, use detailed data to monitor, evaluate, and optimize their functioning (Lokshin, Rijal, \& Monroe, 2018), it seems odd that MOOCs as an industry, MOOC researchers and learning analytics still use grades, the simple proportion of correctly solved items in assessments or the (cumulative) proportion of assessments completed in a course, as a proxy for learners' proficiency (for example, de Barba, Kennedy, \& Ainley, 2016; Guo \& Reinecke, 2014; Phan, McNeil, \& Robin, 2016). These metrics are simple and intuitive but the use of them has a risk of bias due to oversimplification and ignoring factors of learners, content, and context. We suppose that imprecise or biased measures hamper improvement and development of MOOCs and believe it is important to connect theoretically grounded data-driven educational measurement approaches and MOOC research.

In this conceptual paper, we try to establish such a connection. First, we describe the principles of traditional approaches for measuring learners' proficiency in education. Second, we discuss qualities of MOOCs which hamper a direct application of these approaches based on the general principles in MOOCs. Third, we discuss recently developed solutions and potentially applicable approaches for measuring proficiency. Finally, we draw directions in psychometric modeling that might be interesting for future MOOC research.

\section{General Principles for Measuring Proficiency}

The learners' proficiency is a latent construct. We cannot observe or measure it directly. To get the estimates of proficiency we need observable indicators of proficiency and a set of rules for linking the observable side to the latent construct. The typical indicators are learners' responses on assessments, 
while the rules are provided by psychometric theories. There are two common theories in psychometrics - classical test theory and item response theory.

\section{Classical Test Theory}

In 1888, Edgeworth suggested to decompose observed test scores into a true score and an error component (Edgeworth, 1888). Using an example on the evaluation of person essays, he stated that the mean judgment of competent raters represents the true score and deviations from that represent errors (Borsboom, 2005). Later this suggestion was elaborated into a theory which conceptualizes proficiency through the true score concept and now is known as the classical test theory (CTT; Lord \& Novick, 1968; Novick, 1966). The respective classical test model:

$$
Y_{j}=\theta_{j}+\varepsilon_{j}
$$

is the most famous equation in educational and psychological measurement (Borsboom, 2005). According to this model, the test score of the $j$ 'th person $\left(Y_{j}\right)$ is the result of his/her proficiency $\left(\theta_{j}\right)$ with a random measurement error $\left(\varepsilon_{j}\right)$. The error term $\left(\varepsilon_{j}\right)$ has an expected value of zero, and is assumed normally distributed, unrelated to the proficiency: $E\left(\varepsilon_{j}\right)=0, \varepsilon_{j} \sim N\left(0, \sigma_{\varepsilon}^{2}\right)$, and $\rho_{\varepsilon \theta}=0$. Thus, the expected value of $Y_{j}, E\left(Y_{j}\right)$, is $\theta_{j}$. As a result, when persons are given multiple tests measuring the same proficiency, the average score is normally distributed around $\theta_{j}$ with variance $\sigma_{\varepsilon}^{2} / n$ with $n$ being the number of observations. Hence, the more observations, the closer the average score is in general to the proficiency.

The classical test model is simple for understanding which explains the high popularity of CTT among educational scholars and psychologists. At the same time, the simplicity leads to critical disadvantages. First, proficiency measures conceptualized through the test scores have a highly restricted area of generalization (Borsboom, 2005): conclusions are limited to the test itself or to an 
equivalent form, both statistically and in content domain, which is hard to find in practice. Second, proficiency measures are dependent on test difficulty: when the test is difficult, the person receives a low estimate of proficiency and when the test is easy, the person receives a high estimate of proficiency (Hambleton \& Jones, 1993). In practice, it means we cannot be confident about the proficiency measures' comparability, even in case of replacement of a single item in a test. This is not only because these tests might not be equal in difficulty, they can also be different in content. Thus, proficiency measures conceptualized through the same test scores might not reflect the same proficiency in a content domain.

\section{Item Response Theory}

Item response theory (IRT; Lord, 1952; Rasch, 1960; Birnbaum, 1968) was proposed as an alternative to CTT. The main idea of IRT is that a latent construct is considered to be unobserved determinant of a set of observed scores. For instance, a researcher who views proficiency in a specific domain as a latent variable assumes that the proficiency is the common cause of the person's responses to a set of specific test items. IRT presents a broad class of models with nonlinear linking between person's item responses (observable side) and his/her proficiency (latent construct). In the basic IRT model, the Rasch model (Rasch, 1960),

$$
\operatorname{Logit}\left(\pi_{i j}\right)=\ln \left(\frac{\pi_{i j}}{1-\pi_{i j}}\right)=\theta_{j}-\delta_{i} \text { and } Y_{i j} \sim \operatorname{Bernoulli}\left(\pi_{i j}\right),
$$

the probability $\left(\pi_{i j}\right)$ of the correct response of person $j$ to the item $i$ is described by a logistic function of the difference between the person's proficiency parameter $\left(\theta_{j}\right)$ and the item difficulty parameter $\left(\delta_{i}\right)$. To fit the Rasch model, a marginal maximum likelihood procedure is often used to estimate the item difficulty parameters, assuming that the persons are a random sample from a population in 
which the person proficiencies are normally distributed with $\theta_{j} \sim N\left(0, \sigma_{\theta}^{2}\right)$, while the items have fixed difficulty. Individual person parameters can be estimated afterwards using empirical Bayes procedures. Later this measurement model was extended to model complex observed variables (for instance, Bock, 1972; Samejima, 1969; Thissen \& Steinberg, 1984) using complex latent constructs (for instance, Adams, Wilson, \& Wang, 1997; Embretson, 1980; Maris, 1995; Whitely, 1980).

In comparison to CTT, person's proficiency parameters in IRT are independent of the test difficulty. It allows comparing persons even in case of partial replacement of items. However, IRT is demanding in terms of required sample sizes to obtain stable parameter estimates. For instance, Hambleton and Jones (1993) suggest to use a minimum of 500 persons to fit the model.

\section{Issues on Measuring Proficiency in MOOCs}

The key issues which hamper the direct use of the common psychometric techniques in MOOCs are linked to understanding the concept of proficiency itself.

First, both CTT and IRT assume the proficiency does not change within a test (Lord \& Novick, 1968). This way of understanding critically contrasts to the reality of processes in MOOCs and any learning process where the main product is the change of proficiency. MOOCs generate a change in proficiency at multiple levels. The first level is the level of assessment. A MOOC learner is allowed to use several (even an infinite number of) attempts to solve assessment tasks. If the learner fails at one attempt, he/she can be provided with help information, review a video lecture, use external materials, and then make a new attempt. Thus, the learner's proficiency may change with each new attempt to solve the certain task or the assessment in a whole. The second level is the level of a course. A MOOC learner watches video lectures, practices with formative assessments, discusses problems on a course forum. These activities are the main source of learning. 
Obviously, the learner's proficiency is not the same in two certain points of a course. Therefore, we cannot neglect the dynamic character of proficiency while estimating it.

Second, IRT assumes that proficiency (or a set of proficiencies) is a common cause of the learners' responses. However, MOOC learners have a high degree of freedom because of low-stakes of such courses, especially in case of low or no integration in a curriculum. Online learners' performance and retention are linked to a number of unrelated to knowledge emotional and motivational characteristics (de Barba, Kennedy, \& Ainley, 2016; Hart, 2012; Hew \& Cheung, 2014). Thus, the learner's proficiency might not be a single determinant of correctness in his/her responses in MOOCs. Therefore, neglecting the importance of such factors in performance explanation might result in biased conclusions on proficiency learners may perform weakly, not because they have low proficiency, but rather because they experience the lack of motivation.

At the same time there are at least two specific issues related to the observable side, indicators of proficiency, in MOOCs. First, changes in tests are relatively frequent in MOOCs - professors often replace or add new items on the fly. This is a critical limitation for CTT as discussed above, but also induced additional complexity for using IRT as the difficulty of new items typically is not known. A second issue is that IRT requires a relatively large number of items in assessments to provide accurate proficiency measures. Kruyen, Emons, and Sijtsma (2012) stated that the minimally required test length for individual level decisions is 40 items. By contrast, MOOCs often offer 15 or even fewer items in summative assessments which is a significant constraint for direct use of IRT.

As can be seen from the above, the common psychometric models of CTT and IRT are not tailored to use directly for measuring proficiency in MOOCs and should be tuned up accordingly. 


\section{Current Developments on Measuring Proficiency in MOOCs}

Recently, several extensions of the Rasch model were proposed for modeling the learners' performance in MOOCs. These include extensions for modeling the dynamics in proficiency on multiple levels (Abbakumov, Desmet, \& Van den Noortgate, 2018; 2019) and the inclusion of additional latent variables (Abbakumov, Desmet, \& Van den Noortgate, in press).

\section{General IRT Framework}

Extending the Rasch model without running into computational issues of model identification became possible by the use of the reformulation of the Rasch model proposed by Van den Noortgate, De Boeck, and Meulders (2003). In this reformulation based on the principle of cross-classification multilevel models, we have the intercept, and two residual terms referring to the person $j$ and the item $i$ respectively:

$$
\operatorname{Logit}\left(\pi_{i j}\right)=b_{0}+u_{1 j}+u_{2 i}
$$

where $u_{1 j} \sim N\left(0, \sigma_{u 1}^{2}\right)$ and $u_{2 i} \sim N\left(0, \sigma_{u 2}^{2}\right)$, and $Y_{i j} \sim \operatorname{Bernoulli}\left(\pi_{i j}\right)$. As the mean of both residual terms equals zero, the intercept corresponds to the estimated logit of the probability of the correct response for an average person on an average item. The first residual term, $u_{1 j}$, shows the deviation of the expected logit from person $j$ from the mean logit. The higher this deviation, the higher the expected performance. In terms of the original formulation of the Rasch model from Equation 6.2, this residual term can be interpreted as the proficiency of person $j$, and is equivalent to $\theta_{j}$. The second residual term shows the deviation of the expected logit from item $i$ from the overall logit. Here, the larger the residual the higher the probability of the correct response is. In that sense, the residual term $u_{2 i}$ presents the relative difficulty of item $i$, compared to the mean item difficulty, $b_{0}$. Therefore, the difficulty parameter $\delta_{i}$ from the original formulation of 
the Rasch model is equivalent to $-\left(b_{0}+u_{2 i}\right)$ in the reformulation from Equation 6.2. Thus considering both items and persons as random leaves degrees of freedom to estimate the effect of predictors.

\section{Proficiency Dynamics within the Assessment}

As we mentioned above, the key assumption of IRT is that the proficiency does not change within a test (Lord \& Novick, 1968). In MOOCs this assumption is met only partly. We may indeed expect that the learner's proficiency remains constant within particular summative assessment which typically does not lasts longer than 30-45 minutes. However, if the learner takes several attempts, the chances for the correct response grow with each new attempt. The first reason for this is learning. For instance, MOOCs typically provide learners with hints in case of a wrong response. This instructional content is aimed at helping the learner to understand his/her mistake, guiding through relevant learning materials and preparing for the next attempt. The second reason is that sometimes the learner may simply enumerate possibilities, for example, by clicking repeatedly on alternative options in multiple-choice questions.

Abbakumov, Desmet, and Van den Noortgate (2018) proposed to consider two components of proficiency within weekly summative assessment in a MOOC - a constant and a dynamic component, - and introduced the following model for learners' performance:

$$
\begin{gathered}
\operatorname{Logit}\left(\pi_{i j}\right)=b_{0}+\left(b_{10}+b_{1 j}\right) * \operatorname{attempt}_{i j}+u_{1 j}+ \\
u_{2 i} \text { and } Y_{i j} \sim \operatorname{Bernoulli}\left(\pi_{i j}\right)
\end{gathered}
$$

where $b_{0}$ equals the estimated logit of probability of the correct response of an average student on an average item in weekly summative assessment; attempt $_{i j}$ is $0,1,2,3$ or 4 and means the first, the second, the third, the fourth, or the fifth or higher attempt respectively; $b_{10}$ is overall effect of attempt, while $b_{1 j} \sim N\left(0, \sigma_{b 1}^{2}\right)$ 
is a deviation of the attempt effect for student $j$ from the overall effect; and $u_{1 j} \sim N\left(0, \sigma_{u 1}^{2}\right)$ and $u_{2 i} \sim N\left(0, \sigma_{u 2}^{2}\right)$. Thus, the random deviation $u_{1 j}$ can be interpreted as the proficiency of learner $j$, which is hardly changing within summative assessment, and is equivalent to $\theta_{j}$ in the Rasch model from Equation 2, while the dynamic component $\left(b_{10}+b_{1 j}\right) *$ attempt $_{i j}$ shows learner's $j$ individual increase in chances to solve the item $i$ correctly with a new attempt which can be interpreted as learner's $j$ local learning about item $i$ which came with the use of the instructional content associated to item $i$ or just repeated guessing. The authors showed that learners who use a higher number of attempts have lower 'local learning' (this is the increase of the chance on a correct answer with an additional attempt), which can help to distinguish between learners who learn and who use attempts to enumerate the item options.

The researchers also noted that the effect of an additional attempt may vary from item to item, for example, a multiple-choice item with four options could be solved correctly (using simple enumeration) by four attempts maximum, while for solving an open-ended item, where the student should indicate a number or a word, the number of attempts may be much higher. In order to account for this variation, they proposed the following composition of the dynamic component $\left(b_{10}+b_{1 j}+b_{1 i}\right) *$ attempt $_{i j}$, where $b_{1 i} \sim N\left(0, \sigma_{b 1}^{2}\right)$ is a deviation of the attempt effect for item $i$ from the overall effect.

Extending the Rasch model resulted in $6 \%$ improvement in accuracy of predicting the correctness of learners' responses on summative assessment items in comparison to the traditional Rasch model using on the responses from the first attempt only, which was obtained on the data from three MOOCs from the Coursera platform (Abbakumov, Desmet, \& Van den Noortgate, 2018). These improvements show that including learners' responses with accounting for the number of attempts to the analyses gives a more accurate view of the learners' proficiencies. 


\section{Proficiency Dynamics through the Course}

Another type of change in learners' proficiency in MOOCs which is not accounted for in the common psychometric models is growth through the course. To cover this gap, researchers proposed to measure this growth via the estimation of individual effect of the cumulative sum of video lectures a learner watched before a certain assessment task on the correctness of his/her response this task in a MOOC (Abbakumov, Desmet, \& Van den Noortgate, 2019). As video lectures are the central instructional tool in MOOCs, thus the growth in learners' proficiency from video lectures can be considered as the growth through the course. In the proposed Rasch model extension,

$$
\begin{gathered}
\operatorname{Logit}\left(\pi_{i j}\right)=b_{0}+\left(b_{10}+b_{1 j}\right) * \text { video }_{i j}+\cdots+u_{1 j}+ \\
u_{2 i} \text { and } Y_{i j} \sim \operatorname{Bernoulli}\left(\pi_{i j}\right)
\end{gathered}
$$

where $b_{10}$, this is the effect of the progressive sum of videos looked at, can be interpreted as the overall growth through the course, while $b_{1 j}$ is the deviation of the progressive sum effect for student $j$ from the overall effect, interpreted as the deviation of the individual growth through a course from the overall growth over subjects; $u_{1 j}$ and $b_{1 j}$ are assumed to follow univariate normal distributions, $N\left(0, \sigma_{u 1}^{2}\right), N\left(0, \sigma_{b 1}^{2}\right)$, or a multivariate normal distribution $N(\mathbf{0}, \boldsymbol{\Sigma})$ with $\boldsymbol{\Sigma}$ as the variance-covariance matrix. The value of $u_{1 j}$ can be considered as the initial proficiency of learner $j\left(\theta_{0 j}\right)$, while the value $u_{1 j}+\left(b_{10}+b_{1 j}\right) *$ video $_{i j}$ corresponds to the proficiency of learner $j$ at the moment of responding on item $i$ $\left(\theta_{i j}\right)$, when the number of videos looked at by learner $j$ equals $v i d e o_{i j}$.

The use of the extension showed that the probability of the correct response grows with every new watched lecture and the growth effect is specific for individual learners - for some learners, the growth may be intensive, while for some learners it may be almost flat through the whole course. The quality of 
predicting correctness of learners' responses on summative assessment items tested on the data from three MOOCs from the Coursera platform improves with $3.3 \%$ while using the extension in comparison to the use of original Rasch model. This fact promotes the use of extensions as a better approach in measuring the learners' proficiency and its growth in MOOCs.

A complementary solution can be adapted from educational online games. Researchers proposed an IRT model (Kadengye, Ceulemans, and Van den Noortgate, 2014; 2015) where learners' proficiency is considered as a function of time within learning sessions and the time between learning sessions:

$$
\begin{gathered}
\operatorname{Logit}\left(\pi_{i j}\right)=\left(\alpha_{0}+\omega_{0 j}\right)+\left(\alpha_{1}+\omega_{1 j}\right) * \text { wtime }_{i j}+\left(\alpha_{2}+\omega_{2 j}\right) * \text { btime }_{i j}+ \\
v_{i} \text { and } Y_{i j} \sim \operatorname{Bernoulli}\left(\pi_{i j}\right)
\end{gathered}
$$

where $\alpha_{0}$ is the overall initial learners' proficiency, $\omega_{0 j}$ is the deviation of the initial proficiency of learner $j$ from $\alpha_{0}$, wtime $_{i j}$ and btime $_{i j}$ is the amount of time that passed for learner $j$ while respectively using and not using the learning environment, up to the moment learner $j$ 's response to item $i, \alpha_{1}$ and $\alpha_{2}$ are overall population linear time trends within and between sessions respectively, and $\omega_{1 j}$ and $\omega_{2 j}$ are deviations of the time trends from learner $j$ from $\alpha_{1}$ and $\alpha_{2}$ respectively. The learner-specific random effects are assumed to have a multivariate normal distribution, and $v_{i}$ are random item effects with $v_{i} \sim N\left(0, \sigma_{v}^{2}\right)$. Thus, the authors introduce a dynamic concept $\theta_{i j}=\left(\alpha_{0}+\omega_{0 j}\right)+\left(\alpha_{1}+\omega_{1 j}\right) *$ wtime $_{i j}+\left(\alpha_{2}+\omega_{2 j}\right) *$ btime $_{i j}$, which corresponds to the proficiency of learner $j$ at the moment of responding item i. However, to apply this solution in MOOCs, the platform has to log the time a learner works with an online course. This is not yet a common practice. 


\section{Additional Latent Effects on the Performance}

The first additional latent effect on the learners' performance in MOOCs which was tested is interest (Abbakumov, Desmet, \& Van den Noortgate, in press). Interest has been chosen because it is a "critical cognitive and affective motivational variable" (Renninger \& Hidi, 2011, p. 169), which improves learners' performance in different domains. The researchers decided to test the effect of interest in formative assessments in MOOCs because these items are incorporated into video lectures, thus, learners' performance might not only be determined by proficiency, but also by learners' interest to the specific video lecture.

The researchers proposed the following extension:

$$
\begin{aligned}
\operatorname{Logit}\left(\pi_{i j}\right)= & b_{0}+\left(b_{10}+b_{1 j}\right) * \text { interest }_{i j}+\cdots+u_{1 j}+ \\
& u_{2 i} \text { and } Y_{i j} \sim \operatorname{Bernoulli}\left(\pi_{i j}\right)
\end{aligned}
$$

where interest $_{i j}$ reflects learner's $j$ interest to the video lecture in which the formative assessment item $i$ is incorporated in terms of his/her response on a question "Please rate the level of your interest during the video" with five Likerttype options: "very high", "high", "neutral", "low", and "very low" which are scored as $0,-1,-2,-3,-4$ respectively; $b_{0}$ equals the estimated logit of the probability of the correct response of an average learner to an average formative assessment item incorporated into the video lecture of the course in case of very high reported interest; $b_{10}$ reflects the overall effect of interest on the expected performance, this is the expected increase of the logit when interest increases with one unit; however, the effect of interest may not be the same for all learners, thus, to model such individual differences, the researchers used a random deviation of the interest effect for learner $j$ from the overall effect, $b_{1 j} \sim N\left(0, \sigma_{b 2}^{2}\right)$; and $u_{1 j} \sim N\left(0, \sigma_{u 1}^{2}\right)$ and $u_{2 i} \sim N\left(0, \sigma_{u 2}^{2}\right)$. 
As a product of applying this extension an interesting finding was found where the intercept variance, this is the variance between students in the effect of proficiency, was reduced by $25 \%$ by including a random interest effect. This fact provides a more nuanced insight in the role of proficiency on the learners' performance and confirms the importance of taking interest into account. However, there was no significant improvement in response prediction accuracy found compared to a model not taking into account interest.

\section{Further Directions in Measuring Proficiency in MOOCs}

In this section we highlight a set of promising directions for further development of psychometrics of MOOCs: the measurement of complex outcomes and latent constructs, the tracking learners' progress on-the-fly, the improved understanding learners' performance by the use of explanatory psychometric modeling approaches, the advancement in the quality of predictions by increasing the model complexity, the synergy of different psychometric methods and their combination with machine learning for precise and interpretable conclusions on learners.

\section{Measuring Complex Outcomes and Latent Constructs}

Learners interact with $\mathrm{MOOC}$ content in different ways: they watch video lectures, read PDF assignments, discuss on forums, they attempt solving assessments. All these activities are interlaced and result in complex outcomes, for instance, a partly correct response made with a hint, after re-watching the video lecture and after discussing on the forum. To have a more nuanced view on learners' proficiency, in this case a researcher should consider extending a model from polytomous IRT family (see Ostini \& Nering (2005) for an overview) which model outcomes scaled in more than two categories (for example, "correct/ partially correct/ wrong" instead of dichotomous "correct / wrong"). Moreover, a researcher should consider including predictors describing learners' activity before his/her response alongside as well as their interaction. 
MOOCs use not only test-based assessments. An important type of assessment is peer-reviewed assignments. In such assignments a learner's work is assessed by at least three peers using a schema provided by a course professor. An important problem of such assessments is a lower precision or validity due to peers' subjectivism (Admiraal, Huisman, \& van de Ven, 2014; Kravchenko, 2018). For instance, a learner may get low score not because of his/her low proficiency, but because of high severity of the peer who assessed the work. In order to assess and correct for bias that arose by peers' leniency or severity, a researcher should consider tuning up models which look at a learner's score as a common effect of his/her proficiency, difficulty of the task, and raters' effect. These models are well developed in IRT framework (Linacre, 1992; Myford \& Wolfe, 2003; Myford \& Wolfe, 2004).

MOOCs combine multiple domains within one course - one course may form a number of skills. Learners' responses in assessments might be caused by a set of proficiencies, for instance, to solve a specific task in bioinformatics a learner might need a knowledge in calculus, programming, biology. Thus, understanding a single proficiency as a common cause of this response seem to be oversimplified. In this case a researcher should consider a multidimensional solution (Reckase, 2009) which in general case replaces $\theta_{j}$ in the original Rasch model from Equation 6.2 with $\Sigma_{k} b_{i k} \theta_{j k}$ where $\theta_{j k}$ is the proficiency of learner $j$ on the $k$ th dimension, and $b_{i k}$ is the factor loading of item $i$ on dimension $k$.

\section{Tracking the Progress On-the-Fly}

The approaches from Equations 6.5 and 6.6 work for post-hoc measuring, not for dynamic growth tracking. The on-the-fly progress estimation, crucial for navigation and recommendations engines which decide about when to support a learner or to advance him/her through a course, could be realized by the use of the Elo Rating System (ERS; Elo, 1978). The ERS was initially developed for ranking chess players where the rank update is based on the weighted difference in match 
result and expected match result. The researchers (Brinkhuis \& Maris, 2009; Klinkenberg, Straatemeier, \& van der Maas, 2011) suggested to use the ERS to dynamically update learners' proficiency based on the results of solving items in an online educational game. There the proficiency of learner $j$ at the moment of responding item $i$ is computed as $\hat{\theta}_{i j}=\hat{\theta}_{(i-1) j}+K\left\{Y_{i j}-E\left(Y_{i j}\right)\right\}$, where $K$ is the constant term presenting a step size in learners' proficiency update, which in learning environments is typically set to be $0.4, Y_{i j}$ is actual response of learner $j$ on item $i$ which is coded dichotomously, where 0 stands for an incorrect response and 1 stands for a correct response, and $E\left(Y_{i j}\right)$ is his/her expected response on this item. The expected response can be computed using the Rasch model from Equation 6.2, more specifically as a function of the difference between the ability as estimated before the response was given, $\hat{\theta}_{(i-1) j}$, and the difficulty of the item, $\delta_{i}$. This approach is widely used in learning environments (Pelanek, 2016; Oefenweb, n.d.) and is potentially applicable in MOOCs.

\section{Explanatory Modeling}

There are two general psychometric approaches that might be involved in work with learners' responses on assessment items in MOOCs. The first type is the measurement approach. This approach seeks the optimal way of locating an individual learner on the latent scale, the scale of proficiency. In other words, a researcher tries to estimate an individual learner's proficiency as precisely as possible, and all the techniques we discussed above belong to measurement approaches.

The second type is an explanatory approach. This approach is focused on explaining learners' responses in terms of other variables. For instance, a MOOC researcher might be interested in studying the relationship between the learners' performance and their previous learning experience to understand the optimal way to structure this experience in order to improve the performance. For instance, recent results of Abbakumov, Desmet, and Van den Noortgate (2018), showing 
that MOOC learners who are productive with formative assessments have higher chances to solve summative items correctly, may suggest us to try to intensify practice in courses. Another interest would be to explore design variations in the items compose the assessment, to see if performance on the items depends on, specific item features (for instance, multiple choice response or typed response) in order to optimize the assessment composition. As can be seen, the level of conclusions here is not the individual learner, but rather the general inferences that can be made about the relationship of explanatory variables across the learners and the items. Therefore, the explanatory approach might be very useful in $A / B$ tests (large-scale online randomized controlled experiments) which seek the optimal way to organize learning experience within the digital environment, for instance, in comparing two types of video lectures - produced in professional studio (A) and hand-crafted (B) - by their effect on learners' performance in a MOOC.

The explanatory movement has been started by De Boeck and Wilson (2004) with collaborators. Although there are a set of models developed for different explanatory strategies, for instance, to explain item-related or personrelated variance, we find the cross-classification multilevel logistic approach (Van den Noortgate, De Boeck, \& Meulders, 2003) which combines the both strategies to be a universal and flexible framework a MOOC researcher might use. The two approaches, the measurement approach and the explanatory approach, can be combined within this framework.

\section{Improving Prediction}

As we saw above, tuning the common psychometric models results in improvements in the accuracy of predicting learners' responses. However, these improvements are rather small, for instance, 3-6\% (Abbakumov, Desmet, \& Van den Noortgate, 2018; 2019). Thus a researcher might be interested in better predictive capacity from psychometric solutions, for instance, accurate predictions 
on learners' performance are necessary in building adaptive learning experience, for instance, in automated navigation through learning materials or a system of personalized hints and recommendations. There is substantive advancement in boosting predictive power in statistical learning theory, a framework for machine learning based on statistics, which deals with the problem of finding a predictive function based on data (Hastie, Tibshirani, \& Friedman, 2009). In general, these improvements are linked to growing model complexity. A MOOC researcher should consider to move beyond linearity in order to improve the predictive power. To this end, a MOOC researcher can use several techniques, for instance, polynomial regression or regression splines. Polynomial regression extends the linear model by adding predictors, got by raising each of the original predictors to a power (for instance, a quadratic regression uses two variables, $X$, and $X^{2}$, as predictors). This approach provides a simple way to provide a nonlinear fit to data. Regression splines are more flexible than polynomials. They split the range of a variable into $K$ distinct intervals. Within each interval, a polynomial function is fit to the data. Thus, instead of fitting a high-degree polynomial over the entire range of $X$, piecewise polynomial regression involves fitting separate low-degree polynomials over different intervals of $X$. This can produce a very flexible fit. However, advancement in prediction might come alongside with significant decrease in model interpretability which can be a critical constraint for applications for educational purposes. The key focus of a MOOC researcher here is to find optimal quality of prediction without loss in understanding functional relationship between variables.

\section{Mixing Methods}

The popular term "there is no free lunch in statistics" (Wolpert \& Macready, 1997) which means no one method dominates others over all possible situations and data sets spreads on psychometrics of MOOCs as well. For example, the Rasch model extensions provide advantages in understanding learners' 
performance in MOOCs, however, there still is a room in predictive power to fill in. Another example, ERS works well in updating learners' proficiency in online educational games but may suffer from the cold-start problem, when the program does not know a new learner's proficiency level at the beginning of the learning. These examples draw a perspective direction on mixing psychometric approaches and combining them with machine learning methods to cover gaps. For instance, to solve the cold start problem Park, Joo, Cornillie, van der Maas, and Van den Noortgate (2019) combine ERS and explanatory psychometric modeling. The same problem has been addressed in a work of Pliakos and colleagues (Pliakos, et al., 2019) but using a combination of IRT models and decision tree method from machine learning. As can be seen there are several alternative solutions for the same problem can be found.

There are a number of methods in machine learning a researcher may consider to combine with psychometric approaches, for instance, tree-based methods, support vector machines, clustering (Hastie, Tibshirani, \& Friedman, 2009). Using these methods as stand-alone may result in dramatic improvements in quality of conclusions. However, the cost for these improvements is a significant loss in interpretation, for instance, why in a given situation we have high or low performance (or high or low learning), which makes machine learning methods somewhat "black boxes". At the same time, in comparison to many machine learning methods, a major advantage of psychometric models is their explanatory power: they give insight in what works, when and for whom, and therefore may help to further optimize MOOCs. Thus a researcher has to find an equilibrium in such combinations. In principal we agree with a direction on creating models that are interpretable in the first place which is growing up now in data science (Rudin, 2019). 


\section{Conclusion}

Psychometrics of MOOCs is a very recent development in the field. To find an answer on the question of when and why learning does happen in MOOCs, and how these digital learning products do work, it combines a century-old heritage of psychometrics and modern sources of the logged data. It has its unique properties, such as dynamic character of learners' proficiency and composite character of cause of learners' performance. Although it is already showing improvements in understanding the digital learners, its future is linked to moving towards computational direction involving complex data and advanced statistical procedures into modeling multidimensional dynamic constructs and processes in MOOCs. 


\section{REFERENCES}

Abbakumov, D., Desmet, P., \& Van den Noortgate, W. (2018). Measuring student's proficiency in MOOCs: Multiple attempts extensions for the Rasch model. Heliyon, 4(12), 1-15.

Abbakumov, D., Desmet, P., \& Van den Noortgate, W. (2019). Measuring growth in students' proficiency in MOOCs: Two component dynamic extensions for the Rasch model. Behavior Research Methods, 51(1), 332-241.

Abbakumov, D., Desmet, P., \& Van den Noortgate, W. (in press). Rasch model extensions for enhanced formative assessments in MOOCs. Applied Measurement in Education.

Adams, R. J., Wilson, M., \& Wang, W. (1997). The multidimensional random coefficients multinomial logit model. Applied Psychological Measurement, 21, 1-23.

Admiraal, W., Huisman, B., \& van de Ven, M. (2014). Self- and peer assessment in massive open online courses. International Journal of Higher Education, 3(3), 110-128.

Ainley, M. (2007). Being and feeling interested: transient state, mood, and disposition. In P. Schutz, Emotion in Education (pp. 141-157). New York, NY: Academic Press.

Ainley, M., \& Ainley, S. (2006). Between the lines (BTL). Melbourne: Department of psychology, University of Melbourne.

Ainley, M., Hidi, S., \& Berndorff, D. (2002). Interest, learning, and the psychological processes that mediate their relationship. Journal of Educational Psychology, 94, $545-561$.

Akaike, H. (1974). A new look at the statistical model identification. IEEE Transactions on Automatic Control, 19(6), 716-723.

Alario-Hoyos, C., Delgado Kloos, C., Estevez-Ayres, I., Fernandez-Panadero, C., Blasco, J., Pastrana, S., . . Villena-Roman, J. (2016). Interactive activities: the key to learning programming with MOOCs. European MOOCs Stakeholders Summit, (pp. 319-328). Graz, Austria.

Andersen, E. B. (1985). Estimating latent correlations between repeated testings. Psychometrika, 50, 3-16.

Bates, D., Maechler, M., Bolker, B., \& Walker, S. (2015). Fitting linear mixed-effects models using Ime4. Journal of Statistical Software, 67(1), 1-48.

Birnbaum, A. (1968). Some latent trait models and their use in inferring an examinee's ability. In F. M. Lord, \& M. R. Novick, Statistical Theories of Mental Test Scores. Reading, MA: Addison-Wesley.

Bock, R. D. (1972). Estimating item parameters and latent ability when responses are scored in two or more latent categories. Psychometrika, 37, 29-51.

Borsboom, D. (2005). Measuring the Mind: Conceptual Issues in Contemporary Psychometrics. Cambridge: Campridge University Press.

Bozkurt, A., Keskin, N. L., \& de Waard, I. (2016). Research trends in massive open online course $(\mathrm{MOOC})$ theses and dissertations: Surfing the tsunami wave. Open Praxis, 8(3), 203-221. 
Brinkhuis, M. J., \& Maris, G. (2009). Dynamic Parameter Estimation in Student Monitoring Systems. Arnhem, The Netherlands: Cito.

Chyung, S. Y. (2001). Systematic and systemic approaches to reducing attrition rates in online higher education. American Journal of Distance Education, 15(3), 36-49.

Coursera. (2015, February 11). Top Companies Work with University Partners to Help Create Capstone Projects with Real World Applications. Retrieved from Coursera Blog: https://blog.coursera.org/top-companies-work-with-university-partners-to/

Coursera. (2016, June 30). What's new on Coursera: dashboard and course home page updates. Retrieved from Coursera Blog: https://blog.coursera.org/whats-newon-coursera-dashboard-and-course-home/

Coursera. (n.d.-a). Our mission. Retrieved from Coursera: https://www.coursera.org/about

Coursera. (n.d.-b). Partner Resource Center. Retrieved March 2018, from Assessments on Coursera: https://partner.coursera.help/hc/en-us/articles/203597939Assessments-on-Coursera

Coursera. (n.d.-c). Producing engaging video lectures. Retrieved from Coursera Partner Resource Center: https://partner.coursera.help/hc/en-us/articles/203525739Producing-Engaging-Video-Lectures

Davis, F. B. (1964). Educational Measurements and their Interpretation. Belmont, CA: Wadsworth Publishing Company.

de Barba, P. G., Kennedy, G. E., \& Ainley, M. D. (2016). The role of students' motivation and participation in predicting performance in a MOOC. Journal of Computer Assisted Learning, 32(3), 218-231.

De Boeck, P., \& Wilson, M. (2004). Explanatory Item Response Models: A Generalized Linear and Nonlinear Approach. New York, NY: Springer.

De Boeck, P., Bakker, M., Zwister, R., Nivard, M., Hofman, A., Tuerlinckx, F., \& Partchev, I. (2011). The estimation of item response models with the Imer function from the Ime4 package in R. Journal of Statistical Software, 39(12), 1-28.

Deng, R., Benckendorff, P., \& Gannaway, D. (2019). Progress and new directions for teaching and learning in MOOCs. Computers \& Education, 129, 48-60.

Denissen, J. H., Zarrett, N. R., \& Eccles, J. S. (2007). "I like to do it, I'm able, and I know I am": longitudinal couplings between domain-specific achievement, selfconcept, and interest. Child Development, 78, 430-447.

Dewey, J. (1913). Interest and effort in education. Boston, MA: Riverside.

Drasgow, F., \& Lissak, R. (1983). Modified parallel analysis: a procedure for examining the latent dimensionality of dichotomously scored item responses. Journal of Applied Psychology, 68, 363-373.

Ebben, M., \& Murphy, J. S. (2014). Unpacking MOOC scholarly discourse: A review of nascent MOOC scholarship. Learning, Media and Technology, 39(3), 328-345.

Edgeworth, F. Y. (1888). The statistics of examinations. Journal of the Royal Statistical Society, 51, 598-635.

edX. (n.d.). About edX. Retrieved from edX: https://www.edx.org/about-us

Ekanadham, C., \& Karklin, Y. (2015). T-SKIRT: Online estimation of student proficiency in an adaptive learning system. 31st International Conference on Machine Learning. Lille. 
Elo, A. (1978). The Rating of Chessplayers, Past and Present. New York, NY: Arco Publishers.

Embretson, S. (1980). Multicomponent latent trait models for ability tests. Psychometrika, 45, 479-494.

Fisher, G. H. (1976). Some probabilistic models for measuring change. In D. N. De Gruijter, \& L. J. Van der Kamp (Eds.), Advances in Psychological and Educational Measurement (pp. 97-110). New York, NY: Wiley.

Fisher, G. H. (1995). Linear logistic models for change. In G. H. Fischer, \& I. W. Molenaar (Eds.), Rasch Models: Foundations, Recent Developments, and Applications (pp. 157-180). New York, NY: Springer-Verlag.

Greene, J. A., Oswald, C. A., \& Pomerantz, J. (2015). Predictors of retention and achievement in a Massive Open Online Course. American Educational Research Journal, 52(5), 925-955.

Guedes Da Silva, A., Moura Santos, A., Albuquerque Costa, F., \& Viana, J. (2016). Enhancing MOOC videos: design and production strategies. European MOOCs Stakeholders Summit, (pp. 107-122). Graz, Austria.

Guo, P. J., \& Reinecke, K. (2014). Demographic differences in how students navigate through MOOCs. Annual ACM Conference on Learning at Scale. Atlante, USA.

Guo, P. J., Kim, J., \& Rubin, R. (2014). How video production affects student engagement: an empirical study of MOOC videos. Learning at Scale. Atlanta, USA.

Halawa, S., Greene, D., \& Mitchell, J. (2014). Dropout prediction in MOOCs using learner activity features. European MOOCs Stakeholders Summit, (pp. 58-65). Lausanne.

Hambleton, R. K., \& Jones, R. W. (1993). Comparison of Classical Test Theory and Item Response Theory and their applications to test development. Educational Measurement: Issues and Practice, 12(3), 38-47.

Hambleton, R. K., Swaminathan, H., \& Rogers, H. J. (1991). Fundamentals of Item Response Theory. Newbury Park, CA: SAGE Publications.

Hart, C. (2012). Factors associated with student persistence in an online program of study: A review of the literature. Journal of Interactive Online Learning, 11(1), 1942.

Hastie, T., Tibshirani, R., \& Friedman, J. (2009). The Elements of Statistical Learning. New York, NY: Springer-Verlag.

Hew, K. F., \& Cheung, W. S. (2014). Students' and instructors' use of massive open online courses (MOOCs): Motivations and challenges. Educational Research Review, 12, 45-58.

Hidi, S., \& Baird, W. (1988). Strategies for increasing text-based interest and student's recall of expository texts. Reading Research Quarterly, 23, 465-483.

Higher School of Economics. (2019, February 25). HSE Marks 5th Year of Teaching on Coursera. Retrieved from National Research University Higher School of Economics: https://www.hse.ru/en/news/edu/245876785.html

Higher School of Economics. (n.d.-a). Economics for Non-Economists. Retrieved from Coursera: https://www.coursera.org/learn/ekonomika-dlya-neekonomistov

Higher School of Economics. (n.d.-b). Finansial Markets and Institutions. Retrieved from Coursera: https://www.coursera.org/learn/finansovye-rynki 
Higher School of Economics. (n.d.-c). Game Theory. Retrieved from Coursera: https://www.coursera.org/learn/game-theory

Higher School of Economics. (n.d.-d). Introduction to Neuroeconomics: How the Brain Makes Decisions. Retrieved from Coursera: https://www.coursera.org/learn/neuroeconomics

Hill, P. (2013, March 10). Emerging student patterns in MOOCs: A (revised) graphical view. Retrieved from e-Literate: https://mfeldstein.com/emerging-studentpatterns-in-moocs-a-revised-graphical-view/

James, G., Witten, D., Hastie, T., \& Tibshirani, R. (2013). An Introduction to Statistical Learning. New York, NY: Springer.

Kadengye, D. T., Ceulemans, E., \& Van den Noortgate, W. (2014). A generalized longitudinal mixture IRT model for measuring differential growth in learning environments. Behavior Research Methods, 46(3), 823-840.

Kadengye, D. T., Ceulemans, E., \& Van den Noortgate, W. (2015). Modeling growth in electronic learning environments using a longitudinal random item response model. The Journal of Experimental Education, 83(2), 175-202.

Kizilcec, R. F., Piech, C., \& Schneider, E. (2013). Deconstructing disengagement: Analyzing learner subpopulations in massive open online courses. Learning Analytics and Knowledge (LAK) Conference, (pp. 1-10). Leuven.

Klinkenberg, S., Straatemeier, M., \& van der Maas, H. L. (2011). Computer adaptive practice of Maths ability using a new item response model for on the fly ability and difficulty estimation. Computers \& Education, 57, 1813-1824.

Kovanovic, V., Joksimovic, S., Gasevic, D., Owens, J., Scott, A. M., \& Woodgate, A. (2016). Profiling MOOC course returners: How does student behavior change between two course enrollments? Annual ACM Conference on Learning at Scale, (pp. 269-272). Edinburgh.

Krapp, A., Hidi, S., \& Renninger, K. A. (1992). Interest, learning, and development. In K. A. Renninger, S. Hidi, \& A. Krapp, The Role of Interest in Learning and Development (pp. 3-25). Hillsdale, NJ: Lawrence Erlbaum Associates.

Kravchenko, D. (2018). Classical test theory and item response theory in measuring validity of peer-grading in massive open online courses. Voprosy obrazovaniya / Educational Studies Moscow, 4, 99-115.

Kruyen, P. M., Emons, W. H., \& Sijtsma, K. (2012). Test length and decision quality in personnel selection: When is short too short? International Journal of Testing, 12, 321-344.

Linacre, J. M. (1992). Many-Facet Rasch Measurement. Chicago, IL: MESA Press.

Liyanagunawardena, T. R., \& Williams, S. A. (2013). MOOCs: A systematic study of the published literature 2008-2012. The International Review of Research in Open and Distance Learning, 14(3), 202-227.

Lokshin, M. M., Rijal, D., \& Monroe, T. (2018, 10 26). From discovery to scale: Leveraging big data to improve development outcomes. Retrieved from The World Bank: https://blogs.worldbank.org/opendata/discovery-scale-leveragingbig-data-improve-development-outcomes

Lord, F. M. (1952). A Theory of Test Scores. New York, NY: Psychometric Society.

Lord, F. M. (1970). Some test theory for tailored testing. In W. H. Holtzman, ComputerAssisted Instruction, Testing, and Guidance. New York, NY: Harper \& Row. 
Lord, F. M. (1980). Applications of Item Response Theory to Practical Testing Problems. Hillsdale, NJ: Lawrence Erlbaum.

Lord, F. M., \& Novick, M. R. (1968). Statistical Theories of Mental Test Scores. Reading, MA: Addison Wesley Publishing Company.

Maggioncalda, J. (2019). Keynote address. Coursera Partners Conference. London, UK.

Major, C. H., \& Blackmon, S. J. (2016). Massive open online courses: Variations on a new instructional form. New Directions for Institutional Research, 2015(167), 11-25.

Maris, E. (1995). Psychometric latent response models. Psychometrika, 60, 523-547.

McDaniel, M. A., Waddill, P. J., Finstad, K., \& Bourg, T. (2000). The effects of text-based interest on attention and recall. Journal of Educational Psychology, 492-502, 492-502.

Molenaar, I. W. (1995). Some background for Item Response Theory and the Rasch model. In G. H. Fischer, \& I. W. Molenaar (Eds.), Rasch Models: Foundations, Recent Developments, and Applications (pp. 3-14). New York, NY: SpringerVerlag.

Myford, C. M., \& Wolfe, E. W. (2003). Detecting and measuring rater effects using many-facet Rasch measurement: Part I. Journal of Applied Measurement, 4, 386422.

Myford, C. M., \& Wolfe, E. W. (2004). Detecting and measuring rater effects using many-facet Rasch measurement: Part II. Journal of Applied Measurement, 5, 189-227.

Nolen, S. B. (2007). Young children's motivation to read and write: development in social contexts. Cognition and Instruction, 25, 219-270.

Novick, M. R. (1966). The axioms and principal results of classical test theory. Journal of Mathematical Psychology, 3, 1-18.

Oefenweb. (n.d.). Online and adaptive learning tools. Retrieved from Oefenweb: https://www.oefenweb.com/products/

Osborn, V. (2001). Identifying at-risk students in videoconferencing and web-based distance education. American Journal of Distance Education, 15(1), 41-54.

Ostini, N., \& Nering, M. L. (2005). Polytomous Item Response Theory Models. Thousand Oaks, CA: Sage Publications.

Palmer, D. H. (2009). Student interest generated during an inquiry skills lesson. Journal of Research in Science Teaching, 46, 147-165.

Park, J. E., Joo, S., Cornillie, F., van der Maas, H. L., \& Van den Noortgate, W. (2019). An explanatory item response theory method for alleviating the cold-start problem in adaptive learning environments. Behavior Research Methods, 51(2), 895-909.

Parker, A. (2003). Identifying predictors of academic persistence in distance education. United States Distance Learning Association Journal, 17(1), 55-61.

Pelanek, R. (2016). Applications of the Elo rating system in adaptive educational systems. Computers \& Education, 98, 169-179.

Phan, T., McNeil, S. G., \& Robin, B. R. (2016). Students' patterns of engagement and course performance in a Massive Open Online Course. Computers \& Education, 95, 36-44.

Pliakos, K., Jo, S. H., Park, J. Y., Cornillie, F., Vens, C., \& Van den Noortgate, W. (2019). Integrating machine learning into item response theory for addressing the cold 
start problem in adaptive learning systems. Computers \& Education, doi: https://doi.org/10.1016/j.compedu.2019.04.009.

R Core Team. (2013). R: A language and environment for statistical computing. ( $R$ Foundation for Statistical Computing) Retrieved from http://www.R-project.org/

Raffaghelli, J. E., Cucchiara, S., \& Persico, D. (2015). Methodological approaches in MOOC research: Retracing the myth of Proteus. British Journal of Educational Technology, 46(3), 488-509.

Rasch, G. (1960). Probabilistic Models for Some Intelligence and Attainment Tests. Copenhagen: Danish Institute for Educational Research.

Reckase, M. D. (2009). Multidimensional Item Response Theory. Ney York, NY: SpringerVerlag.

Renninger, K. A., \& Hidi, S. (2011). Revisiting the conceptualization, measurement, and generation of interest. Educational Psychologist, 46(3), 168-184.

Rizopoulos, D. (2006). Itm: An R package for latent variable modelling and item response theory analyses. Journal of Statistical Software, 17(5), 1-25.

Rudin, C. (2019). Stop explaining black box machine learning models for high stakes decisions and use interpretable models instead. Nature Machine Intelligence, 1, 206-2015.

Samejima, F. (1969). Estimation of latent ability using a response patternof graded scores. Psychometric Monographs, 18.

Santos, H. L., Klerkx, J., Duval, E., Gago, D., \& Rodrigues, L. (2014). Success, activity and drop-outs in MOOCs An exploratory study on the UNED COMA courses. Learning Analytics and Knowledge (LAK) Conference, (pp. 98-102). Indianapolis.

Schaeffner, E., \& Schiefele, U. (2007). The effect of experimental manipulation of student motivation on the situational representation of text. Learning and Instruction, 17, 755-772.

Shah, D. (2016, December 29). Monetization over massiveness: breaking down MOOCs by the numbers in 2016. Retrieved from EdSurge:

https://www.edsurge.com/news/2016-12-29-monetization-over-massivenessbreaking-down-moocs-by-the-numbers-in-2016

Shah, D. (2017, December 31). Coursera's 2017: year in review. Retrieved from Class Central: https://www.class-central.com/report/coursera-2017-year-review

Shah, D. (2018a, January 22). A product at every price: A review of MOOC stats and trends in 2017. Retrieved from Class Central: https://www.classcentral.com/report/moocs-stats-and-trends-2017

Shah, D. (2018b, October 21). Coursera's 2018 revenue estimated to be $\$ 140$ million. Retrieved from Class Central: https://www.class-central.com/report/coursera2018-revenue-140-million

Thirouard, M., Bernaert, O., Dhorne, L., Bianchi, S., Pidol, L., Remy Crepon, S., \& Petit, Y. (2015). Learning by doing: Integrating a serious game in a MOOC to promote new skills. European MOOCs Stakeholders Summit, (pp. 92-96). Mons, Belgium.

Thissen, D., \& Steinberg, L. (1984). A response model for multiple-choice items. Psychometrika, 49, 501-5019.

Thorndike, E. L. (1935). The interests of adults: the permanence of interests. Journal of Educational Psychology, 26, 401-410. 
Vaida, F., \& Blanchard, S. (2005). Conditional Akaike information for mixed-effects models. Biometrika, 92(2), 351-370.

Van den Noortgate, W., De Boeck, P., \& Meulders, M. (2003). Cross-classification multilevel logistic models in psychometrics. Journal of Educational and Behavioral Statistics, 28, 369-386.

van der Linden, W. J. (Ed.). (2016). Handbook of Item Response Theory, Three Volume Set. Boca Raton, FL: CRC Press.

van der Linden, W. J., \& Glas, C. A. (2000). Computerized Adaptive Testing: Theory and Practice. Norwell, MA: Kluwer.

van der Linden, W. J., \& Hambleton, R. K. (Eds.). (1997). Handbook of Modern Item Response Theory. New York, NY: Springer-Verlag.

Veletsianos, G., \& Shepherdson, P. (2015). Who studies MOOCs? Interdisciplinarity in MOOC research and its changes over time. International Review of Research in Open and Distance Learning, 16(3), 1-17.

Veletsianos, G., Collier, A., \& Schneider, E. (2015). Digging deeper into learners' experiences in MOOCs: Participation in social networks outside of MOOCs, notetaking and contexts surrounding content consumption. British Journal of Educational Technology, 46(3), 570-587.

Verguts, T., \& De Boeck, P. (2000). A Rasch model for detecting learning while solving an intelligence test. Applied Psychological Measurement, 24(2), 151-162.

Verhelst, N. D., \& Glas, C. A. (1993). A dynamic generalization of the Rasch model. Psychometrika, 58(3), 395-415.

Verhelst, N. D., \& Glas, C. A. (1995). Dynamic generalizations of the Rasch model. In G. H. Fischer, \& I. W. Molenaar (Eds.), Rasch Models: Foundations, Recent Developments, and Applications (pp. 181-201). New York, NY: Springer-Verlag.

von Davier, A. A. (2017). Computational psychometrics in support of collaborative educational assessments. Journal of Educational Measurement, 54(1), 3-11.

Wainer, H. (2000). Computerized Adaptive Testing: A Primer. London: Erlbaum.

Wan, H., Ding, J., Gao, X., \& Pritchard, D. (2017). Dropout prediction in MOOCs using learners' study habits features. International Conference on Educational Data Mining (EDM), (pp. 408-409). Wuhan.

Wang, Y., \& Baker, R. (2015). Content or platform: Why do students complete MOOCs? MERLOT Journal of Online Learning and Teaching, 11(1), 17-30.

Wauters, K., Desmet, P., \& Van den Noortgate, W. (2010). Adaptive item-based learning environments based on the item response theory: possibilities and challenges. Journal of Computer Assisted Learning, 26, 549-562.

Whitely, S. E. (1980). Multicomponent latent trait models for ability tests. Psychometrika, 45, 479-494.

Zahn, C., Krauskopf, K., Kiener, J., \& Hesse, F. W. (2014). Designing video for massive open online-education: conceptual challenges from a learner-centered perspective. European MOOCs Stakeholders Summit, (pp. 160-167). Lausanne, Switzerland. 